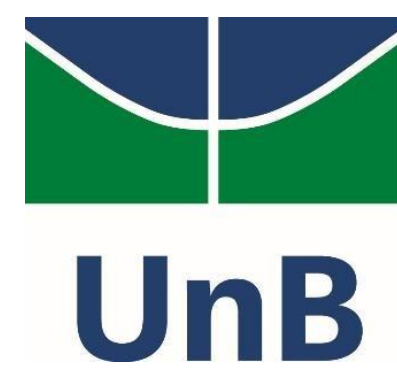

Instituto de Química

Programa de Pós-Graduação em Química

\author{
DISSERTAÇÃO DE MESTRADO
}

ESTUDO DE PROPRIEDADES ENERGÉTICAS DE DÍMEROS VIA MONTE CARLO QUÂNTICO

CASSIUS MARCELLUS COSTA CARVALHO

ORIENTADOR: JOSÉ ROBERTO DOS SANTOS POLITI

Brasília, DF

(2016) 

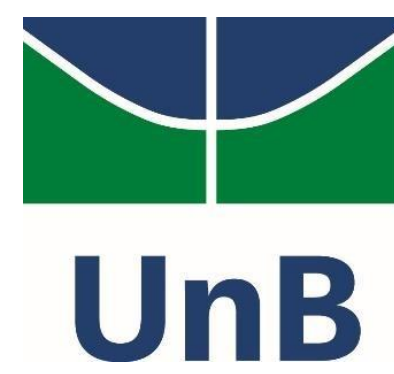

Instituto de Química

Programa de Pós-Graduação em Química

\title{
ESTUDO DE PROPRIEDADES ENERGÉTICAS DE DÍMEROS VIA MONTE CARLO QUÂNTICO
}

Dissertação de mestrado apresentada ao Programa de Pós-Graduação em Química (PPGQ), IQ-UnB, como requisito para a obtenção do título de Mestre em Química.

\author{
CASSIUS MARCELLUS COSTA CARVALHO
}

ORIENTADOR: JOSÉ ROBERTO DOS SANTOS POLITI

Brasília, DF

(2016) 


\section{FOLHA DE APROVAÇÃO}

Comunicamos a aprovação da Defesa de Dissertação de Mestrado do (a) aluno (a) Cassius Marcellus Costa Carvalho, matrícula no 14/0192255, intitulada "Estudo de Propriedades Energéticas de Dímeros via Monte Carlo Quântico", apresentada no (a) Auditório Azul do Instituto de Química (IQ) da Universidade de Brasília (UnB) em 8 de dezembro de 2016.

Prof. Dr. José Roberto dos Santos Politi Presidente de Banca (IO/UnB)

Prof. Dr. João Batista Lopes Martins Membro Titular (IQ/UnB)

Prof. Dr. Ricardo Gargano Membro Titular (IF/UnB)

Prof. Dr. Wiliam Ferreira da Cunha Membro Suplente (IF / UnB)

Em 8 de dezembro de 2016. 


\section{AGRADECIMENTOS}

Agradeço primeiramente a minha família, principalmente aos meus pais por tudo que fizeram por mim, ajudando, aconselhando e apoiando em todas as minhas decisões, além do investimento feito na minha educação. À Karina pela atenção e companheirismo.

À Universidade de Brasília pela oportunidade de realização do mestrado.

A todos os colegas que de alguma forma me ajudaram no decorrer do mestrado.

A todos os professores pela disponibilidade e empenho para transmitir seus conhecimentos. Em especial ao meu orientador, Politi, pela paciência, disponibilidade e dedicação em atender as minhas necessidades acadêmicas para conclusão desse trabalho.

Ao CNPq pelo apoio financeiro. 


\section{RESUMO}

O método Monte Carlo é um método estatístico utilizado para calcular integrais por meio de amostragens aleatórias. Quando esse método é aplicado para calcular propriedades quânticas de sistemas atômicos e moleculares, ele passa a ser denominado Monte Carlo Quântico (MCQ). Os dois métodos mais utilizados com essa denominação são: Monte Carlo Variacional e Monte Carlo de Difusão. Devido à eficiência do MCQ para representar sistemas considerados médios e grandes, resolveu-se utilizá-lo para o cálculo de propriedades energéticas de dímeros com diversas características de interação, como por exemplo, as de Van der Waals. Os dímeros estudados foram: $\mathrm{CH}_{4}-\mathrm{CH}_{4}, \mathrm{CH}_{4}-\mathrm{HF}, \mathrm{CH}_{4}-\mathrm{H}_{2} \mathrm{O}, \mathrm{CH}_{4}-\mathrm{CO}, \mathrm{CH}_{4}-$ $\mathrm{H}_{2}$ e $\mathrm{CH}_{4}$-Ar. Tais dímeros possuem grande importância nas áreas de aplicações astrofísicas e espectroscópica. Com isso, os objetivos principais deste trabalho são: avaliar o MCQ no cálculo da energia total de dímeros e moléculas, bem como no cálculo da energia de interação dos dímeros. A eficiência dos cálculos para tais interações de distintas naturezas também foi analisada. Para isso, as funções de onda dos métodos ab initio Hartree Fock e DFT foram utilizadas. Essas funções eram geradas pelo programa Gaussian09, e assim serviam de entrada para o método MCQ no software Casino. Com a energia total do dímero e as energias das 2 moléculas separadamente, era possível se calcular a energia de interação $(\Delta \mathrm{E})$. Analisando-se os resultados das energias das moléculas e dos dímeros, observou-se que todos estavam em consonância com os valores referenciais, destacando-se o MCQ de Difusão. Também, confirmou-se que os efeitos incluídos nos DFT, não impactavam em melhoria da função de onda no MCQ. Para a energia de interação, houve apenas bons resultados para os dímeros: $\mathrm{CH}_{4}-\mathrm{CH}_{4}, \mathrm{CH}_{4}-\mathrm{HF}$ e $\mathrm{CH}_{4}-\mathrm{H}_{2} \mathrm{O}$. Tal inconsistência nos resultados estava relacionada com as diferentes proporções de melhoria para o dímero e as moléculas. Em outras palavras, a função de onda utilizada não era eficiente na mesma proporção para o dímero e para as moléculas que o compõe. Outra característica importante foi que quanto maior a diferença entre as energias das moléculas que formavam o dímero, maiores eram os desvios da energia de interação. Por fim, se observou que a qualidade dos resultados gerados pelo MCQ, independe da natureza das interações.

Palavras-chave: Monte Carlo. Dímeros. Energia. 


\begin{abstract}
Monte Carlo method is a statistical method used to calculate integrals by means of random samplings. When this method is applied to calculate quantum properties of atomic and molecular systems, it is called Quantum Monte Carlo (QMC). The two most commonly used QMC methods are: Variational Monte Carlo and Diffusion Monte Carlo. QMC was used for the calculation of energetic properties of dimers with several interaction characteristics, such as Van der Waals, due to his efficiency to represent large and medium systems. The studied dimers were: $\mathrm{CH}_{4}-\mathrm{CH}_{4}, \mathrm{CH}_{4}-\mathrm{HF}, \mathrm{CH}_{4}-\mathrm{H}_{2} \mathrm{O}, \mathrm{CH}_{4}-\mathrm{CO}, \mathrm{CH}_{4}-\mathrm{H}_{2}$ and $\mathrm{CH}_{4}$-Ar. These dimers have great importance in the areas of astrophysical and spectroscopic applications. Thus, the main objectives of this work are: to evaluate the QMC in the calculation of total energy of dimers and molecules, as well as in the calculation of the interaction energy of the dimers. The efficiency of calculations for such interactions of different natures was also analyzed. For this, we used the wave functions of the ab initio methods Hartree Fock and DFT. These functions were generated by Gaussian09 program and they were used as input for QMC method in Casino software. With the total energy of the dimer and the energies of the 2 molecules separately, it was possible to calculate the interaction energy $(\Delta \mathrm{E})$. By analyzing the results of the energies of the molecules and the dimers, it was observed that all of them were in line with the referential values, mainly the Diffusion QMC. Also, it was confirmed that the effects included in the DFT did not impact the improvement of the wave function in QMC. There were only good results for the dimers $\mathrm{CH}_{4}-\mathrm{CH}_{4}, \mathrm{CH}_{4}-\mathrm{HF}$ and $\mathrm{CH}_{4}-\mathrm{H}_{2} \mathrm{O}$ regarding the interaction energy. This inconsistency in the results was related to the different proportions of improvement for the dimer and the molecules. In other words, the used wave function was not efficient in the same proportion for the dimer and for the molecules that composed it. Another important characteristic was that the greater the difference between the energies of the molecules that formed the dimer, the greater the deviations of the interaction energy. Finally, it was observed that the quality of the results generated by QMC does not depend on the nature of the interactions.
\end{abstract}

Keywords: Monte Carlo. Dimers. Energy. 


\section{ÍNDICE}

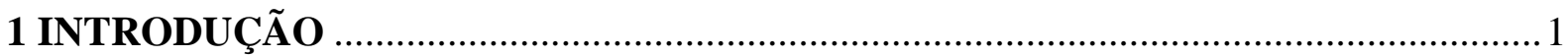

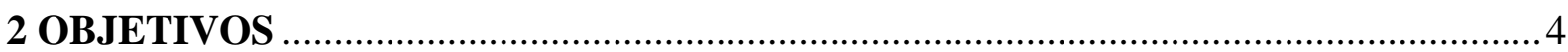

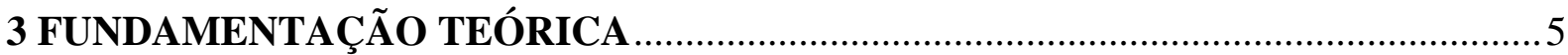

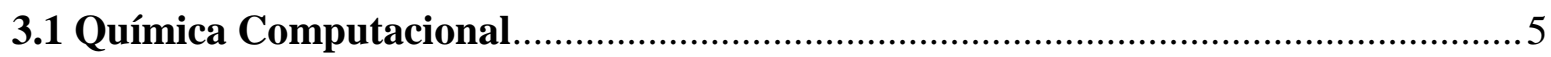

3.2 Monte Carlo Quântico Variacional (MCQV)....................................................... 8

3.3 Monte Carlo Quântico de Difusão (MCQD) .........................................................

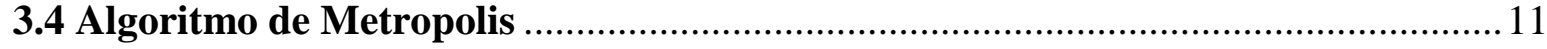

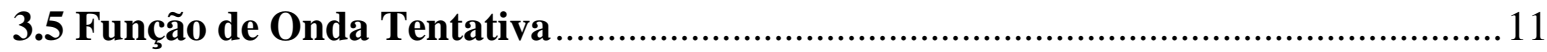

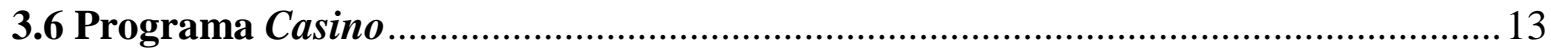

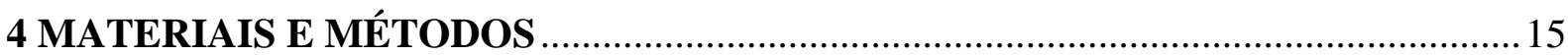

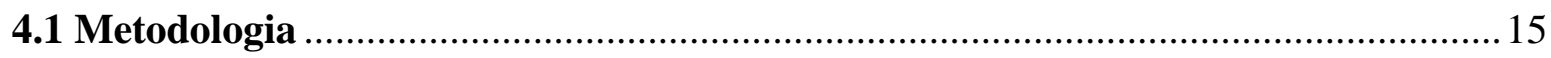

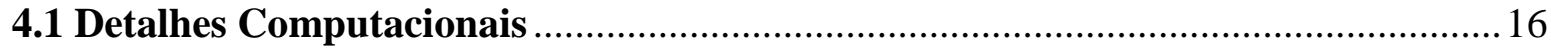

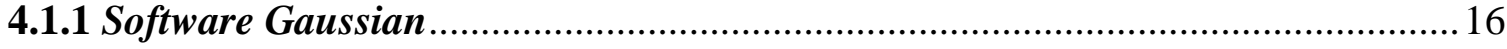

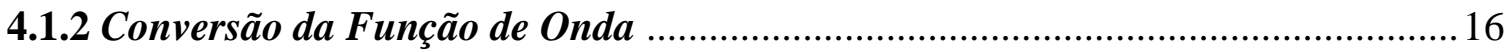

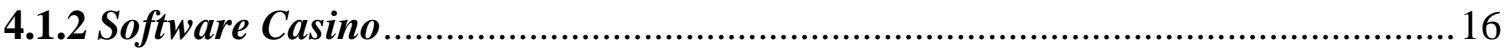

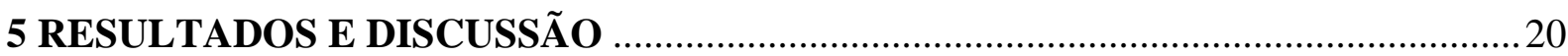

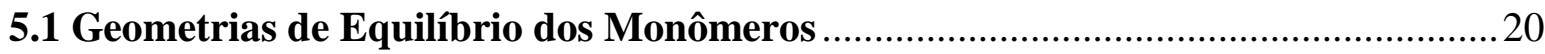

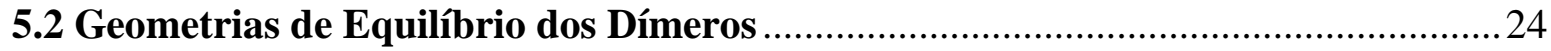

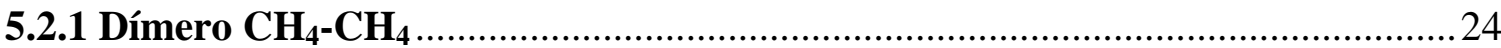

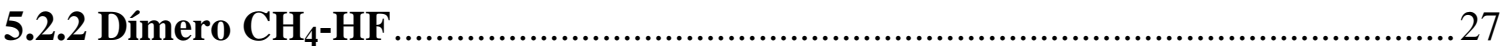

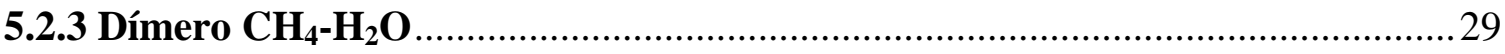

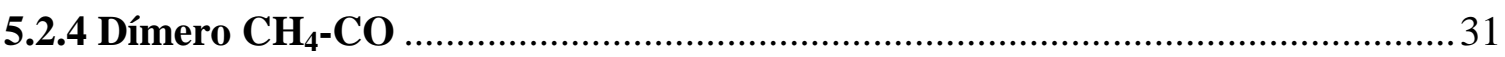

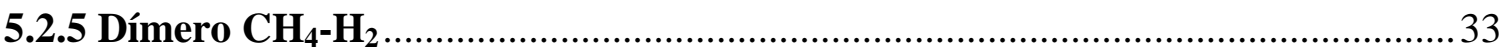

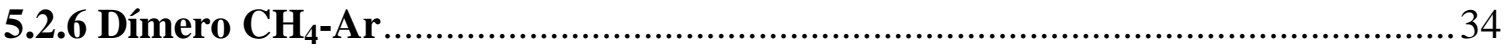

5.3 Simulações Monte Carlo Quântico para as Moléculas............................................ 35

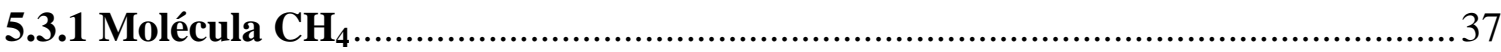

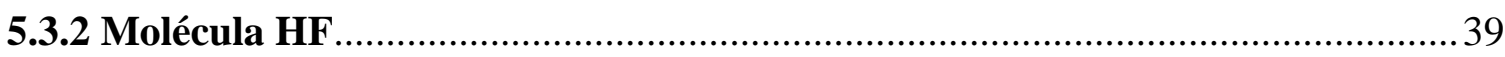

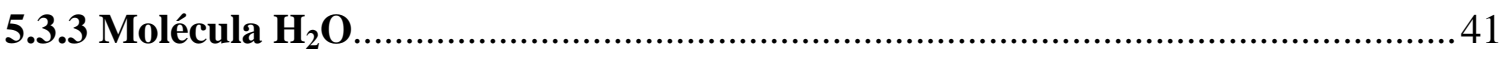

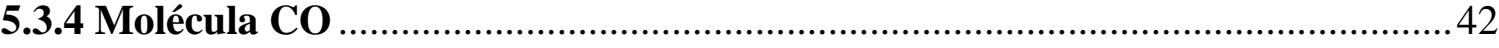

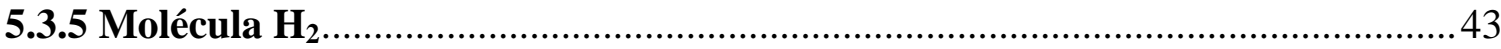




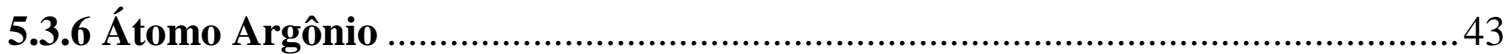

5.4 Simulações Monte Carlo Quântico para os Dímeros.............................................. 44

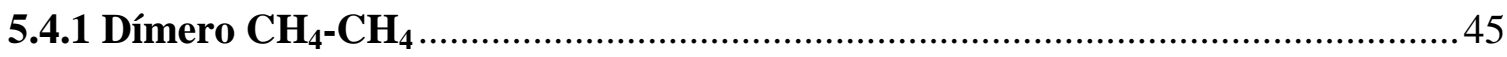

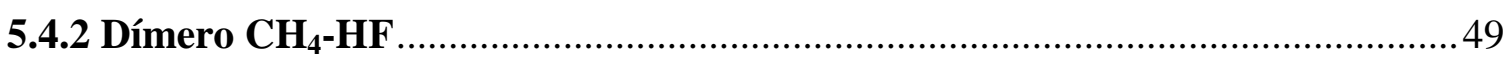

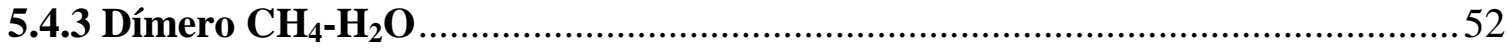

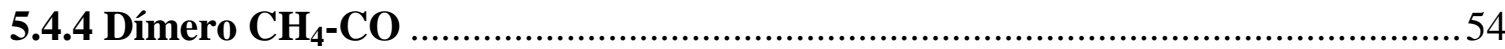

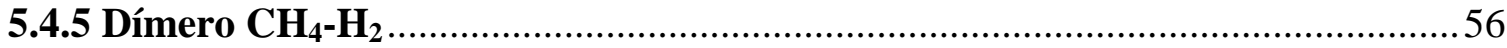

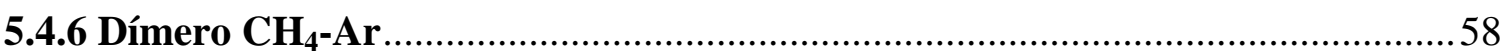

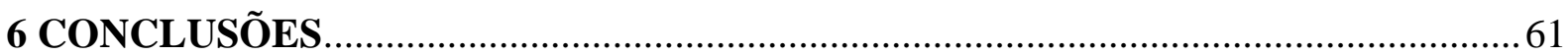

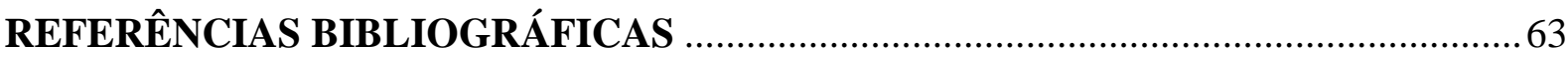




\section{LISTA DE FIGURAS}

Figura 1: Esquema de funcionamento do software Casino (adaptado). ${ }^{53}$.............................. 17

Figura 2: Dímero $\mathrm{CH}_{4}-\mathrm{CH}_{4}$ na sua geometria de equilíbrio................................................25

Figura 3: Dímero $\mathrm{CH}_{4}$-HF na sua geometria de equilíbrio. ..............................................2 27

Figura 4: Dímero $\mathrm{CH}_{4}-\mathrm{H}_{2} \mathrm{O}$ na sua geometria de equilíbrio. ..............................................29

Figura 5: Dímero $\mathrm{CH}_{4}-\mathrm{CO}$ na sua geometria de equilíbrio................................................ 31

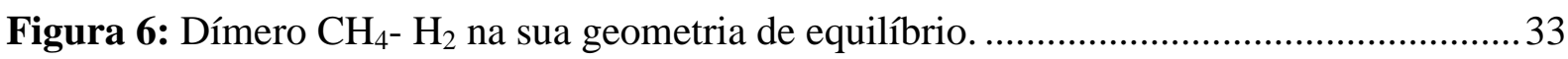

Figura 7: Dímero $\mathrm{CH}_{4}$ - Ar na sua geometria de equilíbrio................................................. 34

Figura 8: Progresso da Simulação do Monte Carlo Quântico de Difusão para molécula $\mathrm{CH}_{4}$.

Figura 9: Erros absolutos para a energia de interação em relação aos referenciais. ............... 47

Figura 10: Erros absolutos para a energia de interação em relação aos referenciais. ..............51

Figura 11: Erros absolutos para a energia de interação em relação aos referenciais..............53

Figura 12: Erros absolutos para a energia de interação em relação aos referenciais..............55

Figura 13: Erros absolutos para a energia de interação em relação ao referencial ..................58

Figura 14: Erros absolutos para a energia de interação em relação aos referenciais. ..............60 


\section{LISTA DE TABELAS}

Tabela 1: Métodos e bases utilizadas no projeto.

Tabela 2: Resultados para comprimento de ligação, ângulo H-C-H e energia na geometria de equilíbrio do $\mathrm{CH}_{4}$ para cada método.

Tabela 3: Resultados para o comprimento de ligação e energia na geometria de equilíbrio da molécula HF para cada método.

Tabela 4: Resultados do comprimento de ligação e energia na geometria de equilíbrio da molécula de água para cada método.

Tabela 5: Resultados do comprimento de ligação e energia na geometria de equilíbrio do CO para cada método.

Tabela 6: Resultados para o comprimento de ligação e energia na geometria de equilíbrio do $\mathrm{H}_{2}$ para cada método.

Tabela 7: Resultados para a energia na geometria de equilíbrio do átomo de Argônio para cada método

Tabela 8: Resultados para o dímero $\mathrm{CH}_{4}-\mathrm{CH}_{4}$, no seu estado de equilíbrio, para cada método.

Tabela 9: Erro Absoluto para a energia de interação.

Tabela 10: Resultados para o dímero $\mathrm{CH}_{4}-\mathrm{HF}$, no seu estado de mínima energia, para cada método.

Tabela 11: Resultados para o dímero $\mathrm{CH}_{4}-\mathrm{H}_{2} \mathrm{O}$, no seu estado de equilíbrio, para cada método.

Tabela 12: Erros relativos da ET e erros absolutos para energia de interação.

Tabela 13: Resultados para o dímero $\mathrm{CH}_{4}-\mathrm{CO}$, no seu estado de equilíbrio, para cada método.

Tabela 14: Resultados para o dímero $\mathrm{CH}_{4}-\mathrm{H}_{2}$, no seu estado de equilíbrio, para cada método.

Tabela 15: Resultados para o dímero $\mathrm{CH}_{4}$ - Ar, no seu estado de equilíbrio, para cada método.

Tabela 16: Resultados das Simulações Monte Carlo Quântico para a molécula $\mathrm{CH}_{4}$. ........... 37

Tabela 17: Resultados das Simulações Monte Carlo Quântico para a molécula HF. ............. 40

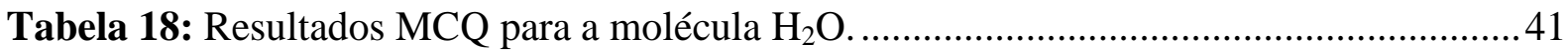

Tabela 19: Resultados das Simulações Monte Carlo Quântico para a molécula CO..............42

Tabela 20: Resultados das Simulações Monte Carlo Quântico para a molécula $\mathrm{H}_{2}$............... 43

Tabela 21: Resultados dos Métodos Monte Carlo Quântico para a átomo Ar........................ 44

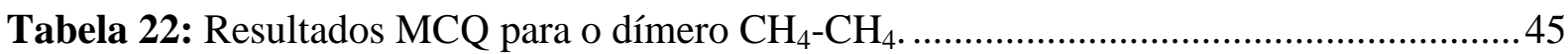

Tabela 23: Resultados para a energia de interação do dímero $\mathrm{CH}_{4}-\mathrm{CH}_{4}$.............................. 46

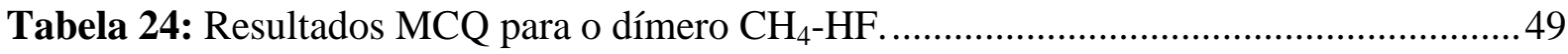

Tabela 25: Resultados para a energia de interação do dímero $\mathrm{CH}_{4}-\mathrm{HF}$. .................................50

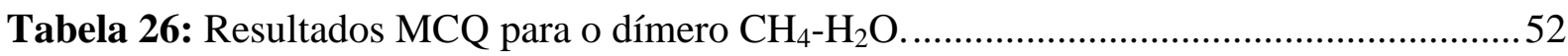

Tabela 27: Resultados para a energia de interação do dímero $\mathrm{CH}_{4}-\mathrm{H}_{2} \mathrm{O}$................................53

Tabela 28: Resultados MCQ para o dímero $\mathrm{CH}_{4}-\mathrm{CO}$.............................................................5

Tabela 29: Resultados para a energia de interação do dímero $\mathrm{CH}_{4}-\mathrm{CO}$.................................55 
Tabela 30: Resultados MCQ para o dímero $\mathrm{CH}_{4}-\mathrm{H}_{2}$

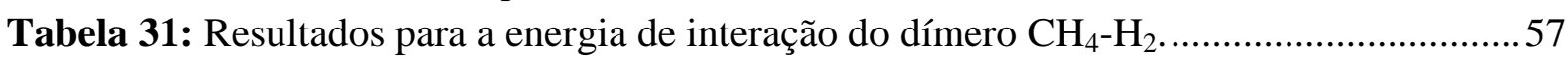

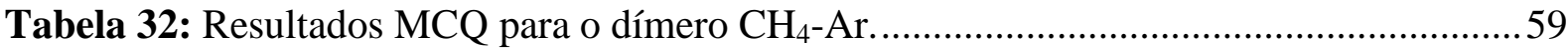

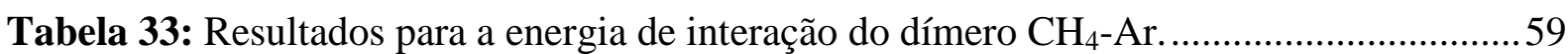




\section{LISTA DE ABREVIATURAS E ACRÔNIMOS}

Ar: Argônio.

BSSE: Erro de Sobreposição de conjunto de Funções de Bases (Basis Set Superposition Error).

CO: Monóxido de Carbono.

DFT: Teoria do Funcional da Densidade (Density Functional Theory).

ET: Energia Total a $0 \mathrm{~K}$.

HF: Fluoreto de Hidrogênio.

hf: Hartree Fock.

MCQ: Monte Carlo Quântico.

$\Delta \mathbf{E}$ : Energia de Interação. 


\section{INTRODUÇÃO}

O Método Monte Carlo é um método estatístico empregado para a resolução de integrais, utilizando para isso, uma sequência de números aleatórios. O princípio geral que rege a integração de Monte Carlo é a associação entre a integral que desejamos calcular e uma probabilidade que pode ser determinada a partir de uma população obtida por meio de um processo randômico.

O método Monte Carlo empregado na química e na física possibilita calcular propriedades do sistema a partir de uma população gerada de acordo com uma distribuição previamente escolhida. As propriedades são calculadas como uma simples média aritmética do seu valor na população gerada. Esse método é aplicado em diversas áreas. Quando ele é usado para calcular propriedades quânticas de sistemas atômicos e moleculares, ele é chamado de Monte Carlo Quântico (MCQ), sendo um dos métodos ab initio mais recentes. ${ }^{1}$

Existem alguns tipos do MCQ, ${ }^{2}$ entre os quais destacam-se: Monte Carlo Quântico Função de Green (MCQFG), Monte Carlo Quântico de Integrais de Caminho(MCQIC), Monte Carlo Quântico Variacional(MCQV) e o Monte Carlo Quântico de Difusão(MCQD). O MCQV e o MCQD são os tipos mais utilizados, e também serão usados como base neste projeto.

O Método Monte Carlo Quântico Variacional é a aplicação do Monte Carlo no princípio variacional da mecânica quântica. O MCQV permite resolver integrais para o cálculo de diversas propriedades atômicas ou moleculares, por meio de uma exploração sistemática do espaço de coordenadas utilizando números aleatórios. Seus resultados dependem da qualidade da função de onda aproximada (contínua, normalizável e com derivadas parciais contínuas). ${ }^{1}$ Já a essência do Método Monte Carlo de Difusão está na analogia matemática entre a equação de Schrödinger dependente do tempo com a equação clássica de difusão. No MCQD, a qualidade da função de onda tentativa não é tão importante como no MCQV.

O MCQV e o MCQD são mais utilizados e geram melhores resultados para cálculos de energias, pois ambos apresentam a vantagem da propriedade de variância nula, ${ }^{2}$ ou seja, quanto menor a variância, melhor será o resultado. Esses métodos têm algumas outras vantagens: ${ }^{3}$ seus algoritmos são mais simples em relação a métodos convencionais de estrutura eletrônica; os algoritmos para o MCQ são facilmente adaptados para computadores paralelos e escalonam linearmente com o número de processadores; funções de onda 
multieletrônicas com dependência explícita das distâncias entre as partículas podem ser utilizadas sem dificuldade; boa convergência para a maioria dos sistemas estudados entre outras.

Apesar dessas vantagens, há muito para se desenvolver nos métodos MCQ, tanto em termos computacionais quanto nos teóricos. Um aspecto que merece uma atenção especial é a escolha da função de onda tentativa que direciona a simulação nos métodos MCQ. Uma vez que boa parte do custo computacional no MCQ se deve ao cálculo das derivadas de primeira e segunda ordem dessa função, a obtenção de uma função de onda tentativa compacta e que mantenha a qualidade dos resultados irá ampliar a área de aplicação desses métodos. Outro aspecto relevante se refere ao Monte Carlo Variacional. A simplicidade desse método permite que ele seja rapidamente compreendido e implementado. Contudo, ele é extremamente dependente da função de onda tentativa escolhida, uma vez que ele não consegue melhorar a descrição do sistema para além dessa função, diferentemente do que ocorre com o Monte Carlo de Difusão. Por isso, o uso do Monte Carlo Variacional neste trabalho é de apenas preparar uma distribuição compatível com uma função de onda tentativa, para ser utilizada como entrada para o cálculo no Monte Carlo Quântico de Difusão e assim favorecer a convergência.

Em relação a cálculos de energias totais, o método MCQ é bastante preciso. ${ }^{4}$ Por isso, há uma grande quantidade de trabalhos que visam o estudo de propriedades energéticas de átomos, moléculas e sistemas mais complexos. ${ }^{5-16}$ A maior parte desses estudos, trabalham com sistemas no estado fundamental, mas há também muitos trabalhos com estados excitados. ${ }^{17-19}$ Com o avanço computacional e o desenvolvimento de novas metodologias e técnicas relacionadas ao MCQ, ampliou-se a sua aplicação para situações mais complexas, como por exemplo, para casos em que se considera o efeito do solvente, para área de materiais em geral e supercondutores. ${ }^{20-23}$

Em relação a dímeros, recentemente, estudou-se o dímero Benzeno-Benzeno ${ }^{24}$ via MCQ Variacional e de Difusão, utilizando fatores de correlação de Jastrow e Backflow. Obteve-se bons resultados para a energia de interação. Tais resultados estavam no mesmo nível dos resultados gerados pelo método coupled-cluster (CCSD(T)). Com isso, confirmouse um bom desempenho para interações de Van der Waals. Também estudou-se o dímero $\mathrm{H}_{2} \mathrm{O}-\mathrm{H}_{2} \mathrm{O} .{ }^{25}$ Aqui, a energia de dissociação foi calculada via MCQ Variacional e de Difusão, utilizando correlações Backflow e também se utilizou uma abordagem com pseudopotenciais. Assim, obteve-se resultados em concordância com o experimental. Outro exemplo de 
trabalho, utilizando MCQ e Dímero, foi para o caso do Benzeno- $\mathrm{H}_{2} \mathrm{O},{ }^{26}$ em que se estudou a curva de energia de ligação. Os resultados para o MCQ ficaram em concordância com o método $\operatorname{CCSD}(\mathrm{T})$ para a maior parte da curva. Mas para distâncias curtas, houve um pequeno desvio em relação ao referencial. Muitos trabalhos em que se têm sistemas fracamente ligados utilizaram o método MCQ como uma das alternativas para retratar tal tipo de interação, já que esse tipo de sistema é um dos grandes desafios enfrentados por outros métodos de cálculo de estrutura eletrônica. ${ }^{27-32}$

O estudo de dímeros pelos métodos da química computacional é cada vez mais frequente, visto a grande importância deles em diversas áreas como: astrofísica, atmosférica entre outras. Alguns dos dímeros utilizados estão presentes em várias atmosferas de planetas e são objetos de estudo de grande interesse, como exemplo, o $\mathrm{CH}_{4}-\mathrm{CH}_{4}$, que está presente na atmosfera de Titan, e foi estudado recentemente. ${ }^{33}$ Estudos de interações entre moléculas das quais metano está envolvido são amplamente estimulados, devido sua importância na produção e consumo de combustíveis fósseis, bem como em aplicações astrofísicas. ${ }^{34}$ Estudaram-se também dímeros com grande importância na área espectroscópica, destacando-

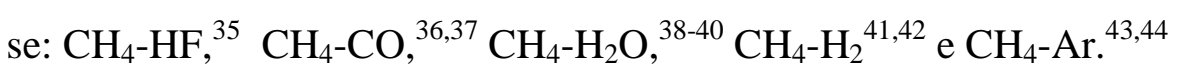

Além da importância em diversas áreas, como já citado, foram escolhidos para esse trabalho, dímeros com diferentes características de interação. Isto permite avaliar a qualidade do método para descrever interações de distintas naturezas. 


\section{OBJETIVOS}

Este projeto tem como objetivos determinar propriedades energéticas de dímeros de camada fechada, principalmente a energia de interação, por meio do Método Monte Carlo Quântico, utilizando como funções de onda tentativa, funções de onda de métodos ab initio de baixo custo computacional (Hartree Fock e DFT). A sensibilidade do Método Monte Carlo Quântico para descrever interações de distintas naturezas, tal como interações de Van der Waals, também foi analisada. A eficiência deste método também foi estudada em relação a dímeros que são conhecidos pela dificuldade de se obter bons resultados utilizando métodos tradicionais da química computacional. 


\section{FUNDAMENTAÇÃO TEÓRICA}

\subsection{Química Computacional}

A Química Computacional, em uma de suas áreas específicas, abrange um conjunto de métodos utilizados para o estudo de problemas químicos por meio de cálculos computacionais, como por exemplo: a geometria molecular, energias de moléculas, reatividade química, entre outras propriedades de interesse químico. O crescimento dessa área da química está relacionado ao desenvolvimento de novas tecnologias no ramo computacional (hardwares e softwares de simulação). ${ }^{45}$

Pode-se dizer que a Química Computacional fundamenta-se na solução aproximada da equação de Schrödinger, dada de forma geral, pela equação 1.

$$
\widehat{H} \Psi=E \Psi
$$

em que $\widehat{H}$ é o operador Hamiltoniano, $\Psi$ é a função de onda (solução da equação de Schrödinger) e $E$ é a energia (autovalor do operador), desde que $\Psi$ seja autofunção do operador $\widehat{H}$, que é dado pela equação 2 , em unidades atômicas.

$$
\widehat{H}=-\sum_{i=1}^{N} \frac{1}{2} \nabla_{i}^{2}-\sum_{A=1}^{M} \frac{1}{2 * M_{A}} \nabla_{A}^{2}-\sum_{i=1}^{N} \sum_{A=1}^{M} \frac{Z_{A}}{r_{i A}}+\sum_{i=1}^{N} \sum_{j>i}^{N} \frac{1}{r_{i j}}+\sum_{A=1}^{M} \sum_{B>A}^{M}\left(Z_{A} Z_{B}\right) / R_{A B}
$$

Para viabilizar a resolução dessa equação, utiliza-se a aproximação de BornOppenheimer, na qual o movimento nuclear é desacoplado do movimento eletrônico. Essa aproximação é fundamentada na ideia de que o núcleo tem uma massa muito maior que a massa do elétron, com isso o elétron se movimenta muito mais rápido em relação ao núcleo, que não sofre uma alteração significativa, podendo ser considerado fixo. ${ }^{46} \mathrm{Com}$ isso, define-se o operador Hamiltoniano eletrônico, que agora depende apenas dos termos eletrônicos, de acordo com a equação 3. Essa descrição é conhecida como Modelo Adiabático. ${ }^{46}$ 


$$
\widehat{H} \text { eletr }=-\sum_{i=1}^{N} \frac{1}{2} \nabla_{i}^{2}-\sum_{i=1}^{N} \sum_{A=1}^{M} \frac{Z_{A}}{r_{i A}}+\sum_{i=1}^{N} \sum_{j>i}^{N} \frac{1}{r_{i j}}
$$

o primeiro termo depois do sinal de igualdade representa a energia cinética de $\mathrm{N}$ elétrons; o segundo termo, representa a energia potencial de atração das combinações de $\mathrm{N}$ elétrons com M núcleos a uma distância $r_{i A}$; o terceiro termo é a energia potencial de repulsão entre as combinações possíveis de elétrons a uma distância $r_{i j}$.

Para a maioria dos sistemas químicos, a Equação 3 não tem solução analítica. ${ }^{46} \mathrm{Com}$ isso, os métodos da química computacional são dados como alternativa para encontrar soluções aproximadas para a equação de Schrödinger.

A função de onda, solução da equação de Schrödinger eletrônica, como visto, depende explicitamente das coordenadas eletrônicas e parametricamente das coordenadas nucleares. ${ }^{46}$ O último termo do Hamiltoniano eletrônico impede que o problema seja solucionado independentemente para cada elétron. A obtenção de $\mathrm{N}$ equações monoeletrônicas, em que $\mathrm{N}$ é o número de elétrons do sistema, é alcançada integrando-se o termo de repulsão eletrônica nas coordenadas dos N-1 elétrons. O comportamento de cada elétron é determinado em cada uma das $\mathrm{N}$ equações e está sujeito ao campo médio gerado pelos demais elétrons. Cada solução de cada uma das equações monoeletrônicas interfere no campo médio das demais. Desse modo, os núcleos sentiriam um campo médio devido aos elétrons, como também o potencial de repulsão entre os próprios núcleos, e com isso tais núcleos se moveriam numa Superfície de Energia Potencial (SEP). ${ }^{46}$ A SEP é muito importante na química computacional, visto que a partir dela é possível encontrar muitas propriedades de interesse químico, como, por exemplo: as constantes espectroscópicas rotacionais-vibracionais.

Como já abordado, os métodos da química computacional são empregados para encontrar soluções aproximadas da equação de Schrödinger. Tais métodos podem ser classificados em 3 tipos: ab initio, semi-empíricos e mecânica molecular. A mecânica molecular utiliza os fundamentos da mecânica clássica para descrever os sistemas químicos, e são utilizados principalmente para sistemas muito grandes. ${ }^{47}$ Os métodos semi-empíricos mesclam teoria com resultados experimentais. ${ }^{48}$ Os métodos de interesse neste projeto são os do tipo ab initio, que diferente dos semi-empiricos não possuem parâmetros experimentais, sendo derivados diretamente de princípios teóricos e utilizam a solução numérica da equação de Schrödinger, com base na aproximação de Born-Oppenheimer. ${ }^{49}$ Neste projeto foram utilizados os seguintes métodos ab initio: 
- Hartree-Fock-Roothaan: foi o primeiro método teórico para o cálculo de estrutura eletrônica de moléculas e é um dos métodos mais populares da Química Computacional, servindo como base para muitos outros. Este método segue o princípio variacional e a referência a Roothaan, se deve ao fato da implementação da expansão dos orbitais moleculares em termos de um conjunto finito de funções de base. $^{52}$

- Teoria de Perturbação de Møller-Plesset (Perturbação de segunda ordem- MP2). A ideia geral da teoria de perturbação é dividir o Hamiltoniano em uma parte que possui autofunções conhecidas (Hamiltoniano não-perturbado) e outra parte denominada perturbação. Assim, a energia exata é dada como uma soma de infinitas contribuições, conhecidas como ordem de perturbação. ${ }^{50}$ Esse método não é um método variacional, e pode ter energias mais baixas que a energia exata do sistema.

- $\operatorname{CCSD}(\mathrm{T})$ : esse método é uma aproximação do esquema "coupled cluster". Tal esquema trata um sistema de muitos elétrons, como um conjunto de aglomerados com poucos elétrons, assim calculam-se as interações entre os elétrons do mesmo grupo, e logo depois entre os diferentes aglomerados. ${ }^{50} \mathrm{O} \operatorname{CCSD}(\mathrm{T})$ abrange as substituições simples, duplas e triplas no operador de cluster e é um dos métodos mais sofisticados e apresentam bons resultados para muitas propriedades químicas de interesse.

- QCISD(T): este é um método multiconfiguracional, o qual também gera bons resultados para muitas propriedades químicas, e pode ser comparado ao $\operatorname{CCSD}(\mathrm{T})$ na qualidade desses resultados, porém ambos os métodos tem a desvantagem de ter um custo computacional alto. ${ }^{50}$ A partir disso, esses dois métodos (CCSD(T), QCISD(T)) foram utilizados como referência de comparação nesse projeto para as moléculas.

- Teoria do Funcional da Densidade (DFT): ${ }^{49}$ é um método ab initio, visto que nas derivações das equações do funcional densidade, nenhum parâmetro precisa ser determinado empiricamente. A diferença do DFT em relação aos ab initio tradicionais está no fato da função de onda do estado fundamental e as propriedades desse estado, serem funcionais da densidade eletrônica. Outra vantagem é que sistemas de tamanho médio a grande podem ser estudados, a um custo computacional menor que outros métodos. Uma desvantagem está associada à escolha do funcional adequado ao sistema em estudo. 


\subsection{Monte Carlo Quântico Variacional (MCQV)}

O método mais simples dentre todos os métodos MCQ é o MCQV, que permite resolver integrais para calcular várias propriedades quânticas, por meio de uma varredura sistemática do espaço de coordenadas, utilizando uma sequência de números aleatórios. Sua designação vem da aplicação do Monte Carlo no princípio variacional da mecânica quântica (Uma função de onda tentativa produzirá valores esperados de energia que, na melhor das hipóteses, serão iguais ou superiores a energia exata do sistema). ${ }^{1}$ De acordo com esse princípio, o valor médio da energia $\mathrm{E}$, é dado por:

$$
\langle E\rangle=\frac{\int \Psi^{*}(q) H \Psi(q) d q}{\int \Psi^{*}(q) \Psi(q) d q}
$$

em que $\Psi$ é a função de onda, H é o operador hamiltoniano e q é o conjunto de coordenadas eletrônicas. A equação 4 pode se reescrita como se segue:

$$
\langle\mathrm{E}\rangle=\frac{\int \Psi^{*}(\mathrm{q}) \Psi(\mathrm{q}) \frac{H \Psi(\mathrm{q})}{\Psi(\mathrm{q})} d q}{\int \Psi^{*}(\mathrm{q}) \Psi(\mathrm{q}) \mathrm{dq}}
$$

O termo $\left(\frac{H \Psi(q)}{\Psi(q)}\right)$ é chamado de Energia Local $\left(\mathrm{E}_{\text {local }}\right)$, que é o valor que a energia assume no ponto q.

Na equação 5 é possível identificar uma densidade de probabilidade, dada pela equação 6:

$$
\rho(q)=\frac{\Psi^{*}(q) \Psi(q)}{\int \Psi^{*}(q) \Psi(q) d q}
$$

Utilizando o teorema do valor médio, a energia média da equação 5 pode ser calculada pela seguinte expressão:

$$
\langle\mathrm{E}\rangle=\left(\lim _{M \rightarrow \infty} \frac{1}{M} \sum_{i=1}^{M} E_{\text {local }}\left(q_{i}\right)\right)_{\rho(\mathrm{q})}
$$


em que $M$ é o número de coordenadas $q$ obtidas ao longo da integração de Monte Carlo, sobre a densidade de probabilidade. O sub-índice $\rho$ indica que os pontos utilizados para o cálculo da média foram selecionados de acordo com a densidade de probabilidade (equação 6). Dessa maneira, converteu-se o cálculo de uma integral em um cálculo de média aritmética. ${ }^{1}$

Quando se trabalha com o cálculo de uma média, pode-se usar uma medida de dispersão para obter uma estimativa de erro. No caso, é usado o desvio-padrão $(\sigma)$, dado pela equação 8:

$$
\sigma=\sqrt{\frac{\left\langle E_{\text {local }}{ }^{2}\right\rangle \rho^{-\left\langle E_{\text {local }}\right\rangle_{\rho}^{2}}}{M-1}}
$$

Desse modo, pode-se controlar o resultado da média pelo valor do desvio-padrão. Assim, se for utilizado o valor exato da função de onda tentativa, o valor do desvio padrão deverá ser igual a zero, ou seja, quanto menor o desvio padrão melhor é a função de onda tentativa. ${ }^{1}$

\subsection{Monte Carlo Quântico de Difusão (MCQD)}

O MCQD foi desenvolvido por meio da associação fenomenológica da equação de Schrödinger com a equação clássica de difusão. ${ }^{1}$ A equação de Schrödinger dependente do tempo para $\mathrm{N}$ partículas com coordenadas q é dada por:

$$
-\frac{\partial \Psi(q, t)}{i \partial t}=-\frac{1}{2} \nabla^{2} \Psi(q, t)+V \Psi(q, t)
$$

em que $V$ é o operador potencial e o $\nabla^{2}$ o operador Laplaciano.

A equação clássica de difusão é escrita como:

$$
-\frac{\partial C}{\partial t}=D \nabla^{2} C+k C
$$

$C$ é a concentração da espécie durante o processo de difusão, $D$ é a constante de difusão e $k$ é a constante de velocidade. 
O componente imaginário da equação de Schrödinger (i) pode ser rearranjado para se ter uma analogia matemática mais efetiva. Com isso, transforma-se o tempo real $(t)$ para tempo imaginário ${ }^{1}(\boldsymbol{\tau}): \tau=\mathrm{i}$.

Com a equação 9, pretende-se obter apenas estados estacionários. Para essa finalidade, deve-se utilizar um parâmetro arbitrário de referência $E_{R}$, para deslocar a energia de referência, garantindo assim, encontrar estados estacionários com energias menores que zero. Após realizada a transformação da coordenada temporal, pode-se escrever a equação 11:

$$
-\frac{\partial \Psi(q, \tau)}{\partial \tau}=-\frac{1}{2} \nabla^{2} \Psi(q, \tau)+\left[V-E_{R}\right] \Psi(q, \tau)
$$

A equação de difusão pode ser separada e avaliada com respeito aos seus dois termos. Desconsiderando o segundo termo da direita, a equação de difusão assume a forma:

$$
-\frac{\partial C}{\partial t}=D \nabla^{2} C
$$

Essa igualdade corresponde à representação do movimento browniano. A solução para essa equação diferencial é conhecida, e ela corresponde a uma função de distribuição gaussiana: ${ }^{1}$

$$
C=(4 \pi D \delta t)^{-\frac{1}{2}} \exp \left[-\frac{x^{2}}{4 D \delta \mathrm{t}}\right]
$$

em que $\delta$ t é o intervalo de tempo.

Por sua vez, desconsiderando o primeiro termo da direita, a equação 10 fica igual a:

$$
-\frac{\partial C(q, t)}{\partial t}=k C(\mathrm{q}, \mathrm{t})
$$

É conhecida também a solução analítica para a equação 14, a qual descreve a cinética de uma reação de primeira ordem: ${ }^{1}$

$$
C(q, \delta t)=e^{(-k \delta t)}
$$


Essa equação representa um processo em que partículas são criadas e destruídas. O fator estatístico que controla esse processo é exatamente a exponencial apresentada na equação 15.

Uma situação de equilíbrio pode ser estabelecida entre a combinação da simulação do movimento browniano com a cinética de primeira ordem, a partir de um formalismo matemático rigoroso. Dessa maneira o MCQD pode resolver essas equações diferenciais utilizando as funções de Green. ${ }^{1}$

\subsection{Algoritmo de Metropolis}

O Algoritmo de Metropolis ${ }^{51}$ tem grande importância para o método Monte Carlo Quântico. Ele é fundamentado na técnica de aceitar ou rejeitar os pontos acessados na simulação no espaço de fase. O algoritmo é concebido de modo a se obter uma amostra que siga uma função de distribuição. ${ }^{51}$ No esquema MCQ, essa função de distribuição é a própria função de densidade de probabilidade. Esse algoritmo segue a seguinte sequência:

1. Inicia-se com um conjunto de coordenadas q, escolhidas de forma arbitrária.

2. Calcula-se a densidade de probabilidade para essas coordenadas escolhidas.

3. Busca-se novas coordenadas q'.

4. Calcula-se novamente a densidade de probabilidade para essa nova coordenada.

5. Faz-se a razão entre a densidade de probabilidade da nova coordenada com a densidade de probabilidade da coordenada antiga.

6. Compara-se essa razão com um número aleatório no intervalo de 0 a 1 . Analisa-se essa comparação: se essa razão for maior que esse número aleatório, aceita-se essa nova coordenada; se for menor, retorna ao passo 3.

7. Calcula-se assim as propriedades de interesse com as melhores configurações.

\subsection{Função de Onda Tentativa}

Os resultados no MCQ são dependentes da qualidade da função de onda aproximada que é utilizada na simulação, principalmente no MCQ Variacional. Tal função de onda deve satisfazer alguns critérios, como: ter seu quadrado integrável; satisfazer condições de cúspide eletrônica e nuclear; possuir valores de energia local finito; apresentar comportamento 
assintótico com o aumento da distância do elétron em relação ao núcleo; deve ser antisimétrica em relação a permutação das coordenadas de dois elétrons. ${ }^{52}$

O princípio de anti-simetria de Pauli é um dos aspectos mais importantes na construção de uma função de onda. Segundo esse princípio, a função de onda deve trocar de sinal quando as coordenadas de dois elétrons são permutadas. ${ }^{52}$ Uma função de onda tentativa típica (Equação 16) em MCQ é dada pelo produto entre Determinantes de Slater $\left(\Psi_{\alpha}\right.$ e $\left.\Psi_{\beta}\right)$ de spins opostos (spins $\alpha$ e $\beta$ ), permitindo desse modo, o cancelamento das coordenadas de spin: ${ }^{52}$

$$
\begin{aligned}
& \Psi(\mathrm{q})=\Psi_{\alpha}\left(q_{\alpha}\right) \Psi_{\beta}\left(q_{\beta}\right), \\
& \Psi_{\alpha}=\left(\frac{1}{\sqrt{N !}}\right)\left|\begin{array}{cccc}
\chi_{1}{ }^{\alpha}(1) & \chi_{1}{ }^{\alpha}(2) & \cdots & \chi_{1}{ }^{\alpha}(\mathrm{N}) \\
\chi_{2}{ }^{\alpha}(1) & \chi_{2}{ }^{\alpha}(2) & \cdots & \chi_{2}{ }^{\alpha}(\mathrm{N}) \\
\vdots & \vdots & \ddots & \vdots \\
\chi_{N}{ }^{\alpha}(1) & \chi_{N}{ }^{\alpha}(2) & \cdots & \chi_{N}{ }^{\alpha}(\mathrm{N})
\end{array}\right| \\
& \Psi_{\beta}=\left(\frac{1}{\sqrt{(2 N-N+1) !}}\right)\left|\begin{array}{cccc}
\chi_{1}{ }^{\beta}(\mathrm{N}+1) & \chi_{1}{ }^{\beta}(\mathrm{N}+2) & \cdots & \chi_{1}{ }^{\beta}(2 \mathrm{~N}) \\
\chi_{2}{ }^{\beta}(\mathrm{N}+1) & \chi_{2}{ }^{\beta}(\mathrm{N}+2) & \cdots & \chi_{2}{ }^{\beta}(2 \mathrm{~N}) \\
\vdots & \vdots & \ddots & \vdots \\
\chi_{N}{ }^{\beta}(\mathrm{N}+1) & \chi_{N}{ }^{\beta}(\mathrm{N}+2) & \cdots & \chi_{N}{ }^{\beta}(2 \mathrm{~N})
\end{array}\right|,
\end{aligned}
$$

em que o termo $\left(\frac{1}{\sqrt{N !}}\right)$ é a constante de normalização para $\alpha$ e $\left(\frac{1}{\sqrt{(2 N-N+1) !}}\right)$ é a constante de normalização para $\beta$. Aqui, os $\mathrm{N}$ elétrons são combinados em $\mathrm{N}$ spin-orbitais $\chi_{i}(\mathrm{i})$.

Uma das formas mais comuns de funções de onda utilizadas no software Casino (programa com o método Monte Carlo Quântico) é denominada função de Slater-Jastrow, ${ }^{53}$ dada por:

$$
\Psi(x)=e^{J(x)} * \sum_{n} c_{n} D_{n}(x)
$$

em que $e^{J(x)}$ é o fator de Jastrow (Jastrow factor), $c_{n}$ são os coeficientes e $D_{n}(x)$ são os determinantes de Slater, representado por: 
$\boldsymbol{D}(\boldsymbol{x})=\left|\begin{array}{cccc}\Phi_{1}\left(x_{1}\right) & \Phi_{1}\left(x_{2}\right) & \ldots & \Phi_{1}\left(x_{N}\right) \\ \Phi_{2}\left(x_{1}\right) & \Phi_{2}\left(x_{2}\right) & \ldots & \Phi_{2}\left(x_{N}\right) \\ \vdots & \vdots & \ddots & \vdots \\ \Phi_{N}\left(x_{1}\right) & \Phi_{N}\left(x_{2}\right) & \ldots & \Phi_{N}\left(x_{N}\right)\end{array}\right|$

$x_{i}$ representa as coordenadas spin-orbital de um elétron i. Os orbitais nesses determinantes podem ser obtidos a partir de cálculos DFT e Hartree-Fock, em que $\Phi_{i}\left(x_{i}\right)$ de forma análoga ao $\chi_{i}(\mathrm{i})$ da Equação 16, representa o produto de uma função espacial e uma função de spin.

Pode-se utilizar a ideia do produto entre Determinantes de Slater $\left(\Psi_{\alpha}\right.$ e $\left.\Psi_{\beta}\right)$ de spins opostos ( $\alpha$ e $\beta$ ) dada na Equação 16, para evitar a utilização das coordenadas de spin e aplicála na Equação 17:

$\Psi(\mathrm{r})=e^{J(r)} * \sum_{n} \boldsymbol{c}_{\boldsymbol{n}} \Psi_{\alpha}\left(r_{1}, r_{2}, \ldots, r_{N}\right) \Psi_{\beta}\left(r_{N+1}, r_{N+2}, \ldots, r_{2 N}\right)$

Observa-se que a nova função de onda depende apenas das coordenadas espaciais (r), visto que houve o cancelamento das coordenadas de spin. O termo $e^{J(r)}$ (Jastrow factor), no método Monte Carlo Quântico, tem a finalidade de diminuir o custo computacional relativo a atingir a barra de erro estatístico, além de melhorar a estabilidade do algoritmo. ${ }^{53}$ Neste projeto, o fator de Jastrow foi desconsiderado, bem como qualquer outro fator de correlação.

\subsection{Programa Casino}

O Casino é um programa utilizado para simulações em Monte Carlo Quântico, ou seja, realizam-se cálculos de estrutura eletrônica por meio do método Monte Carlo Quântico. ${ }^{53}$ Este software foi desenvolvido pela Universidade de Cambridge. Uma das razões para utilização desse software foi a facilidade de aceitação de funções de onda geradas por outros programas de cálculos de estrutura eletrônica, como por exemplo: GAUSSIAN, GAMESS e CRYSTAL.

Podem ser utilizados os métodos Monte Carlo Variacional (MCV) e Monte Carlo de Difusão (MCD). Há a opção de utilizarem os 2 métodos no mesmo cálculo, em que finalizando-se o MCV, utiliza-se a distribuição de pontos gerada na função de onda nesse método e inicia-se o cálculo no MCD, com isso, otimiza-se o processo de geração de pontos iniciais. 
Neste programa, também tem a opção de utilizar parâmetros de correlação. ${ }^{53}$ Os mais utilizados são: Jastrow factor e backflow parameters. Com isso, pode-se obter um menor custo computacional, visto que o número de passos pode ser reduzido. 


\section{MATERIAIS E MÉTODOS}

\subsection{Metodologia}

Os dímeros estudados foram: $\mathrm{CH}_{4}-\mathrm{CH}_{4}, \mathrm{CH}_{4}-\mathrm{HF}, \mathrm{CH}_{4}-\mathrm{H}_{2} \mathrm{O}, \mathrm{CH}_{4}-\mathrm{CO}, \mathrm{CH}_{4}-\mathrm{H}_{2}, \mathrm{CH}_{4}$ Ar. Inicialmente, dividiu-se o procedimento em 3 etapas.

Na primeira etapa foi feito o estudo de cada molécula que compõe cada um dos dímeros, buscando-se otimizar as geometrias e calcular as frequências. Os métodos e as bases utilizadas são dadas na Tabela 1. Utilizou-se para esses cálculos o software Gaussian09.

Tabela 1: Métodos e bases utilizadas no projeto.

\begin{tabular}{|c|c|}
\hline Método & Base \\
\hline CCSD(T) & 6-31+G(2d,p) \\
\hline MP2 & aug-cc-pvtz \\
\hline QCISD(T) & 6-31+G(2d,p) \\
\hline DFT (HSEH1PBE) & aug-cc-pvtz \\
\hline DFT (WB97XD) & aug-cc-pvtz \\
\hline DFT (B97D3) & aug-cc-pvtz \\
\hline Hartree Fock (RHF) & aug-cc-pvtz \\
\hline
\end{tabular}

Os métodos CCSD(T), QCISD(T) e MP2 foram utilizados como métodos de referências para comparação das geometrias e energias, caso não fossem encontrados dados teóricos para essas propriedades.

Na segunda etapa, já com as geometrias de equilíbrio de cada molécula prontas, geraram-se os dímeros com base nessas geometrias calculadas separadamente. Com as estruturas dos dímeros preparadas, calculou-se a geometria de equilíbrio e as frequências para cada dímero, além de gerar as funções de onda para os métodos RHF e DFT.

Na terceira etapa, utilizou-se as funções de onda obtidas pelos métodos RHF e DFT como funções de onda tentativa no método Monte Carlo Quântico. O método Monte Carlo Variacional foi empregado para a obtenção de uma distribuição de pontos compatível com a função de onda tentativa. Essa distribuição foi utilizada como entrada para o cálculo no Monte Carlo Quântico de Difusão. Nesta mesma etapa, já como saída do método Monte Carlo de Difusão, obteve-se a energia, que foi usada para analisar a qualidade das bases empregadas, para o cálculo da energia de interação. O software Casino foi usado para os cálculos Monte Carlo Quântico. 


\subsection{Detalhes Computacionais}

\subsubsection{Software Gaussian}

O software Gaussian09, ${ }^{54}$ um dos programas mais utilizados na química computacional para cálculos de estruturas eletrônicas, foi utilizado principalmente para geração de uma função de onda tentativa. Analisaram-se também por meio desse software, as geometrias de equilíbrio e as frequências dos dímeros e moléculas. Com base nessas análises e comparações com dados disponíveis na literatura ou com cálculos feitos com métodos de referência, buscou-se a melhor representação para cada sistema. Os critérios para convergência seguiram o padrão do programa. ${ }^{54}$

\subsubsection{Conversão da Função de Onda}

Como já visto (Tópico 3.6), uma das vantagens do software Casino é a aceitação de funções de onda geradas por outros programas de cálculos de estrutura eletrônica. O programa Gaussian09 foi utilizado para gerar tais funções de onda. Necessitavam-se apenas dos arquivos de saída nos formatos ".chk" e “.log". Tais formatos eram transformados respectivamente em ".fchk" e ".out". Com isso, utilizava-se o conversor denominado "gaussiantoqmc", criado por Andrew Porter, ${ }^{53}$ disponível em linguagem Fortran. Esta conversão apenas é possível para funções de onda geradas por métodos Hartree Fock e DFT. ${ }^{53} \mathrm{O}$ arquivo de saída dessa conversão é do tipo "gwfn.data", que na nomenclatura do programa Casino, representa uma função gaussiana. ${ }^{53}$ Por fim, utilizava-se o arquivo "gwfn.data" como entrada no programa Casino.

\subsubsection{Software Casino}

Com a função de onda tentativa já formatada no modelo padrão do Casino, realizou-se o cálculo. A Figura 1 detalha o esquema de funcionamento do programa, mostrando-se os arquivos de entrada ("gwfn.data", "correlation.data", "input" e "config.in") e os arquivos de saída ("out", "vmc.hist", “dmc.hist" e "config.out"). 


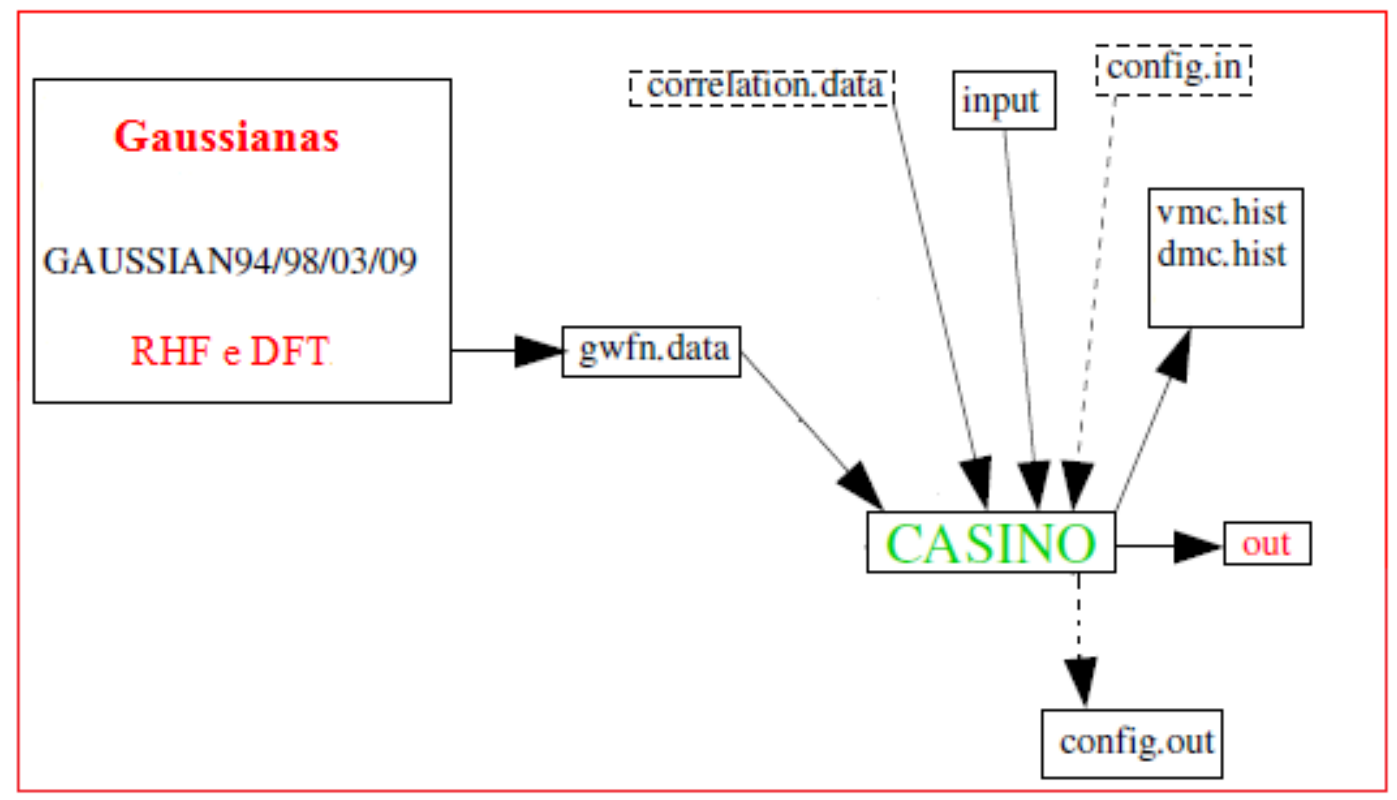

Figura 1: Esquema de funcionamento do software Casino (adaptado). ${ }^{53}$

As funções de onda descritas pelos métodos Hartree Fock e DFT, estão no arquivo "gwfn.data", já que foram utilizadas bases gaussianas. Basicamente neste arquivo estão as informações que descrevem as geometrias de equilíbrio, o conjunto de base e os coeficientes que definem os orbitais. ${ }^{53}$

$\mathrm{O}$ arquivo "correlation.data" contêm todos os parâmetros otimizáveis, que servem como fator de correlação e ajudam no custo computacional. ${ }^{53}$ Os parâmetros utilizados para definir o fator de Jastrow e a função Backflow são exemplos deste caso. Neste trabalho empregou-se o fator de Jastrow apenas para alguns testes em moléculas, e por opção, deixouse de usá-lo, bem como qualquer outro fator de correlação, pois uma das finalidades era analisar a qualidade das funções tentativas e também a eficiência do método Monte Carlo, sem nenhum tipo de dados de correlação.

O "input" é o arquivo que contêm os dados de entrada, necessários para realização do cálculo pelo método Monte Carlo Quântico. Parâmetros principais como: tipo de cálculo (Variacional ou Difusão), número de passos, número de configurações, número de blocos e número de elétrons (spin-down e spin-up) são definidos neste arquivo. ${ }^{53}$ No tipo de cálculo informam-se quais métodos serão utilizados em cada sistema: Monte Carlo Variacional ou Monte Carlo de Difusão. Há a possibilidade também da utilização de ambos os métodos (Variacional e Difusão) no mesmo cálculo, em que sempre se inicia com o método Variacional e logo após o seu término, inicia-se o de Difusão. Tal opção de cálculo com ambos os métodos, foi a utilizada como padrão em todos os cálculos desse projeto. 
O número de passos também é definido no "input". Escolheu-se uma quantidade que retratasse bem o sistema estudado, proporcionando um erro aceitável e um tempo de cálculo que fosse viável para a realização desse trabalho. Com isso, definiu-se 2000000 de passos como parâmetro para a maioria dos cálculos. O número de passos foi padronizado. Desse modo, nos cálculos para os dímeros bem como nos cálculos para os seus monômeros usava-se sempre a mesma quantidade de passos. Tal procedimento resultou em uma melhoria significativa nos resultados da energia de formação.

O número de passos basicamente indica o número total de amostras de energia local. ${ }^{53}$ A fase de acumulação de energia local pode ser dividida em blocos (número de blocos), em que se tem o cálculo da média dessas energias em cada bloco, e no final se calcula a média de todos os blocos. Esta divisão em blocos, não afeta o número total de passos. ${ }^{53}$ Para este projeto, iniciou-se todos os cálculos considerando-se apenas 1 bloco.

Outro parâmetro que influencia na qualidade do resultado e no tempo computacional é o número de configurações, que também é definido no arquivo de entrada. Cada configuração representa como os elétrons estão posicionados. ${ }^{53} \mathrm{~A}$ cada mudança de posições dos elétrons, uma nova configuração é formada, e é calculada uma nova energia. Após muitos testes e analises decidiu-se utilizar para a maior parte dos sistemas estudados, 1000 configurações. Esta quantidade foi suficiente para gerar bons resultados, bem como um tempo computacional razoável para todos os cálculos.

O "passo de tempo" é outro parâmetro que deve ser informado no "input". No caso do método Monte Carlo de Difusão, ele deve ser um valor próximo de zero, pois a função de Green é somente exata se for considerado que o "passo de tempo" tende a zero. ${ }^{53}$ Baseados nesta teoria e também nos dados padrão do programa, utilizaram-se valores de 0,003, 0,002 e 0,0001 para o "passo de tempo" na maioria dos casos. Dependendo da taxa de aceitação (ficar dentro do intervalo desejado), esse valor era ajustado. Esse parâmetro era analisado, por meio da taxa de aceitação de ambos os métodos: próximo dos $50 \%$ para o Variacional e acima de 96\% para o Difusão. Em alguns dímeros foi necessário diminuir o "passo de tempo", para que a taxa de aceitação ficasse dentro do intervalo desejado. No caso do dímero $\mathrm{CH}_{4}$-Ar, para o valor inicial de "passo de tempo" de 0,002, obteve-se uma taxa de aceitação menor que 95\%. Com isso, foram feitos testes e resolveu-se diminuir o valor para 0,0001, encontrando-se uma taxa de aceitação maior que $98 \%$.

Um dos problemas que podem ocorrer durante uma simulação com o método Monte Carlo de Difusão é o da "explosão populacional", ${ }^{53}$ em que o resultado final poderá não 
retratar o sistema estudado. No "input" é possível definir um parâmetro que possa resolver esse problema. Basicamente ele irá iniciar novamente a simulação naquele "bloco" que houve esse problema, por meio da geração de uma nova sequência de números aleatórios, seguindo uma distribuição diferente da atual. Neste projeto esse problema ocorreu com alguns dímeros, como por exemplo o $\mathrm{CH}_{4}-\mathrm{HF}$ e $\mathrm{CH}_{4}-\mathrm{H}_{2} \mathrm{O}$.

O arquivo de saída principal é o que contém o sufixo “.out”. Neste estão todas as informações relativas ao cálculo. As principais informações analisadas foram o valor da energia com seu erro associado para cada método (Variacional e Difusão), bem como as suas taxas de aceitação.

Outro arquivo de saída importante é o "config.out", que contêm as posições finais dos elétrons (configurações) e o estado atual do gerador de números aleatórios. ${ }^{53}$ A importância dele está no fato de poder continuar o cálculo de onde parou, e assim realizar novos testes. Para isso, deve-se transformar o "config.out" em um arquivo de entrada ("config.in"), para a continuação do cálculo.

Os arquivos de saída "dmc.hist" e "vmc.hist" contêm todos os componentes de energias calculados (energia local de cada configuração), respectivamente pelos métodos de difusão e variacional. Esses arquivos são utilizados juntamente com o "config.in" se for necessário a continuação do cálculo do ponto onde parou. 


\section{RESULTADOS E DISCUSSÃO}

\subsection{Geometrias de Equilíbrio dos Monômeros}

As geometrias de equilíbrio calculadas para cada molécula componente dos dímeros foram empregadas para a geração das estruturas iniciais dos dímeros. Nas tabelas abaixo (Tabela 2 a Tabela 7), tem-se os valores dos ângulos de ligação e o comprimento de ligação nos métodos e bases utilizados, para caracterizar a geometria de equilíbrio. Os valores calculados das energias para cada método e base, foram utilizados para o cálculo da energia de interação dos respectivos dímeros, dado no Tópico 5.2. Neste tópico, a energia utilizada é a energia total a 0 Kelvin, para cada molécula. Em todos os casos, os métodos foram calculados no software Gaussian09. Apenas os denominados "Teórico Referencial" é que foram retirados da literatura. Todos os métodos utilizados, que não sejam DFT e Hartree Fock, serviram como base de comparação das grandezas dos resultados, confirmando assim, a qualidade das funções de onda que foram utilizados no Monte Carlo Quântico.

Tabela 2: Resultados para comprimento de ligação, ângulo H-C-H e energia na geometria de equilíbrio do $\mathrm{CH}_{4}$ para cada método.

\begin{tabular}{|c|c|c|c|c|c|c|}
\hline \multicolumn{7}{|c|}{ Molécula $\mathrm{CH}_{4}$} \\
\hline Método/Base & $\begin{array}{l}\text { C-H } \\
(\AA)\end{array}$ & $\begin{array}{c}\mathbf{H}-\mathbf{H} \\
(\AA)\end{array}$ & $\begin{array}{c}\text { H-C-H } \\
\text { (grau) }\end{array}$ & $\begin{array}{c}\text { Energia } \\
\text { (kcal/mol) }\end{array}$ & $\begin{array}{c}\text { Erro } \\
\text { relativo } \\
\text { energia } \\
(\%)\end{array}$ & $\begin{array}{c}\text { Erro } \\
\text { absoluto } \\
\text { energia } \\
\text { (kcal/mol) }\end{array}$ \\
\hline $\operatorname{CCSD}(\mathrm{T})=\mathrm{full} / 6-31+\mathrm{G}(2 \mathrm{~d}, \mathrm{p})$ & 1,088 & 1,7778 & 109,471 & $-25353,78$ & 0,1396 & 35,45 \\
\hline $\mathrm{QCISD}(\mathrm{T})=$ full $/ 6-31+\mathrm{G}(2 \mathrm{~d}, \mathrm{p})$ & 1,088 & 1,7779 & 109,471 & $-25353,91$ & 0,1391 & 35,32 \\
\hline MP2/aug-cc-pvtz & 1,086 & 1,7739 & 109,471 & $-25360,44$ & 0,115 & 28,79 \\
\hline HSEH1PBE/aug-cc-pvtz & 1,088 & 1,7777 & 109,471 & $-25400,41$ & 0,044 & 11,18 \\
\hline WB97XD/aug-cc-pvtz & 1,088 & 1,7763 & 109,471 & $-25426,69$ & 0,147 & 37,46 \\
\hline B97D3/aug-cc-pvtz & 1,092 & 1,7841 & 109,472 & $-25421,51$ & 0,127 & 32,28 \\
\hline hf/aug-cc-pvtz & 1,082 & 1,7665 & 109,471 & $-25234,46$ & 0,609 & 154,77 \\
\hline Téorico Referencial ${ }^{55}$ & 1,087 & 1,7762 & 109,471 & $-25389,23$ & - & - \\
\hline
\end{tabular}

Dentre os métodos empregados neste estudo e levando em consideração a eficiência do método, utilizou-se o método $\operatorname{CCSD}(\mathrm{T})=$ full//6-31+G(2d,p) para a otimização inicial da molécula $\mathrm{CH}_{4}$. Com isso, sua geometria de equilíbrio foi usada como entrada nos demais métodos. Observa-se que os resultados obtidos pelos métodos QCISD(T)=full/6-31+G(2d,p) e MP2/aug-cc-pvtz ficaram bem próximos dos valores gerados pelo método CCSD(T). Para o $\mathrm{CH}_{4}$, em relação à energia, todos os métodos geraram resultados que ficaram na mesma 
grandeza dos valores comparativos, entretanto, o erros absolutos foram significativos, e poderiam afetar no cálculo da energia de interação, visto que, trabalha-se com dímeros fracamente ligados. Dessa maneira, qualquer variação de $1 \mathrm{kcal} / \mathrm{mol}$ ou até menos, pode gerar uma grande diferença no resultado final. Em relação à geometria, também foram bons os resultados. O maior desvio foi para o método Hartree Fock, mas mesmo assim, ele ficou na mesma grandeza do valor do teórico referencial e dos outros métodos mais sofisticados. O método e a base do teórico referencial é o $\operatorname{CCSD}(\mathrm{T})=$ full/aug-cc-pvtz (Tabela 2). Dentre os DFT, o HSEH1PBE/aug-cc-pvtz teve o menor erro comparativo. De maneira geral, todos os métodos foram bons para descrever a geometria de equilíbrio e a energia para o $\mathrm{CH}_{4}$.

Tabela 3: Resultados para o comprimento de ligação e energia na geometria de equilíbrio da molécula HF para cada método.

\begin{tabular}{|c|c|c|c|c|}
\hline \multicolumn{5}{|c|}{ Molécula HF } \\
\hline Método/Base & $\begin{array}{c}\text { H-F } \\
(\mathbf{\AA})\end{array}$ & $\begin{array}{c}\text { Energia } \\
(\mathbf{k c a l} / \mathbf{m o l})\end{array}$ & $\begin{array}{c}\text { Erro relativo } \\
\text { para energia } \\
(\%)\end{array}$ & $\begin{array}{c}\text { Erro absoluto } \\
\text { energia } \\
(\mathbf{k c a l} / \mathbf{m o l})\end{array}$ \\
\hline CCSD(T)=full/6-31+G(2d,p) & 0,920 & $-62913,62$ & 0,104 & 65,44 \\
\hline QCISD(T)=full/6-31+G(2d,p) & 0,920 & $-62914,11$ & 0,103 & 64,95 \\
\hline MP2/aug-cc-pvtz & 0,921 & $-62964,81$ & 0,024 & 14,25 \\
\hline HSEH1PBE/aug-cc-pvtz & 0,920 & $-63001,94$ & 0,036 & 22,88 \\
\hline WB97XD/aug-cc-pvtz & 0,918 & $-63040,40$ & 0,097 & 61,34 \\
\hline B97D3/aug-cc-pvtz & 0,926 & $-63030,55$ & 0,082 & 51,49 \\
\hline hf/aug-cc-pvtz & 0,899 & $-62789,47$ & 0,301 & 189,59 \\
\hline Teórico Referencial ${ }^{55}$ & 0,919 & $-62979,06$ & - & - \\
\hline
\end{tabular}

Para a molécula HF também foi utilizado o método $\operatorname{CCSD}(T)=f u l l / 6-31+G(2 d, p)$ como ponto de partida para o cálculo dos demais métodos. Todos os métodos ficaram na mesma grandeza do valor do teórico referencial (Tabela 3), que é dado pelo método e base: $\operatorname{CCSD}(\mathrm{T})=$ full/aug-cc-pvtz. Para a geometria de equilíbrio, todos os métodos ficaram próximos do valor teórico de 0,919 Å (ligação H-F). O maior erro relativo continuou sendo do hf/aug-cc-pvtz em relação à energia. O HSEH1PBE/aug-cc-pvtz foi o método que gerou o menor erro relativo, dentre os DFT. O método MP2/aug-cc-pvtz foi o método que mais se aproximou do resultado do teórico referencial, mais até que os métodos mais complexos, tais como: CCSD(T) e QCISD(T) na base 6-31+G(2d,p). 
Tabela 4: Resultados do comprimento de ligação e energia na geometria de equilíbrio da molécula de água para cada método.

\begin{tabular}{|c|c|c|c|c|c|}
\hline \multicolumn{6}{|c|}{ Molécula $\mathrm{H}_{2} \mathrm{O}$} \\
\hline Método/Base & $\begin{array}{l}\text { O-H } \\
(\AA)\end{array}$ & $\begin{array}{c}\text { H-O-H } \\
\text { (grau) }\end{array}$ & $\begin{array}{c}\text { Energia } \\
\text { (kcal/mol) }\end{array}$ & $\begin{array}{c}\text { Erro } \\
\text { relativo } \\
\text { energia } \\
(\%)\end{array}$ & $\begin{array}{c}\text { Erro } \\
\text { absoluto } \\
\text { energia } \\
\text { (kcal/mol) }\end{array}$ \\
\hline $\operatorname{CCSD}(T)=$ full/6-31+G(2d,p) & 0,9626 & 105,365 & $-47845,64$ & 0,145 & 69,4 \\
\hline $\mathrm{QCISD}(\mathrm{T})=$ full $/ 6-31+\mathrm{G}(2 \mathrm{~d}, \mathrm{p})$ & 0,9628 & 105,377 & $-47845,74$ & 0,144 & 69,3 \\
\hline MP2/aug-cc-pvtz & 0,9621 & 102,634 & $-47897,13$ & 0,037 & 17,91 \\
\hline HSEH1PBE/aug-cc-pvtz & 0,9585 & 104,930 & $-47933,40$ & 0,038 & 18,36 \\
\hline WB97XD/aug-cc-pvtz & 0,9572 & 105,098 & $-47966,74$ & 0,108 & 51,7 \\
\hline B97D3/aug-cc-pvtz & 0,9650 & 104,335 & $-47958,27$ & 0,090 & 43,23 \\
\hline Teórico Referencial $^{55}$ & 0,9588 & 104,383 & $-47915,04$ & - & - \\
\hline
\end{tabular}

Para a molécula de água $\left(\mathrm{H}_{2} \mathrm{O}\right)$, nota-se o mesmo comportamento dos monômeros já comentados: as geometrias de equilíbrio estão muito próximas do teórico referencial para todos os métodos e bases. As energias calculadas também estão na mesma grandeza do valor de referência, mas podem influenciar no cálculo da energia de interação, já que tais diferenças absolutas em kcal/mol são significativas para interações fracas. O DFT HSEH1PBE/aug-ccpvtz forneceu o menor erro relativo.

De forma geral, os métodos $\operatorname{CCSD}(\mathrm{T})=$ full/6-31+G(2d,p) e QCISD(T)=full/6$31+\mathrm{G}(2 \mathrm{~d}, \mathrm{p})$ tiveram resultados similares para quase todos os casos. O método MP2/aug-ccpvtz também obteve bons resultados e em alguns casos, até superiores que o $\operatorname{CCSD}(\mathrm{T})$ e QCISD(T) na base 6-31+G(2d,p).

Tabela 5: Resultados do comprimento de ligação e energia na geometria de equilíbrio do CO para cada método.

\begin{tabular}{|c|c|c|c|c|}
\hline \multicolumn{5}{|c|}{ Molécula CO } \\
\hline Método/Base & $\begin{array}{c}\text { C-O } \\
(\mathbf{A})\end{array}$ & $\begin{array}{c}\text { Energia } \\
(\mathbf{k c a l} / \mathbf{m o l})\end{array}$ & $\begin{array}{c}\text { Erro relativo } \\
\text { para energia } \\
(\%)\end{array}$ & $\begin{array}{c}\text { Erro absoluto } \\
\text { energia } \\
(\mathbf{k c a l} / \mathbf{m o l})\end{array}$ \\
\hline CCSD(T)=full/6-31+G(2d,p) & 1,1373 & $-70958,37$ & 0,099 & 70,53 \\
\hline QCISD(T)=full/6-31+G(2d,p) & 1,1383 & $-70959,75$ & 0,097 & 69,15 \\
\hline MP2/aug-cc-pvtz & 1,1389 & $-70996,86$ & 0,045 & 32,04 \\
\hline HSEH1PBE/aug-cc-pvtz & 1,1240 & $-71057,70$ & 0,040 & 28,8 \\
\hline WB97XD/aug-cc-pvtz & 1,1237 & $-71107,97$ & 0,111 & 79,07 \\
\hline B97D3/aug-cc-pvtz & 1,1349 & $-71089,68$ & 0,085 & 60,78 \\
\hline Teórico Referencial & 1,1312 & $-71028,90$ & - & - \\
\hline
\end{tabular}


Para a molécula de $\mathrm{CO}$, todos os métodos utilizados descreveram bem a geometria de equilíbrio. Analisando-se os valores das energias geradas pelos métodos, observa-se que dentre os DFT, se destaca o HSEH1PBE/aug-cc-pvtz, que apresentou o menor erro relativo. $\mathrm{O}$ DFT B97D3/aug-cc-pvtz, também retratou bem esse sistema.

Tabela 6: Resultados para o comprimento de ligação e energia na geometria de equilíbrio do $\mathrm{H}_{2}$ para cada método.

\begin{tabular}{|c|c|c|c|c|}
\hline \multicolumn{5}{|c|}{ Molécula $\mathbf{H}_{\mathbf{2}}$} \\
\hline Método/Base & $\begin{array}{c}\mathbf{H - H} \\
(\mathbf{\AA})\end{array}$ & $\begin{array}{c}\text { Energia } \\
\mathbf{( k c a l / m o l )}\end{array}$ & $\begin{array}{c}\text { Erro relativo } \\
\text { para energia } \\
(\boldsymbol{\%})\end{array}$ & $\begin{array}{c}\text { Erro absoluto } \\
\text { energia } \\
(\mathbf{k c a l} / \mathbf{m o l})\end{array}$ \\
\hline CCSD(T)=full/6-31+G(2d,p) & 0,738 & $-731,14$ & 0,638 & 4,7 \\
\hline QCISD(T)=full/6-31+G(2d,p) & 0,738 & $-731,14$ & 0,638 & 4,7 \\
\hline MP2/aug-cc-pvtz & 0,737 & $-731,05$ & 0,651 & 4,79 \\
\hline HSEH1PBE/aug-cc-pvtz & 0,745 & $-733,37$ & 0,335 & 2,47 \\
\hline WB97XD/aug-cc-pvtz & 0,743 & $-738,36$ & 0,342 & 2,52 \\
\hline B97D3/aug-cc-pvtz & 0,745 & $-742,80$ & 0,946 & 6,96 \\
\hline Teórico Referencial ${ }^{55}$ & 0,743 & $-735,84$ & - & - \\
\hline
\end{tabular}

Em relação à geometria de equilíbrio, todos os métodos forneceram bons resultados para o comprimento de ligação (H-H), se comparados com o valor teórico de 0,743 $\AA$. Para a energia, tem-se que todos os métodos empregados forneceram resultados que estavam na mesma grandeza do teórico referencial. Observa-se, que os resultados dos DFT HSEH1PBE/aug-cc-pvtz e WB97XD/aug-cc-pvtz tiveram um erro relativo um pouco menor em relação aos demais métodos, superando até mesmo o $\operatorname{CCSD}(\mathrm{T})=$ full/6-31+G(2d,p) e MP2/aug-cc-pvtz. O maior erro encontrado foi para o DFT B97D3/aug-cc-pvtz.

Tabela 7: Resultados para a energia na geometria de equilíbrio do átomo de Argônio para cada método.

\begin{tabular}{|c|c|c|c|}
\hline \multicolumn{4}{|c|}{ Átomo Ar } \\
\hline Método/Base & $\begin{array}{c}\text { Energia } \\
\mathbf{( k c a l / m o l )}\end{array}$ & $\begin{array}{c}\text { Erro relativo } \\
\text { para energia } \\
(\boldsymbol{\%})\end{array}$ & $\begin{array}{c}\text { Erro absoluto } \\
\text { energia } \\
\text { (kcal/mol) }\end{array}$ \\
\hline CCSD(T)=full/6-31+G(2d,p) & $-330669,55$ & 0,024 & 78,07 \\
\hline QCISD(T)=full/6-31+G(2d,p) & $-330669,57$ & 0,023 & 78,05 \\
\hline MP2/aug-cc-pvtz & $-330712,48$ & 0,012 & 35,14 \\
\hline HSEH1PBE/aug-cc-pvtz & $-330948,43$ & 0,061 & 200,81 \\
\hline WB97XD/aug-cc-pvtz & $-331039,60$ & 0,088 & 291,98 \\
\hline B97D3/aug-cc-pvtz & $-331068,57$ & 0,097 & 320,95 \\
\hline Teórico Referencial & $-330747,62$ & - & \\
\hline
\end{tabular}


A Tabela 7 mostra os resultados das energias geradas para o átomo de argônio (Ar). Percebe-se que a energia para este átomo é muito maior que as energias das demais moléculas já descritas. O átomo de argônio possui 18 elétrons, sendo o átomo com o maior número de elétrons dentre os estudados. De acordo com os erros relativos, percebe-se que todos os métodos geraram resultados que estavam na mesma grandeza do teórico referencial, mas os erros absolutos são bem significativos e podem produzir resultados não compatíveis com a realidade. O menor erro relativo encontrado dentre os DFT foi para o HSEH1PBE/aug-ccpvtz. O método MP2/aug-cc-pvtz obteve o menor erro relativo em relação à energia do sistema.

Dessa forma, os DFT utilizados, produziram bons resultados para todas as moléculas estudadas. Tanto os resultados pertencentes à geometria de equilíbrio, quanto à energia, tiveram erros relativos menores ou próximos de $1 \%$. Isso mostra que as funções de onda produzidas por esses métodos descreveram satisfatoriamente os sistemas estudados. Até mesmo as funções de onda do Hartree Fock, no caso das moléculas $\mathrm{CH}_{4}$ e $\mathrm{HF}$, podem ser consideradas satisfatórias, visto que seus resultados também ficaram na mesma grandeza do teórico referencial.

\subsection{Geometrias de Equilíbrio dos Dímeros}

Todos os cálculos para obtenção das geometrias dos monômeros e dos dímeros foram realizados com o software Gaussian09. Utilizaram-se as geometrias de equilíbrio dos monômeros, calculadas no Tópico 5.1, para a construção das estruturas dos dímeros, facilitando, assim, a convergência dos métodos utilizados.

\subsubsection{Dímero $\mathrm{CH}_{4}-\mathrm{CH}_{4}$}

Para o dímero $\mathrm{CH}_{4}-\mathrm{CH}_{4}$, encontrou-se a estrutura de equilíbrio (mínimo global) dada na Figura 2, pelo método MP2/aug-cc-pvtz. Tal estrutura está baseada no trabalho de Li e Chao, ${ }^{56}$ que estudaram esse dímero utilizando o método e base $\operatorname{CCSD}(\mathrm{T})=$ full/aug-cc-pvdz, obtendo uma boa representação do sistema. O valor da energia de interação desse método está na Tabela 8, sendo o teórico referencial. 


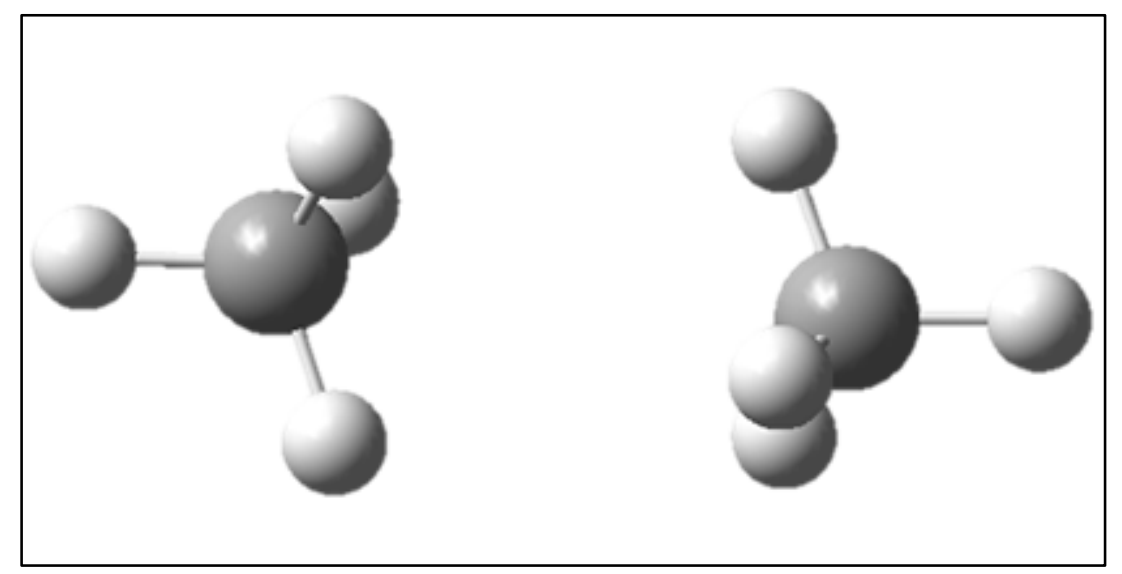

Figura 2: Dímero $\mathrm{CH}_{4}-\mathrm{CH}_{4}$ na sua geometria de equilíbrio.

Para esse dímero, foram calculadas as seguintes propriedades dadas na Tabela 8: "rCC" é a distância entre os átomos de carbono de cada monômero $\mathrm{CH}_{4}$; "rC-H" é a distância entre o átomo de hidrogênio mais próximo (primeiro monômero) e o átomo de carbono (segundo monômero): $\mathrm{H}_{3} \mathrm{CH}-\mathrm{CH}_{4}$; "rH-H" é a distância entre os dois hidrogênios (um de cada monômero) mais próximos; "ET" é a energia total do dímero; " $\Delta \mathrm{E}$ ” é a energia de interação do dímero, dado pela diferença de energia do dímero pela energia de cada monômero (Tópico 5.1): $\Delta \mathrm{E}=\mathrm{ET}\left(\mathrm{CH}_{4}-\mathrm{CH}_{4}\right)-\left(\mathrm{ET}\left(\mathrm{CH}_{4}\right)+\mathrm{ET}\left(\mathrm{CH}_{4}\right)\right)$.

Tabela 8: Resultados para o dímero $\mathrm{CH}_{4}-\mathrm{CH}_{4}$, no seu estado de equilíbrio, para cada método.

\begin{tabular}{|c|c|c|c|c|c|c|}
\hline \multicolumn{8}{|c|}{$\mathbf{C H}_{4}-\mathbf{C H}_{4}$} \\
\hline Método/Base & $\begin{array}{c}\text { rC-C } \\
(\AA)\end{array}$ & $\begin{array}{c}\text { rC-H } \\
(\AA)\end{array}$ & $\begin{array}{c}\mathbf{r H - H} \\
(\AA)\end{array}$ & $\begin{array}{c}\text { Dipolo } \\
(\mathbf{D e b y e})\end{array}$ & $\begin{array}{c}\mathbf{E T} \text { a 0 K } \\
(\mathbf{k c a l} / \mathbf{m o l})\end{array}$ & $\begin{array}{c}\Delta \mathbf{E} \\
(\mathbf{k c a l} / \mathbf{m o l})\end{array}$ \\
\hline MP2/aug-cc-pvtz & 3,620 & 3,400 & 3,037 & 0,0003 & $-50721,47$ & $-0,59$ \\
\hline HSEH1PBE/aug-cc-pvtz & 4,006 & 3,753 & 3,383 & 0,0007 & $-50800,97$ & $-0,15$ \\
\hline B97D3/aug-cc-pvtz & 3,774 & 3,542 & 3,184 & 0,000015 & $-50843,69$ & $-0,67$ \\
\hline Teórico Referencial $^{56}$ & 3,65 & - & - & - & - & $-0,51$ \\
\hline
\end{tabular}

Os métodos que serviram como base para comparação das grandezas dos resultados foram: o MP2/aug-cc-pvtz, calculado no Gaussian09 (para os casos em que não se encontraram dados para todos os parâmetros) e o $\operatorname{CCSD}(\mathrm{T})=$ full/aug-cc-pvdz, o qual é o teórico referencial (Tabela 8), encontrado na literatura.

Para os métodos calculados, observa-se que todos tiveram resultados satisfatórios para a energia total (ET), se comparado com o valor do resultado do método MP2/aug-cc-pvtz, pois as energias calculadas estão na mesma grandeza do valor de referência. Mesmo assim, 
tais energias podem influenciar no cálculo da energia de interação, já que tais diferenças absolutas em kcal/mol são significativas para interações fracas. Desse modo, até valores menores que $1 \mathrm{kcal} / \mathrm{mol}$, podem gerar grande impacto no resultado final. Tal comportamento, também, atinge os demais dímeros estudados, já que todos possuem energia de interação pequena. Os erros relativos foram de $0,16 \%$ para o método HSEH1PBE/aug-cc-pvtz e de 0,24\% para o B97D3/aug-cc-pvtz. Com os métodos WB97XD/aug-cc-pvtz e hf/aug-cc-pvtz não foi possível determinar uma estrutura de equilíbrio para o dímero, pois todas as estruturas obtidas apresentaram frequências negativas. Com isso, resolveu-se utilizar apenas os demais DFT, neste caso.

Considerando a geometria de equilíbrio, tendo o método MP2/aug-cc-pvtz como referência, tem-se que o esquema B97D3/aug-cc-pvtz forneceu melhores resultados que o HSEH1PBE/aug-cc-pvtz, diferentemente do que aconteceu com o resultado da "ET", em que o HSEH1PBE/aug-cc-pvtz foi um pouco melhor. Desse modo, ambas as funções de onda testadas com esses funcionais se mostraram adequadas para representação do sistema e serviram como funções de onda tentativa para entrada no Monte Carlo Quântico.

Pode-se afirmar também que há pouca influência do dipolo nesta interação de metanos. Basicamente se tem interações de Van der Waals, se considerados os valores dos dipolos. O método B97D3/aug-cc-pvtz obteve o menor valor para tal propriedade.

Em relação à energia de interação do dímero $(\Delta \mathrm{E})$, que é um dos cálculos mais sensíveis de energia, vê-se que o método B97D3/aug-cc-pvtz está mais próximo do resultado do teórico referencial. Percebe-se que o método MP2/aug-cc-pvtz também gerou um bom resultado para a $\Delta \mathrm{E}$, se comparado com o teórico referencial. Na Tabela 9, estão os resultados dos erros absolutos, considerando os métodos MP2/aug-cc-pvtz e CCSD(T)/aug-cc-pvdz como referenciais.

Tabela 9: Erro Absoluto para a energia de interação.

\begin{tabular}{|c|c|c|}
\hline \multicolumn{3}{|c|}{ Erro absoluto para $\Delta \mathbf{E}$} \\
\hline Métodos/bases & MP2 (kcal/mol) & CCSD(T) (kcal/mol) \\
\hline HSEH1PBE/aug-cc-pvtz & 0,44 & 0,36 \\
\hline B97D3/aug-cc-pvtz & 0,08 & 0,16 \\
\hline
\end{tabular}

O erro absoluto para o B97D3/aug-cc-pvtz é bem menor que o outro DFT. O HSEH1PBE/aug-cc-pvtz, apesar de ter dado bons resultados, e às vezes até melhor que o B97D3, não obteve um bom resultado para a energia de interação do $\mathrm{CH}_{4}-\mathrm{CH}_{4}$. Se fosse 
considerado apenas o valor da energia de interação para a escolha da função de onda tentativa, escolher-se-ia apenas o método B97D3/aug-cc-pvtz. Como o HSEH1PBE/aug-cc-pvtz obteve bons resultados (Tabela 8 e Tabela 2) para as energias em todos os cálculos e mostrou-se bom para cálculos de geometria de equilíbrio, resolveu-se utilizar também sua função de onda para entrada no Monte Carlo Quântico. Mas mesmo assim, não se pode garantir que os métodos que produziram os melhores resultados para a geometria ou para a energia, também produziriam os melhores resultados no MCQ. A partir disso, pode-se afirmar que todas as funções de onda testadas, que deram resultados aceitáveis, poderiam ser utilizadas no Monte Carlo.

\subsubsection{Dímero $\mathrm{CH}_{4}-\mathrm{HF}$}

Para o dímero $\mathrm{CH}_{4}-\mathrm{HF}$, foram utilizadas as bases e métodos dados na Tabela 10 . Utilizou-se inicialmente, a estrutura da Figura 3, em que o átomo de hidrogênio do monômero $\mathrm{H}-\mathrm{F}$ está voltado para o átomo de carbono do monômero $\mathrm{CH}_{4}$. Essa estrutura foi gerada pelo método MP2/aug-cc-pvtz e está de acordo com o trabalho Chandra e Nguyen. ${ }^{57}$

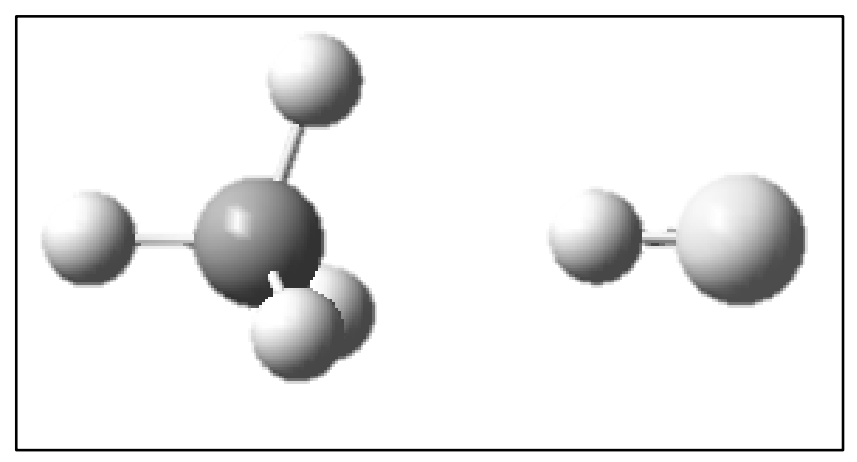

Figura 3: Dímero $\mathrm{CH}_{4}-\mathrm{HF}$ na sua geometria de equilíbrio.

Na Tabela 10, rC-H é a distância entre o carbono do $\mathrm{CH}_{4}$ e o hidrogênio do HF; rC-F é a distância entre o carbono do $\mathrm{CH}_{4}$ e o flúor do HF; rH-H é a distância entre um hidrogênio do $\mathrm{CH}_{4}$ e o hidrogênio do $\mathrm{HF}$ (os mais próximos). 
Tabela 10: Resultados para o dímero $\mathrm{CH}_{4}-\mathrm{HF}$, no seu estado de mínima energia, para cada método.

\begin{tabular}{|c|c|c|c|c|c|c|}
\hline \multicolumn{7}{|c|}{$\mathbf{C H}_{\mathbf{4}}-\mathbf{H F}$} \\
\hline Método/Base & $\begin{array}{c}\text { rC-H } \\
(\mathbf{\AA})\end{array}$ & $\begin{array}{c}\text { rC-F } \\
(\AA)\end{array}$ & $\begin{array}{c}\text { rH-H } \\
(\AA)\end{array}$ & $\begin{array}{c}\text { Dipolo } \\
(\mathbf{D e b y e})\end{array}$ & $\begin{array}{c}\text { ET a 0 K } \\
(\mathbf{k c a l} / \mathbf{m o l})\end{array}$ & $\begin{array}{c}\Delta \mathbf{E} \\
(\mathbf{k c a l} / \mathbf{m o l})\end{array}$ \\
\hline MP2/aug-cc-pvtz & 2,300 & 3,224 & 2,203 & 2,3801 & $-88327,06$ & $-1,81$ \\
\hline HSEH1PBE/aug-cc-pvtz & 2,255 & 3,179 & 2,168 & 2,3419 & $-88403,99$ & $-1,64$ \\
\hline B97D3/aug-cc-pvtz & 2,391 & 3,320 & 2,287 & 2,2436 & $-88453,79$ & $-1,73$ \\
\hline hf/aug-cc-pvtz & 2,675 & 3,574 & 2,534 & 2,1922 & $-88024,46$ & $-0,53$ \\
\hline Teórico Referencial $^{57}$ & 2,33 & - & - & 2,28 & - & $(-1,84) /(-2,14)$ \\
\hline
\end{tabular}

Os métodos utilizados como base para comparação das grandezas foram o MP2/augcc-pvtz, calculado no Gaussian09 e o teórico referencial, encontrado na literatura. Esse é dado pelo método MP2=full/6-311++G(3df,2p).

Nota-se que os parâmetros da geometria de equilíbrio de todos os métodos (até mesmo o hf/aug-cc-pvtz) estão próximos dos resultados calculados pelo método MP2/aug-cc-pvtz e do teórico referencial. Mais uma vez o método WB97XD/aug-cc-pvtz não forneceu uma estrutura de mínima energia, pois em todos os testes estavam presentes frequências negativas.

Nesse dímero há mais influência do dipolo, diferentemente do que aconteceu com o dímero $\mathrm{CH}_{4}-\mathrm{CH}_{4}$, que basicamente possuía interações de Van der Waals.

A “ET" para todos os métodos ficou na mesma grandeza do método referencial MP2. O maior erro relativo encontrado foi de $0,34 \%$ para o método hf/aug-cc-pvtz. O melhor resultado foi do método HSEH1PBE/aug-cc-pvtz. Pelos resultados da geometria de equilíbrio e da "ET", pode-se afirmar que as funções de onda geradas por todos os DFT e pelo Hartree Fock podem ser utilizadas como entrada no Monte Carlo Quântico, pois representaram razoavelmente o sistema $\mathrm{CH}_{4}-\mathrm{HF}$.

Para a energia de interação $(\Delta \mathrm{E})$ do dímero $\mathrm{CH}_{4}-\mathrm{HF}$, nota-se que os DFT tiveram resultados próximos dos valores referenciais. Percebe-se também, que se tem 2 valores de energia de interação $(\Delta \mathrm{E})$ na Tabela 10 . O valor de $-1,84 \mathrm{kcal} / \mathrm{mol}$ é dado pelo método e base: MP2=full/6-311++G(3df,2p) já o valor de $-2,14 \mathrm{kcal} / \mathrm{mol}$ é dado pelo método e base: MP2=full/6-311++G(3df,2pd). Nesse último, fez-se um cálculo single-point, utilizando diferentes expoentes de função, baseados em outro trabalho. Observa-se que em todos os casos houve um erro maior em relação ao método MP2=full/6-311++G(3df,2p). Colocando-se o método MP2/aug-cc-pvtz como referência, verificou-se que o método B97D3/aug-cc-pvtz, teve $0,08 \mathrm{kcal} / \mathrm{mol}$ de erro absoluto e o método HSEH1PBE/aug-cc-pvtz teve $0,17 \mathrm{kcal} / \mathrm{mol}$. Já o hf/aug-cc-pvtz, gerou um resultado pior que os DFT, tendo um erro absoluto de 1,28 
$\mathrm{kcal} / \mathrm{mol}$. Diante disso, as funções de onda geradas pelos dois métodos DFT utilizados poderiam servir de entrada no Monte Carlo Quântico, já que representaram adequadamente o sistema. Até mesmo a função de onda do método Hartree Fock, poderia ser testada.

\subsubsection{Dímero $\mathrm{CH}_{4}-\mathrm{H}_{2} \mathrm{O}$}

A geometria de equilíbrio do dímero $\mathrm{CH}_{4}-\mathrm{H}_{2} \mathrm{O}$, foi obtida pelo método MP2/aug-ccpvtz e está de acordo com o trabalho de Martins et al. ${ }^{58}$ Tal geometria está representada na Figura 4, em que se observa que o átomo de hidrogênio da molécula de água está interagindo com o carbono da molécula de metano.

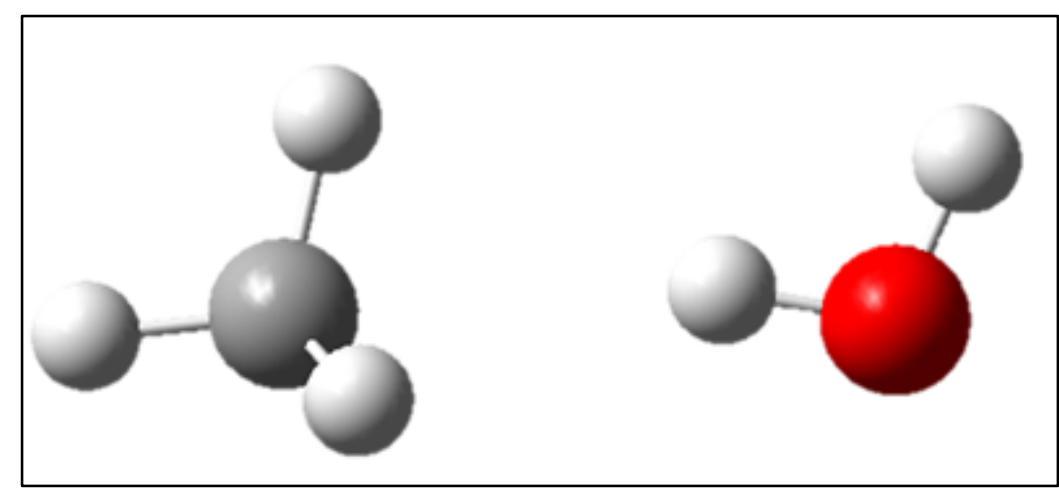

Figura 4: Dímero $\mathrm{CH}_{4}-\mathrm{H}_{2} \mathrm{O}$ na sua geometria de equilíbrio.

Os resultados dos cálculos para esse dímero estão na Tabela 11, em que rC-O é a distância entre o carbono do metano e o oxigênio da molécula de água; rC-H é a distância entre o carbono do $\mathrm{CH}_{4}$ e o hidrogênio mais próximo da $\mathrm{H}_{2} \mathrm{O}$; rH-H é a distância entre o hidrogênio do $\mathrm{CH}_{4}$ e o hidrogênio da $\mathrm{H}_{2} \mathrm{O}$ (os mais próximos).

Tabela 11: Resultados para o dímero $\mathrm{CH}_{4}-\mathrm{H}_{2} \mathrm{O}$, no seu estado de equilíbrio, para cada método.

\begin{tabular}{|c|c|c|c|c|c|c|}
\hline \multicolumn{7}{|c|}{$\mathrm{CH}_{4}-\mathrm{H}_{2} \mathrm{O}$} \\
\hline Método/Base & $\begin{array}{c}\text { rC-O } \\
(\AA)\end{array}$ & $\begin{array}{c}\text { rC-H } \\
(\AA)\end{array}$ & $\begin{array}{c}\text { rH-H } \\
(\AA)\end{array}$ & $\begin{array}{c}\text { Dipolo } \\
\text { (Debye) }\end{array}$ & $\begin{array}{c}\text { ET a 0 K } \\
\text { (kcal/mol) }\end{array}$ & $\begin{array}{c}\Delta \mathbf{E} \\
(\mathrm{kcal} / \mathrm{mol})\end{array}$ \\
\hline MP2/ aug-cc-pvtz & 3,477 & 2,528 & 2,349 & 2,0628 & $-73258,72$ & $-1,15$ \\
\hline HSEH1PBE/aug-cc-pvtz & 3,544 & 2,594 & 2,392 & 1,9464 & $-73334,56$ & $-0,75$ \\
\hline WB97XD/aug-cc-pvtz & 3,514 & 2,557 & 2,349 & 1,9853 & $-73394,52$ & $-1,09$ \\
\hline B97D3/aug-cc-pvtz & 3,617 & 2,665 & 2,478 & 1,8846 & $-73380,88$ & $-1,10$ \\
\hline Teórico Referencial $^{58}$ & - & - & - & - & - & 0,8235 \\
\hline
\end{tabular}


Os métodos que foram utilizados para analisar as grandezas dos resultados foram o MP2/aug-cc-pvtz, calculado no Gaussian09 (para geometria e energia) e o método MP2/augcc-pvqz com correções de contrapeso (CP), denominado teórico referencial na Tabela 11 (para a energia de interação). No trabalho de Martins et $a l,{ }^{58}$ em que se obteve o teórico referencial, havia também resultados para esse dímero com o método MP2/aug-cc-pvtz. Os resultados para a geometria de equilíbrio (rC-O, $\mathrm{rC}-\mathrm{H}$ e $\mathrm{rH}-\mathrm{H})$ estão idênticos ao calculado neste trabalho com o mesmo método e base. Tal fato confirmou que a geometria de equilíbrio estava em conformidade com o teórico referencial. Apesar de ter todos os parâmetros da geometria de equilíbrio iguais, os resultados para a energia de interação $(\Delta \mathrm{E})$ no trabalho referencial estavam corrigidos pelo BSSE (Erro de Superposição de Base). Tal valor para a energia de interação com BSSE foi de $-0,89 \mathrm{kcal} / \mathrm{mol}$ e com isso se observa uma diferença de $0,26 \mathrm{kcal} / \mathrm{mol}$ em relação ao valor dado pelo método MP2/aug-cc-pvtz na tabela 11 .

De acordo com os resultados da Tabela 11, nota-se que para a geometria de equilíbrio, todos os métodos deram bons resultados, ficando em conformidade com o método MP2/augcc-pvtz. O método B97D3/aug-cc-pvtz, para a geometria, teve um desvio um pouco maior que os demais, mas mesmo assim ficou próximo do referencial.

Para este dímero, pode-se notar que há maior influência do dipolo, se comparado com o dímero $\mathrm{CH}_{4}-\mathrm{CH}_{4}$.

Para a energia total, observa-se, que todos os métodos estão em concordância com a grandeza do valor do método MP2, porém os erros absolutos em kcal/mol são significativos, visto que se trabalha com interações fracas. Pelos erros relativos da Tabela12, percebe-se que o método HSEH1PBE/aug-cc-pvtz teve o melhor resultado comparativo. O resultado com o maior erro relativo foi para o método WB97XD/aug-cc-pvtz, mas, mesmo assim, o valor ficou na mesma grandeza dos demais. Levando em consideração apenas a geometria de equilíbrio e a "ET", pode-se concluir que todas as funções de onda dos DFT testados, poderiam ser utilizadas para entrada no Monte Carlo Quântico, pois estariam representando razoavelmente o sistema estudado.

Tabela 12: Erros relativos da ET e erros absolutos para energia de interação.

\begin{tabular}{|c|c|c|}
\hline Métodos & $\begin{array}{c}\text { Erro Relativo p/ } \\
\text { ET }(\boldsymbol{\%})\end{array}$ & $\begin{array}{c}\text { Erro absoluto p/ } \mathbf{\Delta E} \\
\text { (kcal/mol) }\end{array}$ \\
\hline HSEH1PBE/aug-cc-pvtz & 0,10 & 0,4 \\
\hline WB97XD/aug-cc-pvtz & 0,18 & 0,06 \\
\hline B97D3/aug-cc-pvtz & 0,17 & 0,05 \\
\hline
\end{tabular}


Em relação à energia de interação, pode-se analisar pela Tabela 12, que o maior erro absoluto foi para o método HSEH1PBE/aug-cc-pvtz. Os outros 2 métodos DFT tiveram valores semelhantes, com um erro absoluto entre eles de 0,01 kcal $/ \mathrm{mol}$. Desse modo, considerando apenas a energia de interação, pode-se afirmar que as funções de onda geradas pelos DFT WB97XD/aug-cc-pvtz e B97D3/aug-cc-pvtz seriam as melhores opções para início do cálculo no Monte Carlo Quântico. Mesmo assim, não se pode desconsiderar o método HSEH1PBE/aug-cc-pvtz, pois o mesmo também deu bons resultados nas outras propriedades estudadas. Apenas para a energia de interação que tal método teve um desvio maior em relação ao método referencial.

\subsubsection{Dímero $\mathrm{CH}_{4}-\mathrm{CO}$}

Para o Dímero $\mathrm{CH}_{4}-\mathrm{CO}$, foi obtida a geometria apresentada na Figura 5. Utilizou-se o método MP2/aug-cc-pvtz para encontrar esta geometria. Tal geometria está de acordo com o trabalho de Surin et al, ${ }^{59}$ que utilizou o método CCSD(T)-F12a/aVTZ. O método CCSD(T)F12a é bem mais sofisticado que os demais métodos utilizados neste projeto e está na Tabela 13 como teórico referencial. Percebe-se, que a molécula “CO” está inclinada, com o átomo de oxigênio mais próximo da molécula de metano. $\mathrm{O}$ ângulo entre o carbono do $\mathrm{CH}_{4}$, o oxigênio e o carbono da molécula de CO (C-Ô-C) é de aproximadamente $124^{\circ}$. Os outros resultados das geometrias são dados na Tabela 13.

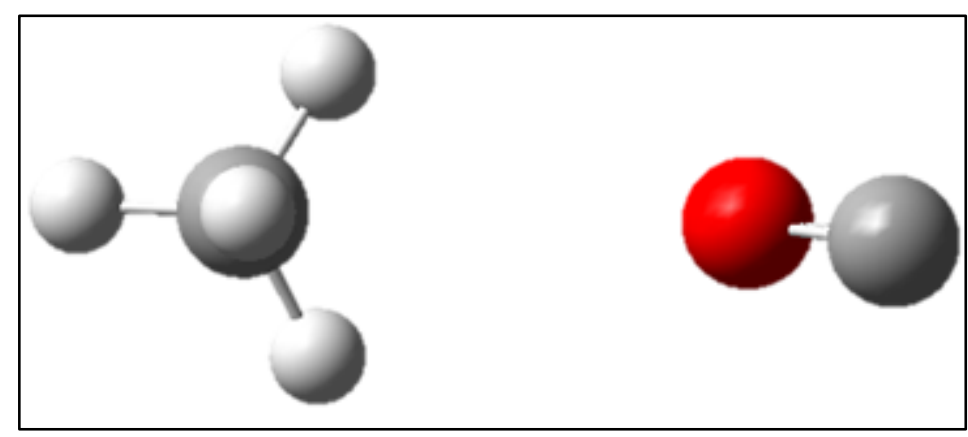

Figura 5: Dímero $\mathrm{CH}_{4}-\mathrm{CO}$ na sua geometria de equilíbrio.

Na Tabela 13, têm-se os resultados das geometrias no mínimo global para cada método, além das propriedades energéticas, em que "rC-C" é a distância entre o carbono do $\mathrm{CH}_{4}$ e o carbono do $\mathrm{CO}$; "rC-O" é a distância entre o carbono do $\mathrm{CH}_{4}$ e o Oxigênio; "rH-O" é a distância entre o hidrogênio (o mais próximo) do $\mathrm{CH}_{4}$ e o oxigênio. 
Tabela 13: Resultados para o dímero $\mathrm{CH}_{4}-\mathrm{CO}$, no seu estado de equilíbrio, para cada método.

\begin{tabular}{|c|c|c|c|c|c|c|}
\hline \multicolumn{7}{|c|}{$\mathbf{C H}_{4}$-CO } \\
\hline Método/Base & $\begin{array}{c}\text { rC-C } \\
(\AA)\end{array}$ & $\begin{array}{c}\text { rC-O } \\
(\AA)\end{array}$ & $\begin{array}{c}\text { rH-O } \\
(\AA)\end{array}$ & $\begin{array}{c}\text { Dipolo } \\
(\text { Debye) }\end{array}$ & $\begin{array}{c}\text { ET a 0 K } \\
(\mathbf{k c a l} / \mathbf{m o l})\end{array}$ & $\begin{array}{c}\Delta \mathbf{E} \\
(\mathbf{k c a l} / \mathbf{m o l})\end{array}$ \\
\hline MP2/aug-cc-pvtz & 4,261 & 3,518 & 3,055 & 0,3204 & $-96358,77$ & $-1,47$ \\
\hline WB97XD/aug-cc-pvtz & 3,531 & 3,713 & 3,136 & 0,0631 & -96534.52 & 0,142 \\
\hline Teórico Referencial ${ }^{59}$ & - & 3,592 & - & - & - & $-0,465$ \\
\hline
\end{tabular}

Dentre os métodos DFT testados, apenas o WB97XD/aug-cc-pvtz conseguiu alcançar o estado mínimo, já que os outros métodos apresentaram frequências negativas em todos os testes.

Em se tratando da geometria de equilíbrio, este DFT teve uma concordância razoável com o método MP2/aug-cc-pvtz e com o teórico referencial. O maior desvio dos parâmetros calculados foi para a distância carbono-carbono (rC-C).

Há também uma diferença nos valores dos dipolos. Mas de maneira geral, observa-se pouca influência do dipolo.

A energia total para este DFT, também ficou em consonância com a grandeza do valor do método referencial MP2.

Por fim, tem-se que o valor da energia de interação obtida pelo WB97XD não concordou com o valor de referência. O mesmo ficou positivo, mostrando que a soma dos valores das energias das 2 moléculas separadamente $\left(\mathrm{CH}_{4}\right.$ e $\left.\mathrm{CO}\right)$ ficou menor que a do dímero. Na prática, isso significa que, de acordo com o resultado da energia de interação dada por este DFT, não haveria a formação do dímero $\mathrm{CH}_{4}$-CO. Percebe-se que o valor da $\Delta \mathrm{E}$ do DFT está mais próximo do resultado dado pelo teórico referencial, obtendo-se um erro absoluto de $0,607 \mathrm{kcal} / \mathrm{mol}$.

Considerando-se apenas a energia total e a geometria, percebe-se que o método WB97XD/aug-cc-pvtz poderia gerar uma boa função de onda para entrada no Monte Carlo. Já pela energia de interação, ele não seria a melhor escolha. Mas como já foi dito, não se pode garantir que as funções de onda que geraram os melhores resultados para geometria e energia, forneceriam os melhores resultados no MCQ. Com isso, para este dímero, todos os testes no método Monte Carlo Quântico foram realizados com a função de onda do WB97XD. 


\subsubsection{Dímero $\mathrm{CH}_{4}-\mathrm{H}_{2}$}

Outro dímero estudado foi o $\mathrm{CH}_{4}-\mathrm{H}_{2}$. Utilizou-se o método MP2/aug-cc-pvtz para encontrar a geometria de equilíbrio, dada na Figura 6.

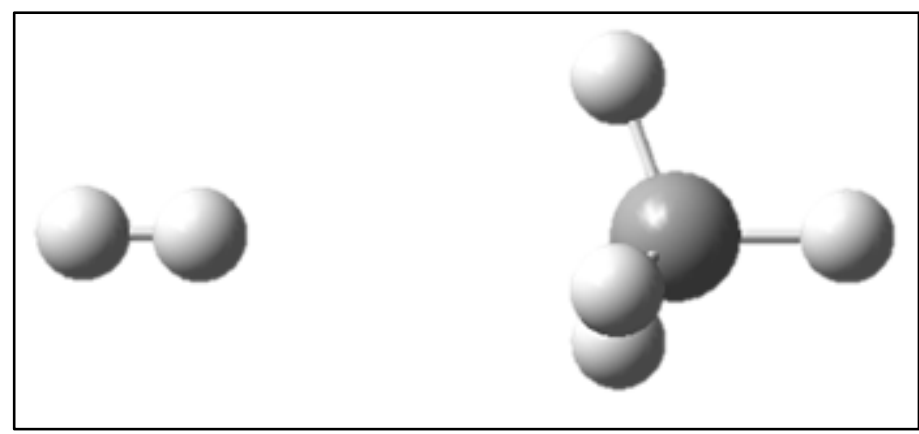

Figura 6: Dímero $\mathrm{CH}_{4}-\mathrm{H}_{2}$ na sua geometria de equilíbrio.

Os métodos testados neste caso foram os DFT HSEH1PBE/aug-cc-pvtz e B97D3/ augcc-pvtz. O DFT WB97XD/aug-cc-pvtz forneceu frequências negativas em todos os testes. Os resultados dos cálculos desses métodos são dados na Tabela 14, em que: "rC-H1" é a distância entre o carbono do $\mathrm{CH}_{4}$ e o hidrogênio do $\mathrm{H}_{2}$ mais próximo do metano; "rC--H2" é a distância entre o carbono do $\mathrm{CH}_{4}$ e o outro hidrogênio do $\mathrm{H}_{2}$; "rH1--H" é a distância entre o hidrogênio do $\mathrm{H}_{2}$ e o hidrogênio do $\mathrm{CH}_{4}$ mais próximos.

Tabela 14: Resultados para o dímero $\mathrm{CH}_{4}-\mathrm{H}_{2}$, no seu estado de equilíbrio, para cada método.

\begin{tabular}{|c|c|c|c|c|c|c|}
\hline \multicolumn{7}{|c|}{$\mathrm{CH}_{4}---\mathrm{H}_{2}$} \\
\hline Método/Base & $\begin{array}{c}\text { rC--H1 } \\
\text { (A) }\end{array}$ & $\begin{array}{c}\text { rC--H2 } \\
\text { (̊̊) }\end{array}$ & $\begin{array}{c}\text { rH1--H } \\
\text { (A) }\end{array}$ & $\begin{array}{c}\text { Dipolo } \\
\text { (Debye) }\end{array}$ & $\begin{array}{c}\text { ET a } 0 \mathrm{~K} \\
\text { (kcal/mol) }\end{array}$ & $\begin{array}{c}\Delta \mathbf{E} \\
\text { (kcal/mol) }\end{array}$ \\
\hline MP2/aug-cc-pvtz & 3,065 & 3,802 & 2,883 & 0,0426 & $-26091,81$ & $-0,32$ \\
\hline HSEH1PBE/aug-cc-pvtz & 3,194 & 3,939 & 3,014 & 0,0403 & $-26133,97$ & $-0,19$ \\
\hline B97D3/aug-cc-pvtz & 3,164 & 3,909 & 2,978 & 0,0430 & $-26164,68$ & $-0,37$ \\
\hline
\end{tabular}

Todos os resultados dos DFT para a geometria de equilíbrio ficaram próximos do método comparativo MP2. O método B97D3/aug-cc-pvtz ficou um pouco melhor que o outro DFT, para a geometria.

Nota-se que o efeito do dipolo é pequeno, podendo-se afirmar que as interações de Van der Waals são dominantes. 
Para a energia total, percebe-se que o método HSEH1PBE/aug-cc-pvtz está mais próximo do valor referencial (MP2). O DFT B97D3/aug-cc-pvtz, teve um erro relativo um pouco maior.

Em relação à energia de interação, pode-se concluir que o método B97D3 teve um melhor resultado, ficando bem próximo do valor de referência (MP2), com um erro absoluto de $0,05 \mathrm{kcal} / \mathrm{mol}$. O HSEH1PBE/aug-cc-pvtz também obteve um resultado razoável, com um erro absoluto de $0,13 \mathrm{kcal} / \mathrm{mol}$.

O método B97D3/aug-cc-pvtz superou o outro DFT em quase todas as propriedades analisadas, e, portanto, descreveu melhor o sistema, obtendo uma ótima energia de interação. Com isso, a sua função de onda foi considerada a melhor opção de entrada para o MCQ.

\subsubsection{Dímero $\mathrm{CH}_{4}-\mathrm{Ar}$}

Analisou-se também o dímero $\mathrm{CH}_{4}$-Ar. Sua geometria de equilíbrio foi encontrada pelo método MP2/aug-cc-pvtz. A Figura 7 mostra a geometria do seu estado mínimo, estando de acordo com o trabalho de Kalugina et al. ${ }^{34}$

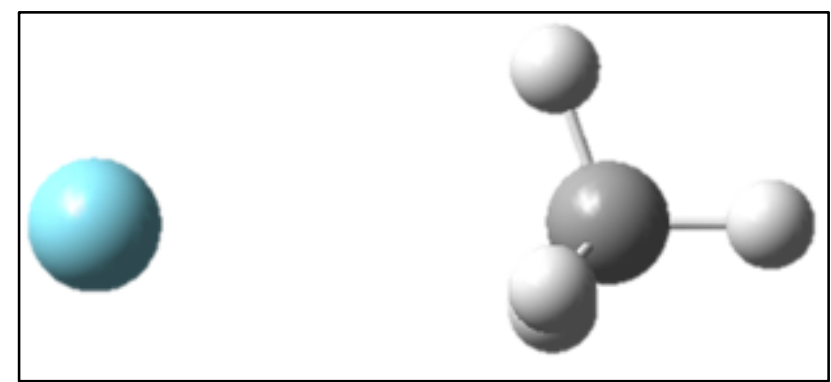

Figura 7: Dímero $\mathrm{CH}_{4}-\mathrm{Ar}$ na sua geometria de equilíbrio.

Na Tabela 15 estão os resultados das geometrias e propriedades energéticas para esse dímero, em que "rC-Ar" é a distância entre o carbono e o argônio; "rH-Ar" é a distância entre o hidrogênio e o argônio. 
Tabela 15: Resultados para o dímero $\mathrm{CH}_{4}$ Ar, no seu estado de equilíbrio, para cada método.

\begin{tabular}{|c|c|c|c|c|c|}
\hline \multicolumn{7}{|c|}{$\mathbf{C H}_{\mathbf{4}}-\mathbf{A r}$} \\
\hline Método/Base & $\begin{array}{c}\text { rC--Ar } \\
(\mathbf{\AA})\end{array}$ & $\begin{array}{c}\text { rH--Ar } \\
(\mathbf{\AA})\end{array}$ & $\begin{array}{c}\text { Dipolo } \\
(\mathbf{D e b y e})\end{array}$ & $\begin{array}{c}\text { ET a 0 K } \\
(\mathbf{k c a l} / \mathbf{m o l})\end{array}$ & $\begin{array}{c}\Delta \mathbf{E} \\
(\mathbf{k c a l} / \mathbf{m o l})\end{array}$ \\
\hline MP2/aug-cc-pvtz & 3,638 & 3,424 & 0,0114 & $-356073,44$ & $-0,52$ \\
\hline B97D3/aug-cc-pvtz & 3,839 & 3,614 & 0,0085 & $-356490,54$ & $-0,46$ \\
\hline Teórico Referencial $^{34}$ & 3,676 & - & 0,0057 & - & $-0,40$ \\
\hline
\end{tabular}

Para esse dímero o método $\operatorname{CCSD(T)/aug-cc-pvqz~foi~utilizado~como~teórico~}$ referencial.

Apenas o DFT B97D3/aug-cc-pvtz conseguiu fornecer uma estrutura estável. Os demais DFT, geraram frequências negativas em todos os testes, e com isso foi apenas possível trabalhar com o método B97D3.

Apesar de esse método ser o único utilizado, observa-se que ele gerou bons resultados para a geometria de equilíbrio, se comparado ao método referencial. Os dois parâmetros analisados em relação à geometria (rC--Ar e rH--Ar) para o DFT, estavam em consonância com o os resultados do método MP2.

Nota-se também que neste sistema há o domínio de interações de Van der Waals. Para tal propriedade, observa-se que o DFT está em concordância com o referencial (MP2).

No que se refere à energia total, pode-se dizer que o resultado do DFT estava na mesma grandeza do resultado gerado pelo método MP2, porém a diferença absoluta em $\mathrm{kcal} / \mathrm{mol}$ é bastante significativa e poderia afetar no cálculo da energia de interação.

Quanto à energia de interação, o método DFT trabalhado se mostrou eficiente, visto que, o mesmo teve um erro absoluto de apenas $0,06 \mathrm{kcal} / \mathrm{mol}$ em relação ao MP2. O erro absoluto desse DFT em relação ao teórico referencial também foi de 0,06 kcal/mol, mas neste caso, a energia do teórico referencial era maior que a do DFT. Outra observação importante é que a energia de interação do teórico referencial foi corrigida pelo BSSE. Desse modo, o B97D3/aug-cc-pvtz descreveu bem todas as propriedades que foram calculadas. Com isso, sua função de onda foi selecionada para iniciar o cálculo com o método Monte Carlo Quântico.

\subsection{Simulações Monte Carlo Quântico para as Moléculas.}

Para todas as moléculas componentes dos dímeros $\left(\mathrm{CH}_{4}, \mathrm{HF}, \mathrm{H}_{2} \mathrm{O}, \mathrm{CO}, \mathrm{H}_{2}\right.$ e Ar), que já tiveram suas geometrias de equilíbrio e outras propriedades analisadas no Tópico 5.1, foram calculadas as energias no Monte Carlo Quântico Variacional e no Monte Carlo 
Quântico de Difusão, escolhendo-se as melhores funções de onda para cada caso. Todos os cálculos realizados neste tópico foram feitos no Software Casino.

Para todas as simulações do MCQ de Difusão foram utilizados 2000000 de passos e 1000 configurações. O passo de tempo foi diferente para cada caso, pois o mesmo era modificado para atingir uma taxa de aceitação dentro da faixa desejável. Assim, utilizou-se um passo de tempo de 0,003 para as moléculas $\mathrm{CH}_{4}$ e $\mathrm{H}_{2}$, um passo de tempo de 0,002 para as moléculas $\mathrm{HF}, \mathrm{H}_{2} \mathrm{O}$ e $\mathrm{Ar}$ e um passo de tempo de 0,0001 para a molécula $\mathrm{CO}$. Com tais passos de tempo, geraram-se taxas de aceitação sempre entre $96 \%$ a $99 \%$.

Pode-se ver na Figura 8, um exemplo do progresso da simulação do MCQ de Difusão para a molécula $\mathrm{CH}_{4}$. Todas as simulações MCQ de moléculas e dímeros seguiram esse mesmo padrão. Inicialmente, nota-se a fase de equilíbrio ou termalização nos primeiros 500000 passos. Tal fase é importante, pois a melhor estimativa de energia dada pelos passos iniciais, normalmente ainda não está no nível das flutuações de energias dadas pelo MCQ de Difusão. Com isso, é requerida uma trajetória prévia, para que se alcancem níveis de energia próximos da média das flutuações e assim ficando mais próximo da convergência. A convergência é alcançada, logo após a fase de equilíbrio, e com isso, inicia-se a fase de acumulação estatística. Observa-se que nessa nova fase, os intervalos de flutuações de energia são bem menores e as energias estão bem mais próximas do valor médio.

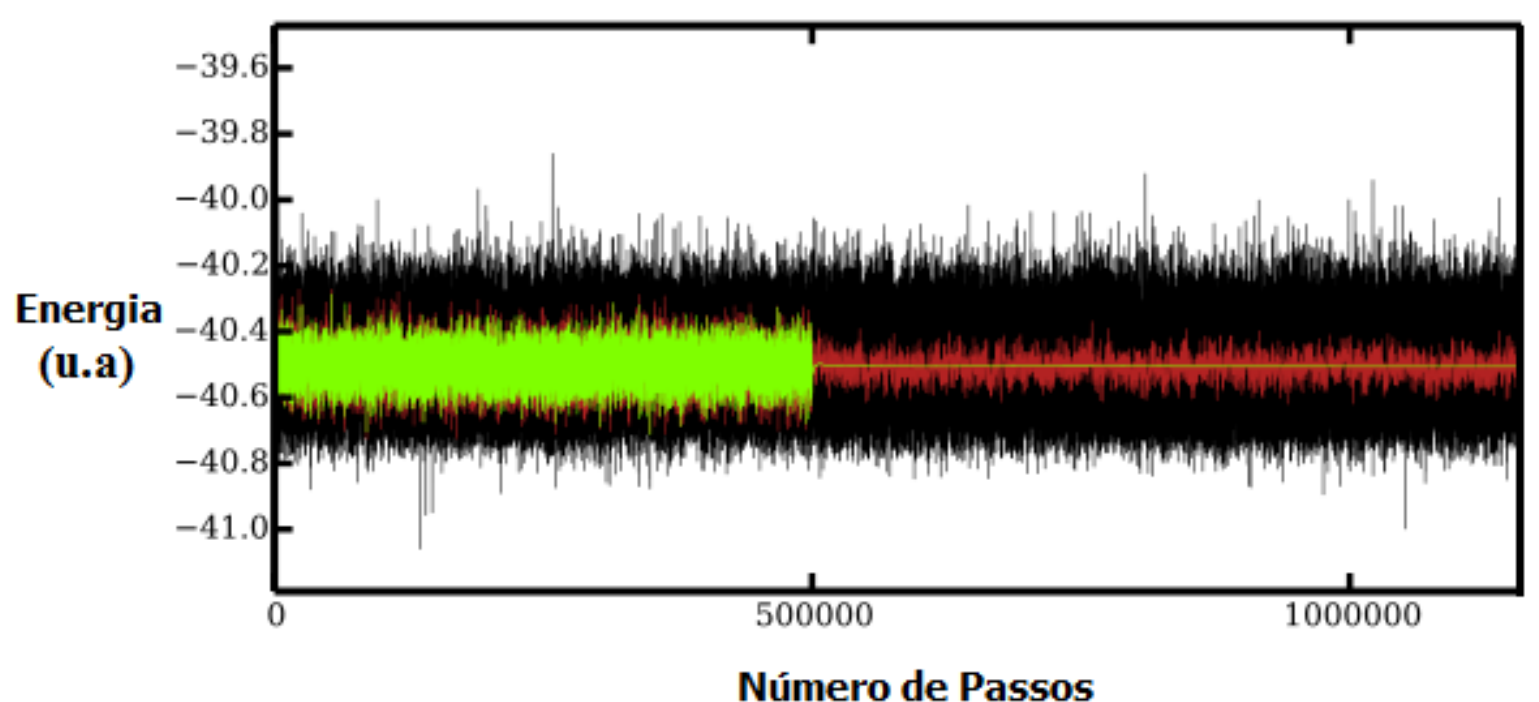

Figura 8: Progresso da Simulação do Monte Carlo Quântico de Difusão para molécula $\mathrm{CH}_{4}$.

A linha preta (Figura 8) representa a energia local de uma dada configuração. A linha vermelha é a energia de referência, a qual é sempre ajustada para controlar os valores das 
energias locais, deixando-as sempre nos mesmos níveis próximos do valor médio. Dessa maneira, a energia de referência, consegue fazer o controle das configurações, evitando "a explosão populacional" (ocorre por meio da utilização excessiva de uma única configuração) ou a destruição total de tal configuração. Por fim, tem-se a linha verde, a qual nos fornece a melhor estimativa de energia pelo cálculo MCQ de Difusão (média de todas as energias).

\subsubsection{Molécula $\mathrm{CH}_{4}$}

Para a molécula $\mathrm{CH}_{4}$, foram realizados cálculos via Monte Carlo Quântico com todas as funções de onda dos métodos DFT, pois em todos os dímeros utilizados, estava presente a molécula de metano. Com isso, o mesmo método utilizado no dímero (explicações da escolha no Tópico 5.4) também foi utilizado nas moléculas que o compõe, pois a energia de interação foi calculada pela diferença entre a energia total do dímero e a soma das energias de cada molécula separadamente. Com isso, todos os cálculos para a energia de interação, foram realizados com a função de onda do mesmo método. Por exemplo: para o dímero $\mathrm{CH}_{4}-\mathrm{CH}_{4}$, foi utilizada a função de onda do método B97D3/aug-cc-pvtz como entrada no Monte Carlo Quântico. Para calcular a energia de interação, calculou-se a energia total para a molécula $\mathrm{CH}_{4}$ também com o método B97D3/aug-cc-pvtz e assim se fez a diferença de energia.

A análise feita na geometria de equilíbrio do $\mathrm{CH}_{4}$ (Tabela 2) mostrou que todos os métodos DFT estavam em concordância com o referencial, e com isso, a função de onda desses métodos estavam aptas para iniciar o cálculo Monte Carlo Quântico. Desse modo, definiu-se 2 critérios para escolhas de funções de onda para as moléculas: o primeiro foi que o mesmo método utilizado no dímero seria utilizado na molécula e o segundo foi analisar se esse mesmo método reproduz a geometria de equilíbrio e a energia total de acordo com os métodos referenciais.

Na Tabela 16, estão os resultados das energias para os métodos Monte Carlo Quântico (MCQ) Variacional e Difusão, para cada função de onda de entrada.

Tabela 16: Resultados das Simulações Monte Carlo Quântico para a molécula $\mathrm{CH}_{4}$.

\begin{tabular}{|c|c|c|c|}
\hline \multirow{2}{*}{$\begin{array}{c}\text { Função de Onda de } \\
\text { Entrada }\end{array}$} & \multicolumn{3}{|c|}{ Energia Total (kcal/mol) } \\
\cline { 2 - 4 } & $\begin{array}{c}\text { MCQ Variacional / } \\
\text { (Erro Padrão) }\end{array}$ & $\begin{array}{c}\text { MCQ Difusão / (Erro } \\
\text { Padrão) }\end{array}$ & Gaussian09 \\
\hline HSEH1PBE/aug-cc-pvtz & $-25234,06 /(+/-0,41)$ & $-25417,22 /(+/-0,20)$ & $-25400,41$ \\
\hline B97D3/aug-cc-pvtz & $-25232,41 /(+/-0,43)$ & $-25417,69 /(+/-0,20)$ & $-25421,51$ \\
\hline WB97XD/aug-cc-pvtz & $-25232,58 /(+/-0,43)$ & $-25417,25 /(+/-0,20)$ & $-25426,69$ \\
\hline
\end{tabular}


Como padrão de análise das grandezas das energias, utilizou-se o método MP2/aug-ccpvtz (-25360,44 kcal/mol), pois o mesmo foi utilizado como padrão de comparação para todos os casos de moléculas e dímeros. O mesmo está disposto na Tabela 2. Com isso, nota-se que todos os resultados das energias estão na mesma grandeza do método referencial MP2. Desse modo, pode-se afirmar que o conversor de função de onda do Gaussian09 para o Casino foi eficiente.

Nota-se que todas as funções de onda, geraram resultados bem próximos no MCQ de Difusão, diferindo apenas nas 2 primeiras casas decimais, e dentro do erro padrão, se igualam. Verifica-se também o mesmo comportamento em relação ao MCQ Variacional. O mesmo forneceu um resultado para a energia maior que o resultado gerado pelo Gaussian09 para todas as funções de onda. O resultado com a função de onda do HSEH1PBE/aug-cc-pvtz, que possui apenas termo de troca-correlação, foi um pouco melhor que a dos 2 DFT que possuem ainda termos de dispersão (WB97XD e B97D3). De modo geral, pode-se afirmar que tanto os termos dispersivos quanto os de troca-correlação dos DFT, apenas impactaram no valor da energia, não alterando a função de onda. Em outras palavras, a função de onda que foi gerada, não sofreu impacto dos efeitos incluídos nos funcionais. Isso pode ser verificado, pelo valor da energia gerado pelo MCQ Variacional, que apenas reproduziu a função de onda. Com isso, se observa a diferença dos valores do Gaussian09 e dos MCQ Variacional, que chegam a ser maiores que $160 \mathrm{kcal} / \mathrm{mol}$. Essa diferença mostra a influencia dos efeitos dos funcionais no valor da energia, e assim se comprova que a função de onda no MCQ não foi influenciada por esses fatores.

No que se refere ao método HSEH1PBE/aug-cc-pvtz, verifica-se que o MCQ Variacional aumentou o valor da energia em 166,35 kcal/mol, se comparado ao resultado do Gaussian09. Já o MCQ de Difusão, diminuiu em 16,81 kcal/mol e com isso se mostrou mais estável que a energia do Gaussian09 para a mesma função de onda. Pelos erros absolutos em relação aos Gaussian09, pode-se afirmar, que a os efeitos de troca-correlação desse DFT não influenciaram na função de onda de entrada do MCQ. Pode-se confirmar esse fato, observando o valor do cálculo Hartree Fock (que também não tem correlação), para a molécula $\mathrm{CH}_{4}$ na Tabela 2, em que o valor de $-25234,46 \mathrm{kcal} / \mathrm{mol}$ está bem próximo do valor gerado no MCQ Variacional (-25234,06 kcal/mol), em que se igualam dentro do erro padrão.

Em relação ao método B97D3/aug-cc-pvtz, a diferença entre os 2 métodos Monte Carlo Quântico, continua na mesma grandeza do caso já descrito. O MCQ Variacional aumentou o valor da energia em 189,1 kcal/mol. O MCQ de Difusão também aumentou o 
resultado da energia em relação ao Gaussian09, mas gerando um desvio bem menor que o variacional, visto que o erro absoluto entre os métodos MCQ de Difusão e o calculado no Gaussian09 foi de apenas 3,82 kcal/mol. Percebe-se que o resultado desse método (B97D3) no Gaussian09 supera o resultado do método HSEH1PBE em aproximadamente $21 \mathrm{kcal} / \mathrm{mol}$. Isso se deve ao fato que para esse DFT, além do efeito de troca-correlação, ainda está presente o termo de dispersão. Por isso, se observa uma melhoria no valor da energia. Tal fato pode ser notado, pelo erro absoluto entre o MCQ Variacional e o Gaussian09 que foi maior que o caso do HSEH1PBE, pois como o MCQ Variacional representa apenas a função de onda e nada mais além da mesma, e esse funcional tem mais efeitos incluídos, consequentemente o erro entre MCQ Variacional e o Gaussian09 deveria também ser maior e isso, de fato aconteceu.

Quanto ao método WB97XD/aug-cc-pvtz, o erro absoluto entre MCQ Difusão e o Gaussian09, foi de 9,44 kcal/mol, verificando-se um aumento no valor da energia. O erro absoluto entre MCQ Variacional e Gaussian09 foi de $194 \mathrm{kcal} / \mathrm{mol}$, também ocorrendo um aumento em relação ao Gaussian09. Nota-se que esse último erro absoluto, foi maior que os demais casos. Tal fato pode estar relacionado com a presença de mais um termo nesse funcional, que é o de "correções de longo alcance", além das influências já citadas nos casos anteriores (troca-correlação e dispersão). Com todas as análises, pode-se afirmar que os efeitos de troca-correlação, dispersão e correções de longo alcance do DFT WB97XD, não impactaram em uma melhoria da função de onda no MCQ.

\subsubsection{Molécula HF}

A simulação com o MCQ, para a molécula HF, foi realizada com as funções de onda dos métodos HSEH1PBE/aug-cc-pvtz e B97D3/aug-cc-pvtz. Utilizou-se inicialmente o primeiro critério de escolha (mesmo método utilizado no dímero $\mathrm{CH}_{4}-\mathrm{HF}$ ) e depois analisouse a qualidade destes 2 métodos. Desse modo, foi constatado que as suas funções de onda estavam aptas para servirem de entrada no Monte Carlo, já que deram bons resultados para a molécula HF (vide Tabela 3).

Na Tabela 17 estão os resultados da energia total para cada função de onda de entrada, nos métodos MCQ Variacional e MCQ de Difusão. 
Tabela 17: Resultados das Simulações Monte Carlo Quântico para a molécula HF.

\begin{tabular}{|c|c|c|c|}
\hline \multirow{2}{*}{$\begin{array}{c}\text { Função de Onda de } \\
\text { Entrada }\end{array}$} & \multicolumn{3}{|c|}{ Energia Total (kcal/mol) } \\
\cline { 2 - 4 } & $\begin{array}{c}\text { MCQ Variacional / } \\
\text { (Erro Padrão) }\end{array}$ & $\begin{array}{c}\text { MCQ } \\
\text { Difusão / (Erro Padrão) }\end{array}$ & Gaussian09 \\
\hline HSEH1PBE/aug-cc-pvtz & $-62786,34 /(+/-0,71)$ & $-63028,79 /(+/-0,22)$ & $-63001,94$ \\
\hline B97D3/aug-cc-pvtz & $-62784,46 /(+/-0,72)$ & $-63028,37 /(+/-0,22)$ & $-63030,55$ \\
\hline
\end{tabular}

Os métodos MP2/aug-cc-pvtz (-62964,81 kcal/mol) e CCSD(T)=full/aug-cc-pvtz ($62979,06 \mathrm{kcal} / \mathrm{mol}$ ) serviram como base para comparação das grandezas dos resultados. Observa-se que todos os resultados estão na mesma grandeza dos valores dos métodos MP2 e $\operatorname{CCSD}(\mathrm{T})$.

Como esperado, as 2 funções de onda no MCQ Variacional, produziram um aumento nos valores das energias em relação ao Gaussian09. Nota-se que os resultados para o MCQ de Difusão, para as 2 funções de onda, são aproximadamente o mesmo, diferenciando-se apenas nas 2 primeiras casas decimais. Diante disso, pode-se concluir que não houve uma melhora significativa, modificando-se a função de onda no MCQ de Difusão e que os efeitos característicos dos funcionais, não influenciaram na melhoria da função de onda no MCQ.

Analisando-se os resultados gerados pela função de onda de entrada, originária do método HSEH1PBE/aug-cc-pvtz, pode-se dizer que o método MCQ de Difusão melhorou (deixou mais estável o valor da energia) o resultado em 26,85 kcal/mol em relação ao Gaussian09. Já o MCQ Variacional aumentou (mais instável) em 215,6 kcal/mol o valor da energia. Percebe-se pela grande diferença de energia do Variacional, que os efeitos de trocacorrelação desse DFT, não impactou na função de onda utilizada no MCQ. Pois o MCQ Variacional, apenas retrata a função de onda testada. De maneira geral, a função de onda do HSEH1PBE/aug-cc-pvtz, calculado no MCQ de Difusão, seria a melhor opção, neste caso.

Em relação ao método B97D3/aug-cc-pvtz, percebe-se que os resultados do MCQ de Difusão e do Gaussian09 diferem em apenas 2,18 kcal/mol. Neste caso, o MCQ de Difusão não conseguiu deixar mais estável o valor da energia. O MCQ Variacional aumentou o valor da energia em 246,09 kcal/mol. Esse erro foi maior que o caso do HSEH1PBE $(215,6$ $\mathrm{kcal} / \mathrm{mol}$ ) e isso foi esperado, visto que o DFT B97D3 tem mais o efeito da correção de dispersão. Desse modo, comprova-se que a função de onda de entrada no MCQ não foi afetada pelos efeitos de troca-correlação e de dispersão desse funcional.

Outro fato que pode confirmar a não influencia dos efeitos presentes nos funcionais nas funções de onda do MCQ, é que a diferença dos 2 valores calculados no Gaussian09 é maior em relação a diferença dos 2 valores calculados pelo MCQ de Difusão. Ou seja, nos 
valores calculados no Gaussian09 estão presentes tais efeitos dos funcionais. Já os valores obtidos pelo MCQ Difusão são aproximadamente o mesmo, para as 2 funções de onda. Com isso, confirma-se que tais efeitos não impactaram em melhoria nas funções de onda no MCQ.

\subsubsection{Molécula $\mathrm{H}_{2} \mathrm{O}$}

Selecionou-se para os cálculos MCQ, para a molécula de água, as funções de onda do método HSEH1PBE/aug-cc-pvtz, visto que o mesmo foi utilizado para o dímero $\mathrm{CH}_{4}-\mathrm{H}_{2} \mathrm{O}$ (Tópico 5.4.3). Tal método utilizado, também produziu bons resultados para a molécula $\mathrm{H}_{2} \mathrm{O}$. Por isso, pode-se concluir que essa função de onda está apta para ser utilizada no MCQ. Na Tabela 18, estão dispostos os resultados das energias para o MCQ.

Tabela 18: Resultados MCQ para a molécula $\mathrm{H}_{2} \mathrm{O}$.

\begin{tabular}{|c|c|c|c|}
\hline \multirow{2}{*}{$\begin{array}{c}\text { Função de Onda de } \\
\text { Entrada }\end{array}$} & $\begin{array}{c}\text { MCQ } \\
\text { VARIACIONAL / } \\
\text { (Erro Padrão) }\end{array}$ & $\begin{array}{c}\text { MCQ } \\
\text { DIFUSÃ̃ / } \\
\text { (Erro Padrão) }\end{array}$ & Gaussian09 \\
\hline HSEH1PBE/aug-cc-pvtz & $-47725,37 /(+/-0,60)$ & $-47955,18 /(+/-0,21)$ & $-47933,40$ \\
\hline
\end{tabular}

Os métodos referenciais utilizados para avaliação dos resultados e comprovação da eficiência do conversor de função de onda do Gaussian09 para o Casino, foram o MP2/ augcc-pvtz $(-47897,13 \mathrm{kcal} / \mathrm{mol})$ e o $\operatorname{CCSD}(\mathrm{T})=$ full/aug-cc-pvtz $(-47915,04 \mathrm{kcal} / \mathrm{mol})$, já descritos na Tabela 8. Nota-se que todos os resultados produzidos pelos métodos Monte Carlo, estão na mesma grandeza desses referenciais e o maior desvio, como esperado, foi para o MCQ Variacional.

Em relação à função de onda do HSEH1PBE/aug-cc-pvtz, o erro absoluto para a energia, entre o MCQ de Difusão e o Gaussian09 foi de 21,78 kcal/mol. Neste caso, houve uma melhora da energia, ou seja, o valor da energia foi diminuído pelo MCQ de Difusão (em relação ao Gaussian09). Já o MCQ Variacional produziu um aumento no valor da energia de 208,03 kcal/mol. Essa grande diferença de energia em relação ao Gaussian09, mostra apenas que o efeito de troca-correlação, que estava presente no cálculo do Gaussian09, não influenciou na função de onda de entrada no MCQ. 


\subsubsection{Molécula CO}

Escolheu-se a função de onda do método WB97XD/aug-cc-pvtz, para entrada no método MCQ. Esta escolha foi baseada no fato do dímero $\mathrm{CH}_{4}-\mathrm{CO}$ ter conseguido resultados coerentes apenas com este DFT. De qualquer forma, os resultados obtidos pelo método WB97XD/aug-cc-pvtz para a molécula CO, foram bons (vide Tabela 5) e com isso, essa função de onda está qualificada para ser utilizada. Os resultados das energias no MCQ são dados pela Tabela 19 .

Tabela 19: Resultados das Simulações Monte Carlo Quântico para a molécula CO.

\begin{tabular}{|c|c|c|c|}
\hline \multirow{2}{*}{$\begin{array}{c}\text { Função de Onda de } \\
\text { Entrada }\end{array}$} & \multicolumn{3}{|c|}{ Energia Total (kcal/mol) } \\
\cline { 2 - 4 } & $\begin{array}{c}\text { MCQ Variacional / } \\
\text { (Erro Padrão) }\end{array}$ & $\begin{array}{c}\text { MCQ } \\
\text { Difusão / (Erro Padrão) }\end{array}$ & Gaussian09 \\
\hline WB97XD/aug-cc-pvtz & $-70767,34 /(+/-0,72)$ & $-71089,80 /(+/-1,29)$ & $-71107,97$ \\
\hline
\end{tabular}

Os métodos MP2/aug-cc-pvtz (-70996,86 kcal/mol) e CCSD(T)=full/aug-cc-pvtz ($71028,90 \mathrm{kcal} / \mathrm{mol}$ ) foram utilizados para avaliação das grandezas dos resultados. Pela Tabela 22, pode-se notar que os valores dos cálculos no MCQ estão na mesma grandeza dos valores referenciais.

O maior desvio foi para o método MCQ Variacional, que aumentou o resultado da energia em 340,63 kcal/mol em relação ao Gaussian09. O MCQ de Difusão, também aumentou o resultado, mas teve um desvio menor em relação ao Gaussian09. Desse modo, percebe-se que os efeitos presentes no funcional WB97XD, não interferiram no cálculo MCQ, visto que não impactaram na função de onda de entrada. Tais efeitos (troca-correlação, dispersão e correções de longo alcance) foram determinantes para gerar o melhor valor de energia no Gaussian09, não interferindo na melhoria da função de onda no MCQ.

Outra observação importante é que o erro padrão dado para a simulação MCQ de Difusão, foi de +/- 1,29, sendo maior que o erro do método MCQ Variacional. Tal fato, também pode influenciar no cálculo da energia de interação, pois devido a sensibilidade desta propriedade, qualquer erro em até 2 casas decimais, pode gerar uma grande diferença no resultado final. 


\subsubsection{Molécula $\mathrm{H}_{2}$}

Selecionou-se a função de onda do método B97D3/aug-cc-pvtz como entrada no MCQ para o dímero $\mathrm{CH}_{4}-\mathrm{H}_{2}$. Por isso, escolheu-se a função de onda desse mesmo método para a molécula de hidrogênio. Observa-se também pela Tabela 6, que este DFT representou razoavelmente a geometria e a energia avaliadas em relação aos referenciais. Dessa forma, pode-se utilizar tal função de onda sem maiores problemas.

Tabela 20: Resultados das Simulações Monte Carlo Quântico para a molécula $\mathrm{H}_{2}$.

\begin{tabular}{|c|c|c|c|}
\hline \multirow{2}{*}{$\begin{array}{c}\text { Função de Onda de } \\
\text { Entrada }\end{array}$} & \multicolumn{3}{|c|}{ Energia Total (kcal/mol) } \\
\cline { 2 - 4 } & $\begin{array}{c}\text { MCQ Variacional / } \\
\text { (Erro Padrão) }\end{array}$ & $\begin{array}{c}\text { MCQ } \\
\text { Difusão / (Erro Padrão) }\end{array}$ & Gaussian09 \\
\hline B97D3/aug-cc-pvtz & $-710,69 /(+/-0,07)$ & $-736,86 /(+/-0,06)$ & $-742,80$ \\
\hline
\end{tabular}

Os métodos utilizados para avaliação da grandeza dos resultados foram: MP2/aug-ccpvtz $(-731,05 \mathrm{kcal} / \mathrm{mol})$ e $\mathrm{CCSD}(\mathrm{T})=$ full/aug-cc-pvtz $(-735,84 \mathrm{kcal} / \mathrm{mol})$. Nota-se que os resultados gerados pelos $2 \mathrm{MCQ}$ estão na mesma grandeza desses valores.

Percebe-se que o resultado do MCQ de Difusão aumentou em 5,94 kcal/mol em relação ao Gaussian09. A energia dada pelo MCQ Variacional foi maior que a do Gaussian09 com essa mesma função de onda, aumentando o valor da energia em 32,11 kcal/mol. Devido a essa diferença, verifica-se que para este caso, o efeito de dispersão do DFT B97D3, também não influenciou em uma melhoria da função de onda no MCQ. Observa-se também que os erros dos 2 métodos, estão aproximadamente iguais, além de ser os menores dentre os casos estudados. Isso se explica, pelo fato de esse sistema ser também o menor de todos, com apenas 2 elétrons.

\subsection{6 Átomo Argônio}

Para este caso, utilizou-se a função de onda do método B97D3/aug-cc-pvtz, já que esse mesmo método gerou bons resultados para o dímero $\mathrm{CH}_{4}$-Ar. Pode-se verificar na Tabela 7, que tal DFT reproduziu bem a geometria de equilíbrio e a energia em relação aos referenciais, tornando-se assim, apto para ser utilizado no MCQ.

A Tabela 21 mostra os resultados da energia para os métodos MCQ Variacional e de Difusão. 
Tabela 21: Resultados dos Métodos Monte Carlo Quântico para o átomo Ar.

\begin{tabular}{|c|c|c|c|}
\hline \multirow{2}{*}{$\begin{array}{c}\text { Função de Onda de } \\
\text { Entrada }\end{array}$} & $\begin{array}{c}|c| \\
\text { MCQ Variacional / } \\
\text { (Erro Padrão) }\end{array}$ & $\begin{array}{c}\text { MCQ } \\
\text { Difusão / (Erro Padrão) }\end{array}$ & Gaussian09 \\
\cline { 2 - 5 } B97D3/aug-cc-pvtz & $-330579,72 /(+/-1,74)$ & $-331029,36 /(+/-0,33)$ & $-331068,57$ \\
\hline
\end{tabular}

Os métodos de avaliação de grandeza foram: MP2/aug-cc-pvtz (-330712,48 kcal/mol) e $\operatorname{CCSD}(\mathrm{T})=$ full/aug-cc-pvtz $(-330747,62 \mathrm{kcal} / \mathrm{mol})$. Verifica-se que todos os resultados gerados pela função de onda do método B97D3/aug-cc-pvtz estão na mesma grandeza dos valores dados pelos métodos MP2 e CCSD(T).

No que se refere à função de onda do método B97D3/aug-cc-pvtz, verifica-se que o MCQ Variacional forneceu uma energia maior que o respectivo DFT no Gaussian09. O erro absoluto entre eles foi de 488,85 kcal/mol. O mesmo comportamento ocorreu com o MCQ de Difusão em relação ao Gaussian09, mas a diferença entre os mesmos foi bem menor $(39,21$ $\mathrm{kcal} / \mathrm{mol}$ ). Dentre os elementos utilizados, o átomo de argônio foi o que tinha o maior número de elétrons (18 elétrons), consequentemente, o maior valor para a energia. Tal fato pode influenciar na qualidade dos resultados da energia de interação, pois também se notam grandes desvios em kcal/mol.

Devido aos desvios dos cálculos MCQ em relação aos gerados pelo Gaussian09, constatou-se que a função de onda no MCQ não foi afetada pelos efeitos de troca-correlação e de dispersão desse funcional, por isso se verifica um valor de energia mais estável que o gerado pelo Gaussian09.

\subsection{Simulações Monte Carlo Quântico para os Dímeros.}

Os mesmos procedimentos utilizados para as moléculas foram feitos para todos os dímeros nas simulações MCQ. Todos foram comparados em relação ao método MP2, mantendo-se uma padronização na comparação.

Quanto às simulações MCQ, para todos os dímeros foram utilizados 2000000 de passos e 1000 configurações. O passo de tempo foi diferente para cada caso, pois o mesmo era modificado para atingir uma taxa de aceitação dentro da faixa desejável. Assim, utilizouse um passo de tempo de 0,003 para o dímero $\mathrm{CH}_{4}-\mathrm{CH}_{4}$, um passo de tempo de 0,002 para os dímeros $\mathrm{CH}_{4}-\mathrm{HF}, \mathrm{CH}_{4}-\mathrm{H}_{2} \mathrm{O}$ e $\mathrm{CH}_{4}-\mathrm{H}_{2}$ e um passo de tempo de 0,0001 para os dímeros $\mathrm{CH}_{4}-$ 
$\mathrm{CO}$ e $\mathrm{CH}_{4}$-Ar. Com tais passos de tempo, geraram-se taxas de aceitação sempre entre $96 \%$ a 98\%. O progresso das simulações seguiu o mesmo comportamento já descrito na Figura 8.

\subsubsection{Dímero $\mathrm{CH}_{4}-\mathrm{CH}_{4}$}

Foram realizados vários testes para o dímero $\mathrm{CH}_{4}-\mathrm{CH}_{4}$, tanto no software Gaussian09 como no Casino. Os resultados obtidos para esse dímero serviram como base, para as escolhas dos outros parâmetros de entrada dos outros dímeros estudados.

Para este caso, utilizaram-se as funções de onda dos métodos HSEH1PBE/aug-cc-pvtz e B97D3/aug-cc-pvtz. Como explicado no Tópico 5.2.1, essas 2 funções de onda deram bons resultados para a geometria de equilíbrio. Já em relação à energia de interação, apenas o método B97D3/aug-cc-pvtz gerou um resultado razoável. Como não se sabe, se a influência do erro na energia é maior por parte do dímero ou por parte da molécula em ambos os DFTs, resolveu-se testar esses 2 métodos como entrada no Monte Carlo. Os resultados das simulações MCQ para o dímero $\mathrm{CH}_{4}-\mathrm{CH}_{4}$ estão na Tabela 22.

Tabela 22: Resultados MCQ para o dímero $\mathrm{CH}_{4}-\mathrm{CH}_{4}$.

\begin{tabular}{|c|c|c|c|}
\hline \multirow{2}{*}{$\begin{array}{c}\text { Função de Onda de } \\
\text { Entrada }\end{array}$} & \multicolumn{3}{|c|}{ ENERGIA TOTAL (kcal/mol) } \\
\cline { 2 - 5 } & $\begin{array}{c}\text { MCQ Variacional / } \\
\text { (Erro Padrão) }\end{array}$ & $\begin{array}{c}\text { MCQ Difusão / } \\
\text { (Erro Padrão) }\end{array}$ & Gaussian09 \\
\hline HSEH1PBE/aug-cc-pvtz & $-50463,92 /(+/-0,59)$ & $-50835,95 /(+/-0,31)$ & $-50800,97$ \\
\hline B97D3/aug-cc-pvtz & $-50462,28 /(+/-0,58)$ & $-50836,01 /(+/-0,27)$ & $-50843,69$ \\
\hline
\end{tabular}

Utilizou-se como referência, o método MP2/aug-cc-pvtz $(-50721,47 \mathrm{kcal} / \mathrm{mol})$. Verifica-se que todos os resultados estão na mesma grandeza do valor referencial, com isso, mais uma vez, se confirma a eficiência do conversor Gaussian09-Casino. Nota-se que o maior desvio foi para o MCQ Variacional em relação ao Gaussian09, com a função de onda do B97D3. O valor da energia mais estável foi gerado pelo Gaussian09, com o método B97D3.

O MCQ de Difusão (HSEH1PBE) melhorou o resultado da energia (mais estável), em relação ao Gaussian09 com a mesma função de onda, em aproximadamente $35 \mathrm{kcal} / \mathrm{mol}$. Já o MCQ Variacional (HSEH1PBE) forneceu um resultado para a energia maior que o respectivo DFT no Gaussian09. Tal diferença foi maior que $330 \mathrm{kcal} / \mathrm{mol}$. Com essa diferença em relação ao Variacional, constata-se que o efeito de troca-correlação do funcional HSEH1PBE não impactou na função de onda de entrada no MCQ. Pois se assim fosse, o valor da energia 
gerado pelo MCQ Variacional deveria ser aproximadamente igual ao gerado pelo Gaussian09, no qual estão presentes os efeitos desse funcional.

Tanto o MCQ de Difusão quanto o MCQ Variacional com a função de onda do método B97D3, tiveram um aumento no valor da energia em relação ao Gaussian09. Tais desvios foram de 7,68 kcal/mol para o Difusão e 381,41 kcal/mol para o Variacional. Do mesmo modo como foi explicado para o caso do HSEH1PBE, os efeitos presentes no funcional B97D3 (troca-correlação e dispersão) também não impactaram em uma melhoria da função de onda no MCQ.

O fato de os efeitos presentes nos funcionais não influenciarem nos resultados do MCQ podem ser confirmados pelos valores aproximadamente iguais do MCQ Difusão (HSEH1PBE) e MCQ Difusão (B97D3).

Um dos objetivos principais deste projeto foi o estudo da energia de interação para os dímeros no Monte Carlo Quântico. A maior dificuldade para calcular essa energia está relacionada com a precisão dos resultados, tanto para o dímero quanto para as moléculas que o compõe. O Gaussian09 está padronizado para gerar os resultados sempre no mesmo erro padrão. Com isso, observam-se resultados razoáveis para a energia de interação, até mesmo para métodos menos sofisticados. Já para o Casino, não se tem esse mesmo nível de padronização. A maior dificuldade foi padronizar todos os cálculos, levando em consideração a qualidade dos resultados e o tempo computacional para todas as moléculas e dímeros. Mesmo assim, nem sempre foi possível colocar todos os cálculos no mesmo patamar de qualidade e isso se reflete diretamente no resultado da energia de interação.

A sensibilidade dessa propriedade foi analisada para o dímero $\mathrm{CH}_{4}-\mathrm{CH}_{4} \cdot \mathrm{Na}$ Tabela 23, pode-se ver os resultados para a energia de interação, calculados no Casino e no Gaussian09 com as mesmas funções de onda.

Tabela 23: Resultados para a energia de interação do dímero $\mathrm{CH}_{4}-\mathrm{CH}_{4}$.

\begin{tabular}{|c|c|}
\hline Método & $\begin{array}{c}\text { Energia de Interação } \\
(\mathbf{\Delta E}) \mathbf{~ k c a l} / \mathbf{m o l}\end{array}$ \\
\hline MCQ Variacional (HSEH1PBE) & 4,20 \\
\hline MCQ Variacional (B97D3) & 2,54 \\
\hline MCQ Difusão (HSEH1PBE) & $-1,51$ \\
\hline MCQ de Difusão (B97D3) & $-0,63$ \\
\hline Gaussian09 (HSEH1PBE) & $-0,15$ \\
\hline Gaussian09 (B97D3) & $-0,67$ \\
\hline Gaussian09 (MP2) $^{\text {(M) }}$ & $-0,59$ \\
\hline Teórico Referencial $^{56}$ & $-0,51$ \\
\hline
\end{tabular}


Aqui, também utilizou-se os métodos MP2 e CCSD (teórico referencial) já discutidos no Tópico 5.2.1, para avaliação dos resultados. Nota-se que os melhores resultados foram obtidos com a função de onda do método B97D3. Observa-se valores positivos dados pelo método MCQ Variacional, para ambas as funções de onda utilizadas. Teoricamente, isso indica que de acordo com esse método, não haveria formação do dímero $\mathrm{CH}_{4}-\mathrm{CH}_{4}$, nas condições definidas. Com isso, a comparação foi feita apenas com os métodos que ao menos conseguiram prever a formação do dímero.

A Figura 9 mostra os erros absolutos para a energia de interação. Foi feita a comparação tanto com o método MP2 quanto com o CCSD(T), dados na Tabela 23.

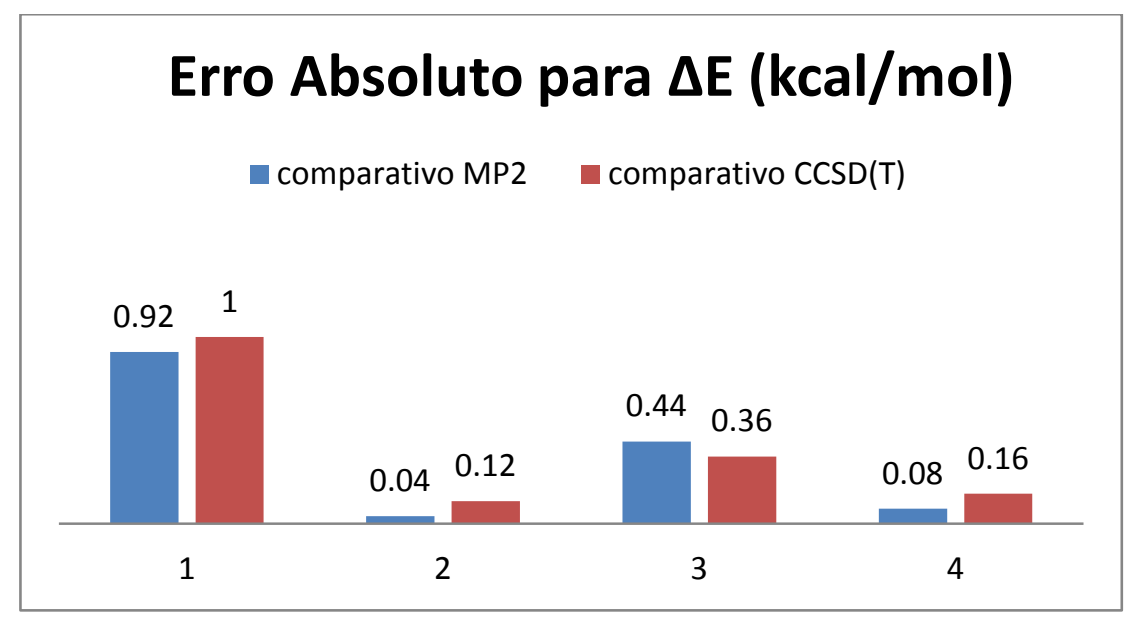

1 - MCQ Difusão (HSEH1PBE)

2 - MCQ Difusão (B97D3)

3 - Gaussian09 (HSEH1PBE)

4 - Gaussian09 (B97D3)

Figura 9: Erros absolutos para a energia de interação em relação aos referenciais.

De acordo com a Figura 9, verifica-se que os maiores erros foram para a função de onda do DFT HSEH1PBE no método MCQ de Difusão. O resultado para essa mesma função de onda no Gaussian09 teve um erro absoluto bem menor.

A função de onda do B97D3 no MCQ de Difusão produziu os menores erros absolutos. Isso indica que o método MCQ de Difusão conseguiu melhorar os resultados se comparados com os resultados gerados no Gaussian09 com a mesma função de onda, tendo como referenciais os métodos MP2 e o $\operatorname{CCSD}(\mathrm{T})$.

Percebe-se que as energias calculadas no MCQ de Difusão para o dímero (Tabela 22) e a molécula $\mathrm{CH}_{4}$ (Tabela 16) produziram melhoras em proporções diferentes em relação ao Gaussian09. Tal melhora em proporções diferentes, é uma das responsáveis pelos resultados ruins gerados para a energia de interação, neste e em outros casos. Por exemplo: para o dímero $\mathrm{CH}_{4}-\mathrm{CH}_{4}$ o erro relativo entre o método MCQ Difusão (B97D3) e o Gaussian09 (B97D3) foi de apenas $0,0151 \%$. Para a molécula $\mathrm{CH}_{4}$, o erro relativo entre esses 2 métodos 
foi de $0,0150 \%$. Percebe-se que a melhora dos resultados tanto para o dímero como para a molécula, ficaram na mesma proporção (praticamente iguais). Por isso, observa-se que os resultados obtidos no Gaussian09 (-0,67 kcal/mol) e no Casino (-0,63 kcal/mol) estão bem próximos. Já para a função de onda do método "HSEH1PBE", verifica-se uma variação maior nas diferenças das energias. Assim, para o dímero, o erro relativo entre o MCQ Difusão (HSEH1PBE) e o Gaussian09 (HSEH1PBE) foi de 0,068\%. Para a molécula, essa mesma diferença foi de $0,066 \%$. Parece irrelevante essa diferença na proporção, mas deve-se levar em conta que o valor da energia para a molécula é utilizada 2 vezes para o cálculo da energia de interação. Com isso e somado a outros possíveis erros, a energia de interação saiu de $-0,15$ $\mathrm{kcal} / \mathrm{mol}$ para $-1,51 \mathrm{kcal} / \mathrm{mol}$.

No Casino, tentou-se uniformizar todos os procedimentos de entrada, para que no final, os resultados de todos os cálculos interligados, estivessem no mesmo erro padrão, ou bem próximos. Em alguns casos não se conseguiu uma boa padronização. A partir disso, para este caso, notou-se que as maiores diferenças de erro padrão entre os cálculos do dímero e das moléculas que o compõe, geraram os piores resultados. Como por exemplo: o erro padrão para o cálculo de energia total do dímero $\mathrm{CH}_{4}-\mathrm{CH}_{4}$ no método $\mathrm{MCQ}$ Variacional (HSEH1PBE) foi de +/- 0,59 kcal/mol. O erro padrão desse mesmo método para a molécula $\mathrm{CH}_{4}$ foi de $+/-0,41 \mathrm{kcal} / \mathrm{mol}$. A diferença entre esses 2 erros foi a maior encontrada e consequentemente gerou o pior resultado $(4,2 \mathrm{kcal} / \mathrm{mol})$ dentre todos os métodos utilizados para este dímero. Por outro lado, a menor diferença de erros encontrada foi entre o erro padrão para o $\mathrm{CH}_{4}-\mathrm{CH}_{4}(+/-0,27 \mathrm{kcal} / \mathrm{mol})$ e o erro para a molécula $\mathrm{CH}_{4}(+/-0,2 \mathrm{kcal} / \mathrm{mol})$, ambos com o método MCQ de Difusão (B97D3). Como consequência, esse menor erro entre dímero e moléculas gerou o melhor resultado para a energia de interação (-0,63 kcal/mol). Tal fato relatado foi apenas uma constatação para este caso do dímero $\mathrm{CH}_{4}-\mathrm{CH}_{4}$. Isso não quer dizer que o erro padrão seria o maior responsável pelos grandes desvios em relação aos referenciais. Ele somado com outros fatores, como o caso da diferença de proporcionalidade, já descrita, podem influenciar na qualidade dos resultados.

Seria possível diminuir ainda mais as incertezas em relação aos causadores dos maiores desvios nos resultados para a energia de interação, fixando-se o erro padrão em um valor abaixo de $10^{-3} \mathrm{em} \mathrm{kcal} / \mathrm{mol}$. Pois dentro desse intervalo de erro, a influência sobre o valor da energia total, seria insignificante. Consequentemente, também não afetaria o cálculo da energia de interação. O ideal seria que o erro padrão (abaixo de $10^{-3}$ ) fosse o mesmo para os cálculos do dímero e das moléculas componentes desse dímero. Tentou-se realizar esse 
procedimento, mas para viabilizá-lo seria necessário um prazo bem maior, visto o alto custo computacional para o MCQ. Por isso, o critério de convergência não foi definido pelo erro padrão, pois não se tinha uma estimativa real do tempo computacional, para um erro abaixo de $10^{-3}$. Com isso, esse critério foi definido pelo número total de passos, no qual tal quantidade de passos deveria ser suficientemente grande para gerar bons resultados com erros aceitáveis e um tempo computacional viável.

Uma alternativa para reduzir o tempo computacional, seria o uso de pseudopotenciais, ${ }^{3}$ evitando-se assim utilizar todos os elétrons no cálculo. Outro modo seria utilizar dados de correlação. Dessa maneira, poderia se utilizar menos passos ou menos configurações, impactando diretamente no tempo computacional. Essas seriam algumas soluções que poderiam ser implementadas para melhorar o valor da energia de interação, atingindo um nível desejável de erro padrão, em um tempo computacional razoável. Porém, a finalidade deste projeto, também, é mostrar a eficiência do MCQ sem nenhum tipo de correlação ou novos mecanismos. Sendo assim, essas soluções citadas poderão ser utilizadas em trabalhos futuros.

\subsubsection{Dímero $\mathrm{CH}_{4}-\mathrm{HF}$}

Em relação ao dímero $\mathrm{CH}_{4}-\mathrm{HF}$, utilizou-se as funções de onda dos DFT HSEH1PBE e B97D3 para início do cálculo no MCQ. Ambos os métodos produziram bons resultados para a geometria de equilíbrio, e até para a energia de interação (Tabela 10), como já descritos no Tópico 5.2.2. Até mesmo o método Hartree Fock, poderia ser utilizado para este caso, visto que também descreveu razoavelmente esse sistema. Apenas para constar, o valor da energia total, calculado no MCQ de Difusão com a função de onda do Hartree Fock foi de aproximadamente $-88447,23 \mathrm{kcal} / \mathrm{mol}$ com um erro padrão de $+/-1,57 \mathrm{kcal} / \mathrm{mol}$.

Tabela 24: Resultados MCQ para o dímero $\mathrm{CH}_{4}-\mathrm{HF}$.

\begin{tabular}{|c|c|c|c|}
\hline \multirow{2}{*}{$\begin{array}{c}\text { Função de Onda de } \\
\text { Entrada }\end{array}$} & \multicolumn{3}{|c|}{ ENERGIA TOTAL (kcal/mol) } \\
\cline { 2 - 5 } & $\begin{array}{c}\text { MCQ Variacional / } \\
\text { (Erro Padrão) }\end{array}$ & $\begin{array}{c}\text { MCQ Difusão / } \\
\text { (Erro Padrão) }\end{array}$ & Gaussian09 \\
\hline HSEH1PBE/aug-cc-pvtz & $-88022,28 /(+/-0,83)$ & $-88448,12 /(+/-0,31)$ & $-88403,99$ \\
\hline B97D3/aug-cc-pvtz & $-88014,46 /(+/-0,83)$ & $-88446,89 /(+/-0,29)$ & $-88453,79$ \\
\hline
\end{tabular}

O método MP2/aug-cc-pvtz $(-88327,06 \mathrm{kcal} / \mathrm{mol})$ foi utilizado para avaliação das grandezas dos resultados. Percebe-se que todos os valores estão na mesma grandeza do 
referencial. Os erros obtidos pelo método MCQ Variacional foram iguais para as 2 funções de onda. Os erros para o MCQ de Difusão ficaram bem próximos.

Nota-se que para a função de onda do método HSEH1PBE, o MCQ de Difusão conseguiu deixar mais estável o valor da energia total, se comparado ao Gaussian09. O erro absoluto entre eles foi de 44,13 kcal/mol. Já o MCQ Variacional forneceu um valor para a energia maior que o valor do Gaussian09 para a mesma função de onda. O erro absoluto entre Variacional e Gaussian09 foi de 381,71 kcal/mol. Como já visto nos casos anteriores, tais erros mostram que os cálculos realizados no MCQ não foram afetados pelo efeito de trocacorrelação do DFT HSEH1PBE.

No que se refere à função de onda do B97D3, verifica-se que o MCQ de Difusão aumentou o valor da energia em 6,9 kcal/mol em relação ao Gaussian09. O MCQ Variacional também produziu um aumento no valor da energia em relação ao Gaussian09, mas com um erro absoluto (439,33 kcal/mol) bem maior que o caso do MCQ de Difusão. A partir desses desvios, também foi possível constatar que a função de onda de entrada no MCQ não sofreu impactos relacionados com os efeitos presentes no funcional B97D3 (troca-correlação e dispersão).

Para o dímero $\mathrm{CH}_{4}-\mathrm{HF}$, a energia de interação para cada método pode ser observada na Tabela 25.

Tabela 25: Resultados para a energia de interação do dímero $\mathrm{CH}_{4}-\mathrm{HF}$.

\begin{tabular}{|c|c|}
\hline Método & $\begin{array}{c}\text { Energia de Interação } \\
(\mathbf{\Delta E}) \mathbf{~ k c a l} / \mathbf{m o l}\end{array}$ \\
\hline MCQ Variacional (HSEH1PBE) & $-1,88$ \\
\hline MCQ Variacional (B97D3) & 2,41 \\
\hline MCQ Difusão (HSEH1PBE) & $-2,11$ \\
\hline MCQ de Difusão (B97D3) & $-0,83$ \\
\hline Gaussian09 (HSEH1PBE) & $-1,64$ \\
\hline Gaussian09 (B97D3) & $-1,73$ \\
\hline Gaussian09 (MP2) $^{\text {Gandian }}$ & $-1,81$ \\
\hline Teórico Referencial $^{57}$ & $(-1,84) /(-2,14)$ \\
\hline
\end{tabular}

Os métodos comparativos para a energia de interação foram: o MP2/aug-cc-pvtz ($1,81 \mathrm{kcal} / \mathrm{mol}$ ) e o Teórico Referencial, já explicado no Tópico 5.2.2, em que se tem o método MP2=full nas bases: $6-311++\mathrm{G}(3 \mathrm{df}, 2 \mathrm{p}) \quad(-1,84 \mathrm{kcal} / \mathrm{mol})$ e $6-311++\mathrm{G}(3 \mathrm{df}, 2 \mathrm{pd}) \quad(-2,14$ 
$\mathrm{kcal} / \mathrm{mol}$ ). Calculou-se o erro absoluto utilizando o método MP2 nas bases aug-cc-pvtz e 6$311++\mathrm{G}(3 \mathrm{df}, 2 \mathrm{pd})$. Pois tiveram 2 faixas diferentes de valores.

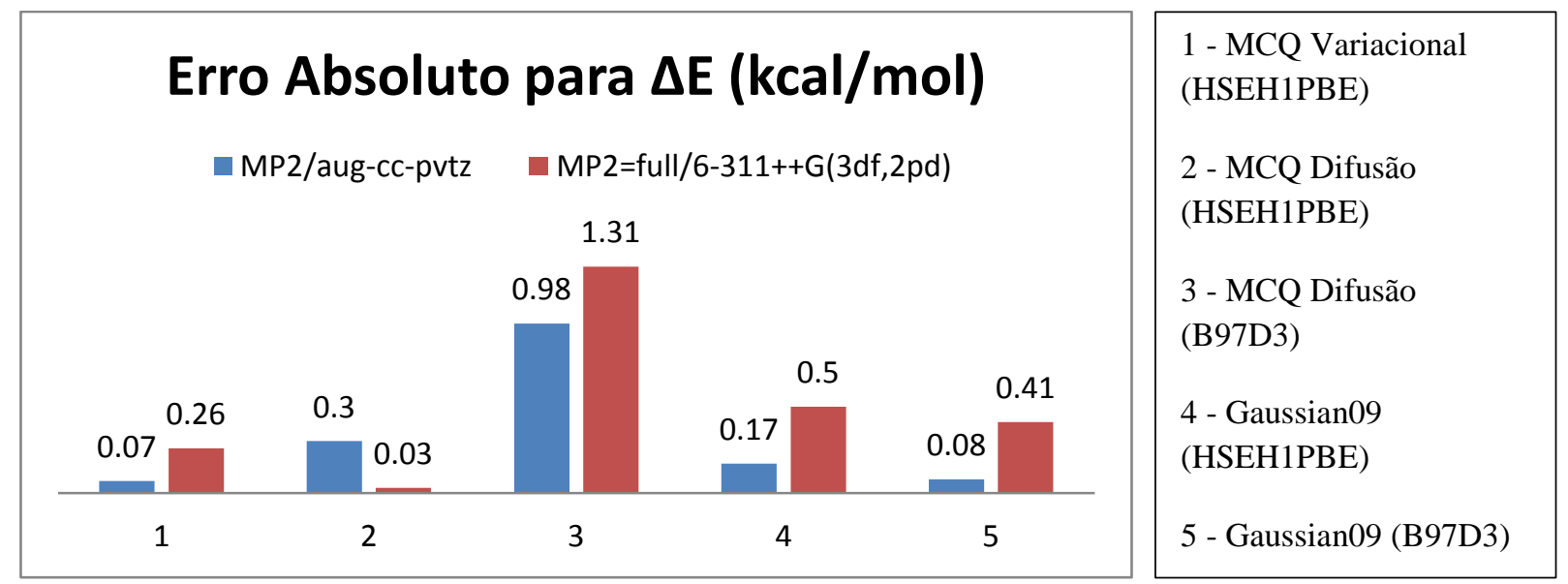

Figura 10: Erros absolutos para a energia de interação em relação aos referenciais.

Tendo o MP2/aug-cc-pvtz como referencia, observa-se que o método MCQ Variacional (HSEH1PBE) conseguiu um ótimo resultado. Mesmo que esse resultado seja inesperado, ele pode ter sua explicação no fato do MCQ Variacional depender exclusivamente da função de onda tentativa. Se tal função de onda representar muito bem o sistema, pode-se afirmar que o resultado será satisfatório. Neste caso, em relação à energia e a geometria de equilíbrio, o método HSEH1PBE gerou os melhores resultados comparativos para o dímero $\mathrm{CH}_{4}$-HF (Tabela 10), para a molécula $\mathrm{CH}_{4}$ (Tabela 2) e para a molécula HF (Tabela 3). Como houve uma ótima descrição da geometria de equilíbrio e da energia para esses 3 casos, o MCQ Variacional conseguiu gerar um ótimo resultado, pois retratou ótimas funções de onda. Outra explicação está relacionada à melhoria proporcional. Os erros relativos entre os métodos MCQ Variacional (HSEH1PBE) e Gaussian09 (HSEH1PBE) para o dímero $\mathrm{CH}_{4}-\mathrm{HF}$, molécula $\mathrm{HF}$ e molécula $\mathrm{CH}_{4}$, foram $0,43 \%, 0,34 \%$ e $0,65 \%$ respectivamente. Mesmo que os erros não estejam na mesma proporção de desvio, eles conseguiram se compensarem, melhorando o resultado de $-1,64 \mathrm{kcal} / \mathrm{mol}$ para $-1,88 \mathrm{kcal} / \mathrm{mol}$. Assim, houve uma combinação, que resultou no cancelamento de erros (diferença de energia entre dímero e moléculas), aproximando-se dos valores comparativos.

Diferentemente do que ocorreu com o HSEH1PBE, O MCQ Variacional (B97D3) não conseguiu nem ao menos prever a formação do dímero, produzindo um valor positivo para essa energia. 
Colocando-se o método MP2=full/6-311++G(3df,2pd) como referencial, pela Figura 10, se observa que o método MCQ de Difusão (HSEH1PBE), gerou o melhor resultado comparativo, com apenas 0,03 kcal/mol de diferença. O MCQ de Difusão (B97D3) gerou os maiores desvios em relação aos comparativos.

Os erros relativos entre o MCQ Difusão (HSEH1PBE) e o Gaussian09 (HSEH1PBE) para o dímero $\mathrm{CH}_{4}-\mathrm{HF}$, a molécula $\mathrm{HF}$ e a molécula $\mathrm{CH}_{4}$ foram 0,050\%, 0,043\% e 0,066\% respectivamente. Com isso, verifica-se que se teve uma compensação de erros e consequentemente, houve uma melhora significativa no resultado de $-1,64 \mathrm{kcal} / \mathrm{mol}$ para $-2,11$ $\mathrm{kcal} / \mathrm{mol}$.

De modo geral, a função de onda do método HSE conseguiu melhorar o resultado no MCQ Variacional e também no MCQ Difusão, para ambos os dados comparativos. A função de onda desse método, conseguiu descrever muito bem os sistemas do dímero e das 2 moléculas $\left(\mathrm{CH}_{4} \mathrm{e} \mathrm{HF}\right)$. Pode-se notar ainda, que os erros padrão ficaram no mesmo patamar.

\subsubsection{Dímero $\mathrm{CH}_{4}-\mathrm{H}_{2} \mathrm{O}$}

Para o dímero $\mathrm{CH}_{4}-\mathrm{H}_{2} \mathrm{O}$, apenas foi possível obter resultados MCQ utilizando a função de onda do DFT HSEH1PBE. Os resultados estão disponíveis na Tabela 26.

Tabela 26: Resultados MCQ para o dímero $\mathrm{CH}_{4}-\mathrm{H}_{2} \mathrm{O}$.

\begin{tabular}{|c|c|c|c|}
\hline \multirow{2}{*}{$\begin{array}{c}\text { Função de Onda de } \\
\text { Entrada }\end{array}$} & \multicolumn{3}{|c|}{ ENERGIA TOTAL (kcal/mol) } \\
\cline { 2 - 5 } & $\begin{array}{c}\text { MCQ Variacional / } \\
\text { (Erro Padrão) }\end{array}$ & $\begin{array}{c}\text { MCQ Difusão / } \\
\text { (Erro Padrão) }\end{array}$ & Gaussian09 \\
\hline HSEH1PBE/aug-cc-pvtz & $-72960,24(+/-0,73)$ & $-73374,79 /(+/-0,31)$ & $-73334,56$ \\
\hline
\end{tabular}

O método utilizado para comparação de grandezas foi o MP2/aug-cc-pvtz (-73258,72 $\mathrm{kcal} / \mathrm{mol}$ ). Nota-se que os resultados ficaram em conformidade com o referencial.

Percebe-se pela Tabela 26, que o MCQ de Difusão diminuiu o valor da energia em relação ao Gaussian09 em 40,23 kcal/mol, deixando-a mais estável. Contrariamente, o MCQ variacional aumentou o valor da energia em 374,32 kcal/mol, para essa mesma função de onda. Devido a essa grande diferença, foi possível constatar que o efeito de troca-correlação, incluído nesse DFT, não afetou o cálculo MCQ.

Em relação à energia de interação para tal dímero, observa-se pela Tabela 27, que o método MCQ Variacional, produziu o melhor resultado comparativo, superando até mesmo o MCQ de Difusão para essa propriedade. 
Tabela 27: Resultados para a energia de interação do dímero $\mathrm{CH}_{4}-\mathrm{H}_{2} \mathrm{O}$.

\begin{tabular}{|c|c|}
\hline Método & $\begin{array}{c}\text { Energia de Interação } \\
(\mathbf{\Delta E}) \mathbf{~ k c a l} / \mathbf{m o l}\end{array}$ \\
\hline MCQ Variacional (HSEH1PBE) & $-0,81$ \\
\hline MCQ Difusão (HSEH1PBE) & $-2,39$ \\
\hline Gaussian09 (HSEH1PBE) & $-0,75$ \\
\hline Gaussian09 (MP2) & $-1,15$ \\
\hline Teórico Referencial $^{58}$ & $-0,8235$ \\
\hline
\end{tabular}

Verifica-se que o MCQ Variacional, teve apenas 0,01 kcal/mol aproximadamente de diferença para o teórico referencial, que foi dado pelo método MP2/aug-cc-pvqz. E ainda conseguiu melhorar o resultado em relação ao Gaussian09.

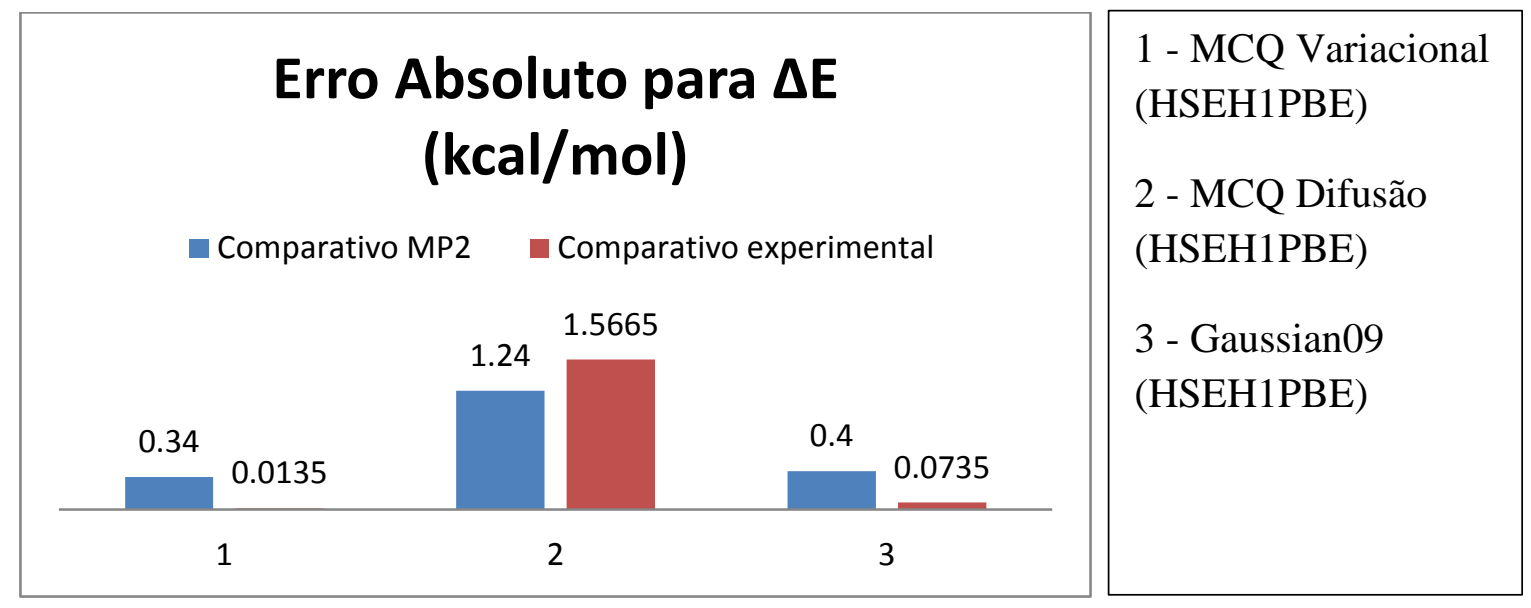

Figura 11: Erros absolutos para a energia de interação em relação aos referenciais.

O valor da energia de interação, calculado no Gaussian09, também ficou próximo do teórico referencial. Tal valor foi melhorado pelo MCQ Variacional, com a mesma função de onda. O método Variacional, como já explicado, apenas retrata a função de onda tentativa, e depende exclusivamente da qualidade de tal onda. Como observado, essa função de onda representou bem o sistema estudado, tanto para o dímero, quanto para as 2 moléculas $\left(\mathrm{CH}_{4} \mathrm{e}\right.$ $\mathrm{H}_{2} \mathrm{O}$ ), com isso, gerou também um bom resultado para este caso. Os erros relativos entre o MCQ Variacional (HSEH1PBE) e o Gaussian09 (HSEH1PBE) para o dímero $\mathrm{CH}_{4}-\mathrm{H}_{2} \mathrm{O}$, para a molécula $\mathrm{H}_{2} \mathrm{O}$ e para molécula $\mathrm{CH}_{4}$ foram $0,51 \%, 0,43 \%$ e $0,65 \%$ respectivamente. Com isso, verifica-se que se teve uma compensação de erros. Assim, nota-se que o resultado melhorou de $-0,75 \mathrm{kcal} / \mathrm{mol}$ para $-0,81 \mathrm{kcal} / \mathrm{mol}$. 
O MCQ de Difusão teve o maior desvio. Mesmo assim, dentro do erro padrão, seria possível realizar uma combinação de resultados (energias do dímero e moléculas) que produzisse um resultado próximo ao referencial. O ideal, para se ter uma comparação efetiva, era buscar o mesmo nível de erro, para as 3 parcelas de energias (1 dímero +2 moléculas) utilizadas no cálculo da energia de interação e diminuir ainda mais o erro para no mínimo 3 casas decimais. Porém, como já foi explicado, não foi possível realizar esse procedimento.

\subsubsection{Dímero $\mathrm{CH}_{4}-\mathrm{CO}$}

A função de onda do método WB97XD foi a única que conseguiu gerar resultados para este dímero (Tópico 5.2.4). Mesmo assim, pode-se verificar que os resultados para a geometria de equilíbrio do dímero $\mathrm{CH}_{4}-\mathrm{CO}$ tiveram uma concordância razoável com o referencial.

Os resultados para a simulação no MCQ estão organizados na Tabela 28.

Tabela 28: Resultados MCQ para o dímero $\mathrm{CH}_{4}-\mathrm{CO}$.

\begin{tabular}{|c|c|c|c|}
\hline \multirow{2}{*}{$\begin{array}{c}\text { Função de Onda de } \\
\text { Entrada }\end{array}$} & \multicolumn{3}{|c|}{ ENERGIA TOTAL (kcal/mol) } \\
\cline { 2 - 4 } & $\begin{array}{c}\text { MCQ Variacional / } \\
\text { (Erro Padrão) }\end{array}$ & $\begin{array}{c}\text { MCQ Difusão / (Erro } \\
\text { Padrão) }\end{array}$ & Gaussian09 \\
\hline WB97XD/aug-cc-pvtz & $-95993,61 /(+/-0,84)$ & $-96512,67 /(+/-1,81)$ & $-96534,52$ \\
\hline
\end{tabular}

O método referencial foi o MP2/aug-cc-pvtz $(-96358,77 \mathrm{kcal} / \mathrm{mol})$. Com isso se observa que todos os resultados estão na mesma grandeza do referencial. Apesar de ter o maior erro padrão, o MCQ de Difusão apresentou um resultado bem melhor que o Variacional em relação à energia total. Porém, ele forneceu um valor para a energia maior que o resultado calculado no Gaussian09 com a mesma função de onda.

Como visto, tanto o MCQ Variacional quanto o de Difusão, aumentaram o valor da energia em relação ao Gaussian09, ou seja, a energia mais estável foi produzida pelo Gaussian09, com o DFT WB97XD. Os erros absolutos do Gaussian09 em relação ao MCQ Variacional e MCQ de Difusão foram 540,91 kcal/mol e 21,85 kcal/mol, respectivamente. Nota-se que o grande desvio dado em relação ao Variacional, serviu para confirmar a não inclusão dos efeitos do funcional WB97XD (troca-correlação, dispersão e correções de longo alcance) nos cálculos MCQ. 
No tocante à energia de interação, nota-se pela Tabela 29, que nenhum método conseguiu uma boa representação para essa propriedade. O DFT WB97XD calculado no Gaussian09, não conseguiu prever a formação do dímero $\mathrm{CH}_{4}-\mathrm{CO}$, pois produziu um resultado positivo. A mesma coisa aconteceu com o MCQ Variacional: além de não conseguir prever a formação do dímero, ainda teve um grande desvio em relação aos referenciais. $\mathrm{O}$ teórico referencial da Tabela 29 é o mesmo já descrito no Tópico 5.2.4.

Tabela 29: Resultados para a energia de interação do dímero $\mathrm{CH}_{4}-\mathrm{CO}$.

\begin{tabular}{|c|c|}
\hline Método & $\begin{array}{c}\text { Energia de Interação } \\
(\mathbf{\Delta E}) \mathbf{k c a l} / \mathbf{m o l}\end{array}$ \\
\hline MCQ Variacional (WB97XD) & 6,31 \\
\hline MCQ de Difusão (WB97XD) & $-5,62$ \\
\hline Gaussian09 (WB97XD) & 0,142 \\
\hline Gaussian09 (MP2) & $-1,47$ \\
\hline Teórico Referencial $^{59}$ & $-0,465$ \\
\hline
\end{tabular}

O MCQ de Difusão conseguiu prever a formação do dímero, mas mesmo assim, o valor gerado, teve um grande desvio em relação ao referencial, como pode ser visto na Figura 12.

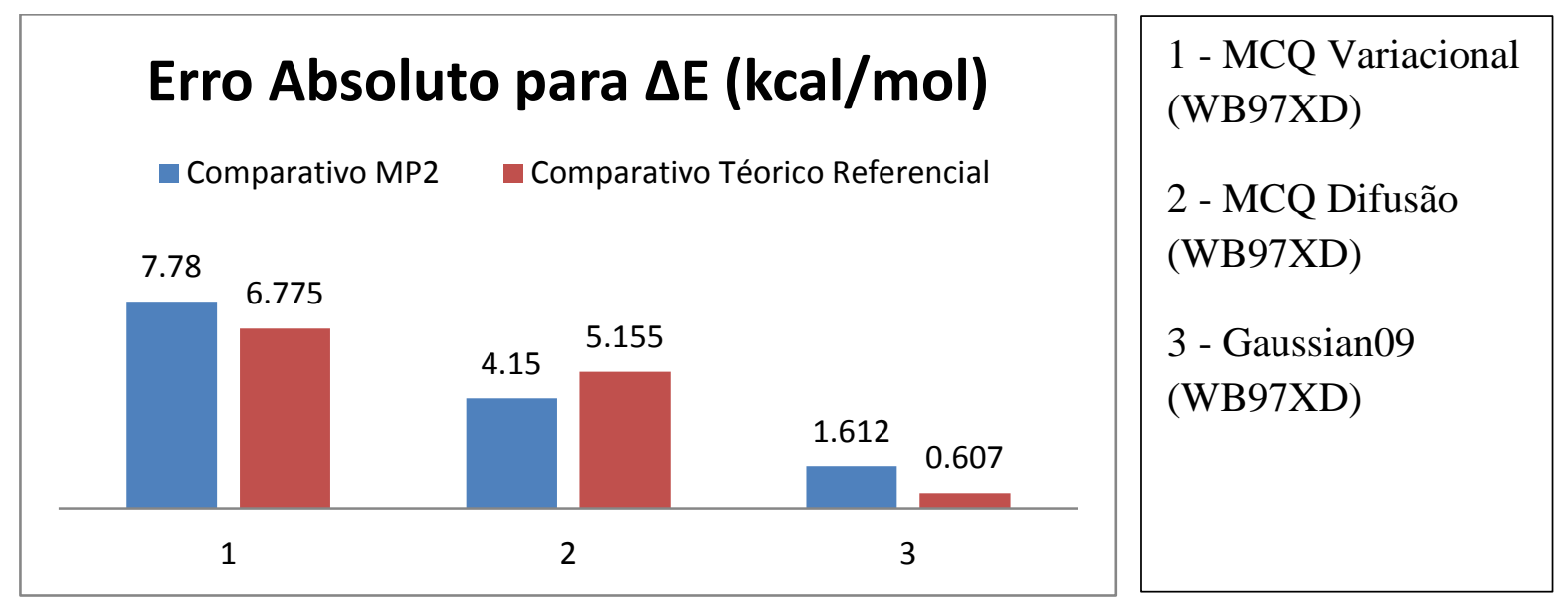

Figura 12: Erros absolutos para a energia de interação em relação aos referenciais.

Os valores ruins fornecidos pelos métodos MCQ para a energia de interação, podem ser explicados, em parte, pela escolha do método DFT, que não conseguiu nem prever a formação do dímero no Gaussian09. Outra explicação é dada pela desproporcionalidade de melhoria na energia dada pelo MCQ para o dímero e as 2 moléculas separadamente. Os erros 
relativos entre o MCQ Difusão e o Gaussian09 para o dímero $\mathrm{CH}_{4}-\mathrm{CO}$, para a molécula $\mathrm{CO}$ e para molécula $\mathrm{CH}_{4}$ foram $0,022 \%, 0,025 \%$ e $0,037 \%$ respectivamente. Com isso, verifica-se que o grande desvio dado pelo $\mathrm{CH}_{4}$ gerou tais resultados ruins, e os erros se somaram. As dimensões dos erros parecem insignificantes, mas neste projeto, trabalha-se com grandezas na faixa entre $10^{4}$ e $10^{5} \mathrm{em} \mathrm{kcal} / \mathrm{mol}$. E qualquer variação de 2 casas decimais, influencia de forma relevante no valor da energia de interação.

Outra observação importante está relacionada com o erro padrão. Para MCQ de Difusão, têm-se os seguintes erros: dímero $\mathrm{CH}_{4}-\mathrm{CO}(+/-1,81 \mathrm{kcal} / \mathrm{mol})$, molécula $\mathrm{CH}_{4}(+/-$ $0,22 \mathrm{kcal} / \mathrm{mol})$ e molécula $\mathrm{CO}(+/-1,29 \mathrm{kcal} / \mathrm{mol})$. Observa-se assim, a grande diferença de valores do erro padrão. Além disso, se for levado em consideração apenas o valor do erro padrão, verifica-se que para o dímero $\mathrm{CH}_{4}-\mathrm{CO}$ e para a molécula $\mathrm{CO}$, esse valor do erro, é bem maior que a própria energia de interação do dímero, dado pelo teórico referencial $(-0,465$ $\mathrm{kcal} / \mathrm{mol}$ ). Por isso, qualquer pequena variação dentro do erro padrão, para qualquer um dos 3 elementos, pode gerar um grande desvio em relação ao valor referencial.

Se o único interesse deste projeto fosse encontrar a energia total, os valores e erros estariam bons o suficiente, pois a variação do erro padrão não influenciaria de forma significativa no valor total da energia.

Dentro do prazo disponível, não foi possível realizar novos testes e procedimentos para melhoria do valor da energia de interação para esse dímero. Uma solução que poderia melhorar esse valor seria aumentar o número de passos ou configurações e ainda utilizar fatores de correlação, podendo-se até utilizar as alternativas já descritas no Tópico 4.4.1, para reduzir o custo computacional. Outra solução seria utilizar as funções de onda de novos DFT não testados, pois para esse dímero, apenas conseguiu-se um ponto de mínimo, utilizando a função de onda do WB97XD, que como visto, não foi a melhor opção.

\subsubsection{Dímero $\mathrm{CH}_{4}-\mathrm{H}_{2}$}

Quanto ao dímero $\mathrm{CH}_{4}-\mathrm{H}_{2}$, apenas foi possível encontrar um ponto de mínimo, com o DFT B97D3. De maneira geral, em relação à energia total, a função de onda do método B97D3, conseguiu gerar resultados na mesma grandeza dos referenciais tanto para o dímero (Tabela 30), quanto para as moléculas (Tabela 16 e Tabela 20). 
Tabela 30: Resultados MCQ para o dímero $\mathrm{CH}_{4}-\mathrm{H}_{2}$.

\begin{tabular}{|c|c|c|c|}
\hline \multirow{2}{*}{$\begin{array}{c}\text { Função de Onda de } \\
\text { Entrada }\end{array}$} & \multicolumn{3}{|c|}{ ENERGIA TOTAL (kcal/mol) } \\
\cline { 2 - 4 } & $\begin{array}{c}\text { MCQ Variacional / } \\
\text { (Erro Padrão) }\end{array}$ & $\begin{array}{c}\text { MCQ Difusão / } \\
\text { (Erro Padrão) }\end{array}$ & Gaussian09 \\
\hline B97D3/aug-cc-pvtz & $-25942,49 /(+/-0,42)$ & $-26154,00 /(+/-0,21)$ & $-26164,68$ \\
\hline
\end{tabular}

O método MP2 $(-26091,81 \mathrm{kcal} / \mathrm{mol})$ foi utilizado como referencial. Nota-se que todos os métodos MCQ ficaram na mesma grandeza do referencial e os erros padrão foram os menores dentre todos os dímeros.

Verifica-se que o MCQ de Difusão aumentou o valor da energia em relação ao Gaussian09, em 10,68 kcal/mol. O mesmo comportamento foi seguido pelo MCQ Variacional, mas em uma proporção de aumento maior $(222,19 \mathrm{kcal} / \mathrm{mol})$. Mais uma vez, o grande valor do erro absoluto, confirma que os efeitos presentes no DFT B97D3, não influenciaram nos cálculos MCQ.

No que concerne à energia de interação para o dímero $\mathrm{CH}_{4}-\mathrm{H}_{2}$, pode-se verificar pela Tabela 31, que os métodos MCQ não conseguiram prever a formação desse dímero, visto que tais energias estão positivas. Nota-se também que os valores das energias dos $2 \mathrm{MCQ}$ ficaram bem próximos um do outro.

Tabela 31: Resultados para a energia de interação do dímero $\mathrm{CH}_{4}-\mathrm{H}_{2}$.

\begin{tabular}{|c|c|}
\hline Método & $\begin{array}{c}\text { Energia de Interação } \\
(\mathbf{\Delta E}) \mathbf{~ k c a l} / \mathbf{m o l}\end{array}$ \\
\hline MCQ Variacional (B97D3) & 0,61 \\
\hline MCQ de Difusão (B97D3) & 0,55 \\
\hline Gaussian09 (B97D3) & $-0,37$ \\
\hline Gaussian09 (MP2) & $-0,32$ \\
\hline
\end{tabular}

O método B97D3 utilizado no Gaussian09 conseguiu um resultado muito próximo do valor calculado pelo método de referencia MP2. Apesar de essa função de onda ter dado bons resultados no Gaussian09 e também para os cálculos das energias do dímero (Tabela 30) e das 2 moléculas (Tabelas 16 e 20) no MCQ de Difusão, ela não conseguiu nem ao menos prever a formação do dímero, de acordo com o resultado da energia de interação. Mesmo assim, é possível encontrar um valor bem próximo do referencial MP2, fazendo-se combinações entre os 3 valores de energia, dentro do erro padrão dado. Tal fato mostra a grande sensibilidade dessa propriedade. 
Uma das possíveis causas para esses resultados ruins foi à desproporcionalidade das melhorias dadas pelo MCQ. Os erros relativos entre o MCQ Difusão e o Gaussian09 para o dímero $\mathrm{CH}_{4}-\mathrm{H}_{2}$, para a molécula $\mathrm{H}_{2}$ e para molécula $\mathrm{CH}_{4}$ foram $0,041 \%, 0,80 \%$ e $0,015 \%$ respectivamente. Nota-se assim, uma grande desproporcionalidade nos erros. Com isso, não houve compensação e sim, soma de erros.

Outra importante observação, foi em relação a grande diferença de energia entre as 2 moléculas componentes do dímero. Por exemplo, as moléculas $\mathrm{CH}_{4} \mathrm{e}_{2}$ formam esse dímero. A energia total para o $\mathrm{CH}_{4}$ pelo MCQ de Difusão (B97D3) foi de $-25417,69 \mathrm{kcal} / \mathrm{mol}$. Para a molécula $\mathrm{H}_{2}$ foi de $-736,86 \mathrm{kcal} / \mathrm{mol}$. Percebe-se que a energia do $\mathrm{H}_{2}$ representa apenas, aproximadamente $3 \%$ da energia do $\mathrm{CH}_{4}$. Para esses dímeros que a diferença de energia entre as molécula era bem significativa, os resultados para a energia de interação eram ruins. $\mathrm{O}$ mesmo aconteceu para o dímero $\mathrm{CH}_{4}$-Ar (Tópico 5.4.6) que também tinha essa grande diferença de energia entre suas moléculas.

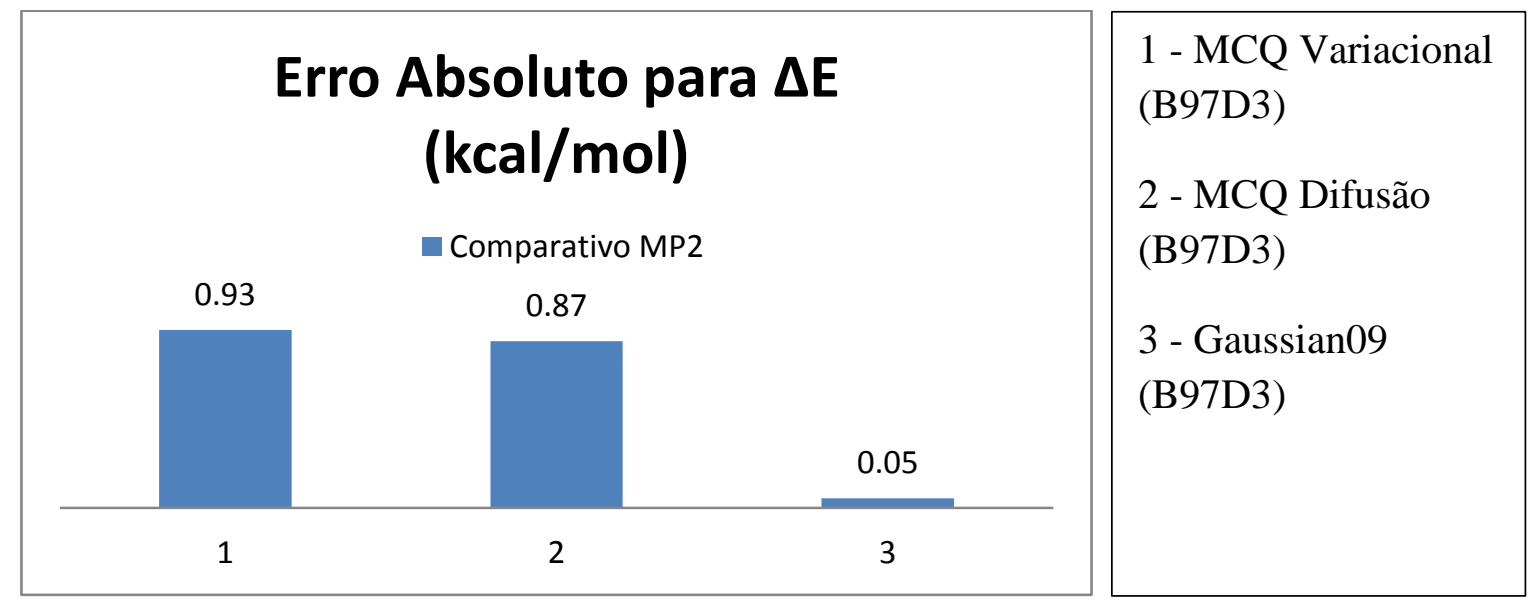

Figura 13: Erros absolutos para a energia de interação em relação ao referencial

Como se pode notar pela Figura 13, a melhor opção para esse cálculo foi utilizando o método DFT B97D3 no Gaussian09.

\subsubsection{Dímero $\mathrm{CH}_{4}$-Ar}

No que se refere à interação Metano-Argônio, utilizou-se apenas a função de onda do DFT B97D3 como entrada no Monte Carlo Quântico. Pode-se verificar na Tabela 15, que 
para esse dímero, tal DFT gerou bons resultados. Os resultados das simulações MCQ estão organizados na Tabela 32.

Tabela 32: Resultados MCQ para o dímero $\mathrm{CH}_{4}-\mathrm{Ar}$.

\begin{tabular}{|c|c|c|c|}
\hline \multirow{2}{*}{$\begin{array}{c}\text { Função de Onda de } \\
\text { Entrada }\end{array}$} & \multicolumn{3}{|c|}{ ENERGIA TOTAL (kcal/mol) } \\
\cline { 2 - 4 } & $\begin{array}{c}\text { MCQ Variacional / } \\
\text { (Erro Padrão) }\end{array}$ & $\begin{array}{c}\text { MCQ Difusão / (Erro } \\
\text { Padrão) }\end{array}$ & Gaussian09 \\
\hline B97D3/aug-cc-pvtz & $-355818,31 /(+/-1,77)$ & $-356457,06 /(+/-0,42)$ & $-356490,54$ \\
\hline
\end{tabular}

O método utilizado como referencial foi o MP2/aug-cc-pvtz $(-356073,44 \mathrm{kcal} / \mathrm{mol})$. Percebe-se que todos os resultados estão na mesma grandeza do referencial.

Ambos MCQ aumentaram o valor da energia em relação ao resultado do Gaussian09, com a mesma função de onda, ou seja, o resultado do Gaussian09 foi o mais estável. O erro absoluto entre o Gaussian09 e MCQ de Difusão foi de 33,48 kcal/mol. Já a diferença em relação ao Variacional foi de $672,23 \mathrm{kcal} / \mathrm{mol}$. Ainda que esse erro absoluto calculado em relação ao Variacional para o dímero $\mathrm{CH}_{4}$-Ar aparente ser bem superior se comparado aos erros absolutos dos outros dímeros, tais erros, em termos relativos, são equivalentes. Mais uma vez, esse grande desvio em relação ao Variacional, mostra que os cálculos MCQ não foram impactados pelos efeitos de troca-correlação e dispersão do funcional B97D3.

No que diz respeito à energia de interação, observa-se pela Tabela 33, que os métodos MCQ não conseguiram representar essa propriedade, apesar de prever a formação do dímero $\mathrm{CH}_{4}-\mathrm{Ar}$.

Tabela 33: Resultados para a energia de interação do dímero $\mathrm{CH}_{4}$-Ar.

\begin{tabular}{|c|c|}
\hline Método & $\begin{array}{c}\text { Energia de Interação } \\
(\mathbf{\Delta E}) \mathbf{k c a l} / \mathbf{m o l}\end{array}$ \\
\hline MCQ Variacional (B97D3) & $-6,18$ \\
\hline MCQ de Difusão (B97D3) & $-10,01$ \\
\hline Gaussian09 (B97D3) & $-0,46$ \\
\hline Gaussian09 (MP2) & $-0,52$ \\
\hline Teórico Referencial $^{34}$ & $-0,40$ \\
\hline
\end{tabular}

Percebe-se pela Figura 14, que o MCQ Variacional obteve um desvio menor que o de Difusão. Mesmo assim, os erros são bem consideráveis. O resultado fornecido pelo Gaussian09 com o mesmo DFT foi muito bom, ficando bem próximo dos referenciais. 


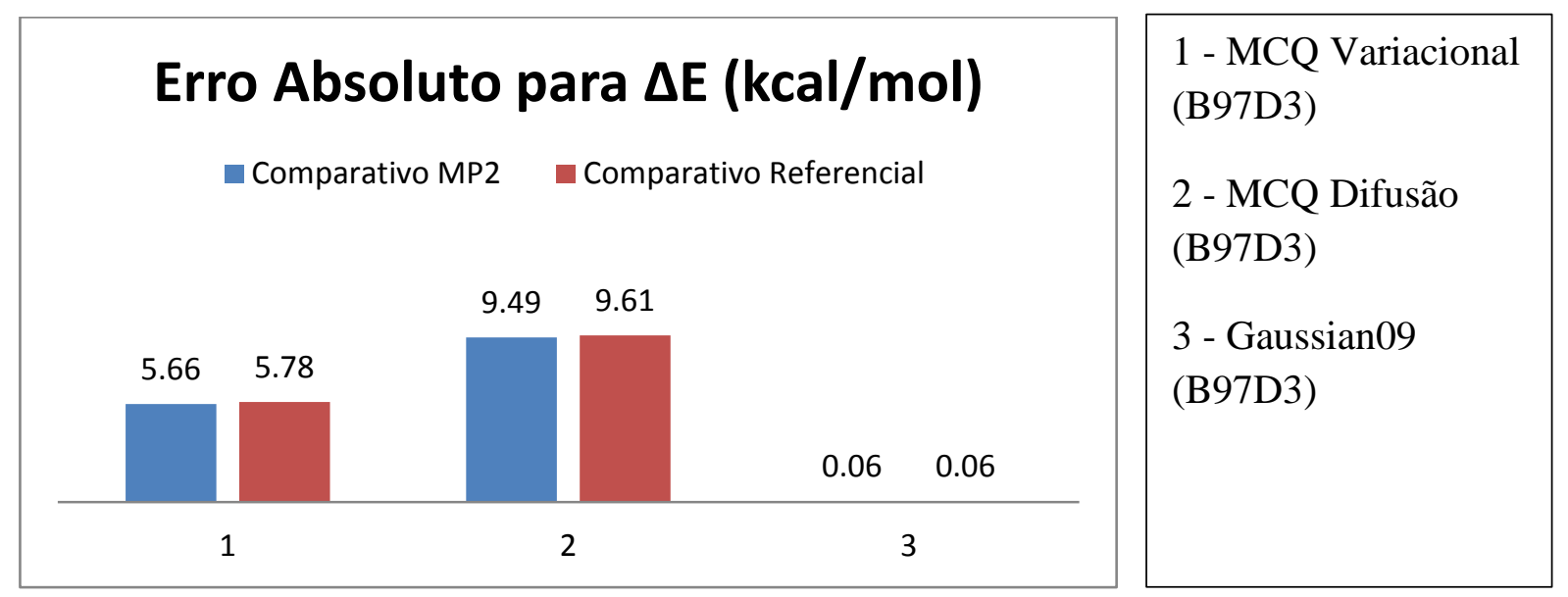

Figura 14: Erros absolutos para a energia de interação em relação aos referenciais.

Em relação aos resultados ruins no MCQ para esta propriedade, verificou-se que tais resultados podem estar associados ao problema da grande diferença de energia entre as 2 moléculas, como descrito no caso do $\mathrm{CH}_{4}-\mathrm{H}_{2}$. Aqui, a energia da molécula $\mathrm{CH}_{4}$ representa menos de $8 \%$ da energia do argônio. Como visto, os resultados para os dímeros que possuem essa característica de grande diferença de energia entre as moléculas, normalmente foram bem ruins. 


\section{CONCLUSÕES}

Em relação à energia total, para dímeros e moléculas, pode-se concluir que todos os métodos DFT utilizados foram suficientes para gerar resultados na mesma grandeza dos referenciais, tanto no Gaussian09 como no Casino. O MCQ de Difusão gerou melhores resultados que o MCQ Variacional para todos os casos, se comparados com os métodos referenciais. Também, o MCQ de Difusão conseguiu obter resultados de energias mais estáveis em relação ao Gaussian09, apenas quando se utilizou o DFT HSEH1PBE. Constatouse que os efeitos incluídos nos funcionais (troca-correlação, dispersão e correções de longo alcance), não impactavam nos cálculos MCQ. De modo geral, todos os resultados produzidos pelo MCQ estavam na mesma grandeza dos referenciais.

Quanto à energia de interação $(\Delta \mathrm{E})$ dos dímeros, pode-se concluir que tal propriedade se mostrou bem sensível a qualquer variação de energia dentro do erro padrão. Em alguns casos o erro padrão de apenas um dos componentes do dímero, já era maior que a própria energia de interação. Conclui-se também, que os erros padrão deveriam ser menores para resultados mais confiáveis para essa propriedade.

Conseguiram-se bons resultados para a $\triangle \mathrm{E}$, pelo método $\mathrm{MCQ}$, para os dímeros $\mathrm{CH}_{4}-$ $\mathrm{CH}_{4}, \mathrm{CH}_{4}-\mathrm{HF}$ e $\mathrm{CH}_{4}-\mathrm{H}_{2} \mathrm{O}$. As explicações para tais resultados foram: boas funções de onda utilizadas; melhoria da energia do dímero na mesma proporção da energia das moléculas que compõe tal dímero, como aconteceu para o $\mathrm{CH}_{4}-\mathrm{CH}_{4}$ com o método MCQ de Difusão (B97D3); compensação de erros, quando as proporções de melhoria não eram iguais, mas estavam próximas (caso do $\mathrm{CH}_{4}-\mathrm{HF}$ e $\mathrm{CH}_{4}-\mathrm{H}_{2} \mathrm{O}$ com o MCQ Variacional (HSEH1PBE) e $\mathrm{CH}_{4}$-HF com MCQ Difusão (HSEH1PBE)); quando as diferenças entre as energias das moléculas componentes dos dímeros não eram grandes, pois se verificou que quanto menor a diferença entre as energias das moléculas, melhores eram os resultados.

Já os dímeros $\mathrm{CH}_{4}-\mathrm{CO}, \mathrm{CH}_{4}-\mathrm{H}_{2}$ e $\mathrm{CH}_{4}$-Ar, no tocante à energia de interação $(\Delta \mathrm{E})$, tiveram resultados ruins gerados pelo MCQ. As principais explicações para tais resultados foram que as funções de onda do mesmo método não foram boas para todos os componentes, gerando-se diferentes proporções de melhoria da energia para o dímero e para as moléculas, e ainda não houve compensação de erros. Observou-se também, que quanto maior a diferença de energia entre as moléculas componentes do dímero, maiores eram os desvios. Apenas para constar, esses 3 dímeros tiveram diferenças de energias entre as moléculas, maiores que as dos dímeros que deram bons resultados. 
No que diz respeito à eficiência do MCQ, para os diversos tipos de interações, pode-se concluir, que a eficiência de tal método, não depende do tipo de dominância nas interações. Houve bons resultados para interações dominadas por Van der Waals, como aconteceu no caso do dímero $\mathrm{CH}_{4}-\mathrm{CH}_{4}$. Contrariamente, obtiveram-se resultados ruins para esse mesmo tipo de interação, como aconteceu no caso do $\mathrm{CH}_{4}$-Ar. Também, conseguiu-se representar bem, interações com uma influência maior do dipolo, como foi o caso do $\mathrm{CH}_{4}-\mathrm{HF}$ e $\mathrm{CH}_{4}$ $\mathrm{H}_{2} \mathrm{O}$. Posto isso, pode-se afirmar que a qualidade dos resultados gerados pelo $\mathrm{MCQ}$, independe da natureza das interações. 


\section{REFERÊNCIAS BIBLIOGRÁFICAS}

(1) Politi, J. R. S.; Custódio, R.; Morgon, N. H.; Coutinho, K. Métodos de química teórica e modelagem molecular; Editora Livraria da Física, 2007.

(2) Angelotti, W. F. D. Tese de Doutorado; Universidade Estadual de Campinas 2009.

(3) Angelotti, W. F. D.; Fonseca, A. L. d.; Torres, G. B.; Custodio, R. Química Nova 2008, 31, 433.

(4) Austin, B. M.; Zubarev, D. Y.; Lester Jr, W. A. Chemical reviews 2011, 112, 263.

(5) Booth, G. H.; Cleland, D.; Thom, A. J.; Alavi, A. The Journal of chemical physics 2011, 135, 084104.

(6) Deible, M. J.; Kessler, M.; Gasperich, K. E.; Jordan, K. D. The Journal of chemical physics 2015, 143, 084116.

(7) Fracchia, F.; Filippi, C.; Amovilli, C. Journal of Computational Chemistry 2014, 35, 30.

(8) Ganesh, P.; Kim, J.; Park, C.; Yoon, M.; Reboredo, F. A.; Kent, P. R. Journal of Chemical Theory and Computation 2014, 10, 5318.

(9) Harkless, J. A. W.; Irikura, K. K. International Journal of Quantum Chemistry 2006, 106, 2373.

(10) Hongo, K.; Maezono, R. International Journal of Quantum Chemistry 2012, 112, 1243.

(11) Mostaani, E.; Drummond, N.; Fal'ko, V. Physical Review Letters 2015, 115, 115501.

(12) Nemec, N.; Towler, M. D.; Needs, R. The Journal of chemical physics 2010, 132, 034111.

(13) Pang, T. American Journal of Physics 2014, 82, 980.

(14) Sarsa, A.; Buendia, E.; Galvez, F.; Maldonado, P. The Journal of Physical Chemistry A 2008, 112, 2074.

(15) Scemama, A.; Caffarel, M.; Oseret, E.; Jalby, W. Journal of Computational Chemistry 2013, 34, 938 .

(16) Zhang, H.; Cheng, X.-L.; Chiesa, S. International Journal of Quantum Chemistry 2011, 111, 4452 .

(17) Dubecký, M.; Derian, R.; Mitas, L.; Štich, I. The Journal of chemical physics 2010, 133, 244301.

(18) Send, R.; Valsson, O.; Filippi, C. Journal of chemical theory and computation 2011, 7, 444.

(19) Dupuy, N.; Bouaouli, S.; Mauri, F.; Sorella, S.; Casula, M. The Journal of chemical physics 2015, 142, 214109.

(20) Attaccalite, C.; Sorella, S. Physical review letters 2008, 100, 114501.

(21) Kashurnikov, V. A.; Krasavin, A. V. Physics Letters A 2014, 378, 2894.

(22) Parker, W. D.; Wilkins, J. W.; Hennig, R. G. physica status solidi (b) 2011, 248, 267.

(23) Wagner, L. K. International Journal of Quantum Chemistry 2014, 114, 94.

(24) Azadi, S.; Cohen, R. E. The Journal of chemical physics 2015, 143, 104301.

(25) Gurtubay, I. G.; Needs, R. J. The Journal of chemical physics 2007, 127, 124306.

(26) Ma, J.; Alfè, D.; Michaelides, A.; Wang, E. The Journal of chemical physics 2009, $130,154303$.

(27) Hongo, K.; Watson, M. A.; Sánchez-Carrera, R. S.; Iitaka, T.; Aspuru-Guzik, A. The Journal of Physical Chemistry Letters 2010, 1, 1789.

(28) Ma, J.; Michaelides, A.; Alfè, D. The Journal of chemical physics 2011, 134, 134701.

(29) Mella, M.; Anderson, J. B. The Journal of chemical physics 2003, 119, 8225. 
(30) Santra, B.; Michaelides, A.; Fuchs, M.; Tkatchenko, A.; Filippi, C.; Scheffler, M. The Journal of chemical physics 2008, 129, 194111.

(31) Sorella, S.; Casula, M.; Rocca, D. The Journal of chemical physics 2007, 127, 014105.

(32) Wu, X.; Hu, X.; Dai, Y.; Du, C.; Chu, S.; Hu, L.; Deng, J.; Feng, Y. The Journal of chemical physics 2010, 132, 204304.

(33) Buryak, I.; Kalugina, Y.; Vigasin, A. Journal of Molecular Spectroscopy 2013, 291, 102.

(34) Kalugina, Y. N.; Lokshtanov, S. E.; Cherepanov, V. N.; Vigasin, A. A. The Journal of chemical physics 2016, 144, 054304.

(35) Legon, A. C.; Roberts, B. P.; Wallwork, A. L. Chem. Phys. Lett. 1990, 173, 107.

(36) Liu, Y.; Jager, W. The Journal of chemical physics 2004, 121, 6240.

(37) Xia, C.; Walker, K. A.; McKellar, A. R. W. The Journal of chemical physics 2001, $114,4824$.

(38) Cao, Z.; Tester, J. W.; Trout, B. L. The Journal of chemical physics 2001, 115, 2550.

(39) Dore, L.; Cohen, R.; Schmuttenmaer, C.; Busarow, K.; Elrod, M.; Loeser, J.; Saykally, R. The Journal of chemical physics 1994, 100, 863.

(40) Suenram, R. D.; Fraser, G. T.; Lovas, F. J.; Kawashima, Y. The Journal of chemical physics 1994, 101, 7230.

(41) McKellar, A. R. W.; Roth, D. A.; Pak, I.; Winnewisser, G. The Journal of chemical physics 1999, 110, 9989.

(42) Rond, C.; Hamann, S.; Wartel, M.; Lombardi, G.; Gicquel, A.; Röpcke, J. Journal of Applied Physics 2014, 116, 093301.

(43) El-Kader, M. Journal of advanced research 2013, 4, 501.

(44) Wangler, M.; Roth, D. A.; Pak, I.; Winnewisser, G.; Wormer, P. E. S.; van der Avoird, A. Journal of Molecular Spectroscopy 2003, 222, 109.

(45) Lewars, E. G. Computational chemistry: introduction to the theory and applications of molecular and quantum mechanics; Springer Science \& Business Media, 2010.

(46) Mohallem, J. R.; Prudente, F. V.; Morgon, N. H.; Coutinho, K. Métodos de Química Teórica e modelagem molecular; Editora Livraria da Física, 2007.

(47) Martinez, L.; Borin, I. A.; Skaf, M. S.; Morgon, N. H.; Coutinho, K. Métodos de Química Teórica e modelagem molecular; Editora Livraria da Física, 2007.

(48) Simas, A. M.; Rocha, G. B.; Morgon, N. H.; Coutinho, K. Métodos de química teórica e modelagem molecular; Editora Livraria da Física, 2007.

(49) Morgon, N. H.; Custodio, R. Química Nova 1995, 18, 44.

(50) Castro, M. A.; Canuto, S.; Morgon, N. H.; Coutinho, K. Métodos de química teórica e modelagem molecular; Editora Livraria da Física, 2007.

(51) Metropolis, N.; Rosenbluth, A. W.; Rosenbluth, M. N.; Teller, A. H.; Teller, E. The Journal of chemical physics 1953, 21, 1087.

(52) Politi, J. R. S. Tese de Doutorado, Universidade Estadual de Campinas, 2005.

(53) Needs, R.; Towler, M.; Drummond, N.; Rios, P. L. 2015.

(54) Frisch, M.; Trucks, G.; Fox, D. Gaussian, Wallingford, CT 2009.

(55) http://webbook.nist.gov; acessada em Outubro de 2015.

(56) Li, A. H.-T.; Chao, S. D. Journal of Molecular Structure: THEOCHEM 2009, 897, 90.

(57) Chandra, A. K.; Nguyen, M. T. The Journal of Physical Chemistry A 1998, 102, 6865.

(58) Martins, J. o. B.; Politi, J. R.; Garcia, E.; Vilela, A. F.; Gargano, R. The Journal of Physical Chemistry A 2009, 113, 14818.

(59) Surin, L. A.; Tarabukin, I. V.; Panfilov, V. A.; Schlemmer, S.; Kalugina, Y. N.; Faure, A.; Rist, C.; van der Avoird, A. The Journal of chemical physics 2015, 143, 154303. 